Portland State University

PDXScholar

Spring 5-27-2015

\title{
The Role of Emotional Support Consistency and Child Risk Factors in Predicting Pre-K Cognitive and Social-Emotional Development
}

Amy Lynn Cannell-Cordier Portland State University

Follow this and additional works at: https://pdxscholar.library.pdx.edu/open_access_etds

Part of the Developmental Psychology Commons, and the Education Commons Let us know how access to this document benefits you.

\section{Recommended Citation}

Cannell-Cordier, Amy Lynn, "The Role of Emotional Support Consistency and Child Risk Factors in Predicting Pre-K Cognitive and Social-Emotional Development" (2015). Dissertations and Theses. Paper 2366.

https://doi.org/10.15760/etd.2364

This Thesis is brought to you for free and open access. It has been accepted for inclusion in Dissertations and Theses by an authorized administrator of PDXScholar. For more information, please contact pdxscholar@pdx.edu. 
The Role of Emotional Support Consistency and Child Risk Factors in Predicting Pre-K Cognitive and Social-Emotional Development

by

Amy Lynn Cannell-Cordier

A thesis submitted in partial fulfillment of the requirements for the degree of

\author{
Master of Science \\ in \\ Psychology
}

Thesis Committee:

Andrew J. Mashburn, Chair

Robert W. Roeser

Ellen A. Skinner

Portland State University

2015 
(C) Amy Lynn Cannell-Cordier 


\begin{abstract}
The quality of children's daily experiences in preschool classrooms is predictive of their school readiness and later achievement (Duncan et al., 2007; La Paro \& Pianta, 2000). One particularly important aspect of these experiences is the quality of emotional support provided by teachers and peers in the classroom (Hamre \& Pianta, 2005; Howes et al., 2008; Mashburn, 2008; National Center on Quality Teaching and Learning, 2012). Traditionally, emotional support quality has been calculated as the average of ratings taken across the school year and is meant to represent children's average daily experience, without regard to any variability which exists within the ratings over time.

The bioecological model of development (Bronfenbrenner \& Morris, 1998; 2006) points out the necessity of considering in what ways learning experiences occur over time when drawing links between children's daily lives and later outcomes. In addition, attachment theory (Ainsworth, 1979; Bowlby, 1973) highlights the foundational nature of caregivers' consistency of emotional responses over time in helping young children develop skills and competencies. This study continues a line of research focused on investigating the stability of high-quality interactions as a possible mechanism through which children's optimal cognitive and social-emotional development occurs in preschool classrooms (Curby, Brock, \& Hamre, 2013; Curby et al., 2011; Zinsser, Bailey, Curby, Denham, \& Bassett, 2013).
\end{abstract}

The current study examined the role of children's socioeconomic and behavioral risk factors, teachers' mean emotional support, and teachers' emotional support consistency in predicting children's cognitive and social-emotional development in 
preschool. Children's socioeconomic and behavioral risk factors (socioeconomic status, gender, age, race, ethnicity, English Language Learner status, and self-regulation) negatively predicted both baseline scores and development over the course of the year on the cognitive measures (early math and language and literacy). Low levels of teacherrated student self-regulation at the beginning of the year significantly negatively predicted baseline scores and development on all academic and social-emotional measures. Contrary to most previous research, teachers' mean emotional support was not found to be a significant contributor to children's development when considered with child risk factors, except in the case of receptive vocabulary. The consistency of teachers' emotional support, however, was predictive of several measures of children's development of academic skills when controlling for child risk factors. A significant interaction between English Language Learner status and emotional support consistency was found in predicting development of expressive vocabulary skills. Multilevel models combining child characteristics, mean emotional support, and emotional support consistency suggest that child risk factors and emotional support consistency predict language and literacy development, above and beyond mean emotional support. Followup analyses also suggest that, under conditions of relatively high emotional support, consistency is especially important in predicting children's development of cognitive and social-emotional skills. 


\section{Dedication}

This thesis is dedicated to the two halves of my whole:

\section{Lillian Jewell and Kassandra Lyann.}

You have always been and will always be the reasons I do what I do 


\section{Acknowledgements}

First and foremost I would like to thank my mother, Dr. Barbara Tourgee, for showing me that graduate school is best done at the least opportune moment. I must also give huge thanks to my advisor, Dr. Andy Mashburn, and the entire CEEDR team. You are all amazing and your feedback helped me see the bright spots in clouds of data.

My most heartfelt thanks go to my fiancé, Ken Sieglinger. I could not have done this without you by my side, at my back, and in my life. Your support and love have seen me through things we could never have imagined.

I would also like to acknowledge Cameron Sieglinger, upon whom I hope I impressed the fun of doing research and statistics and their ongoing value in life. And finally, Professor Ralph Waldo Aussiedoodle and Sir Isaac Newton: my most loyal companions and biggest fans who also happened to keep my lap warm and a smile on my face while I was writing. 
Table of Contents

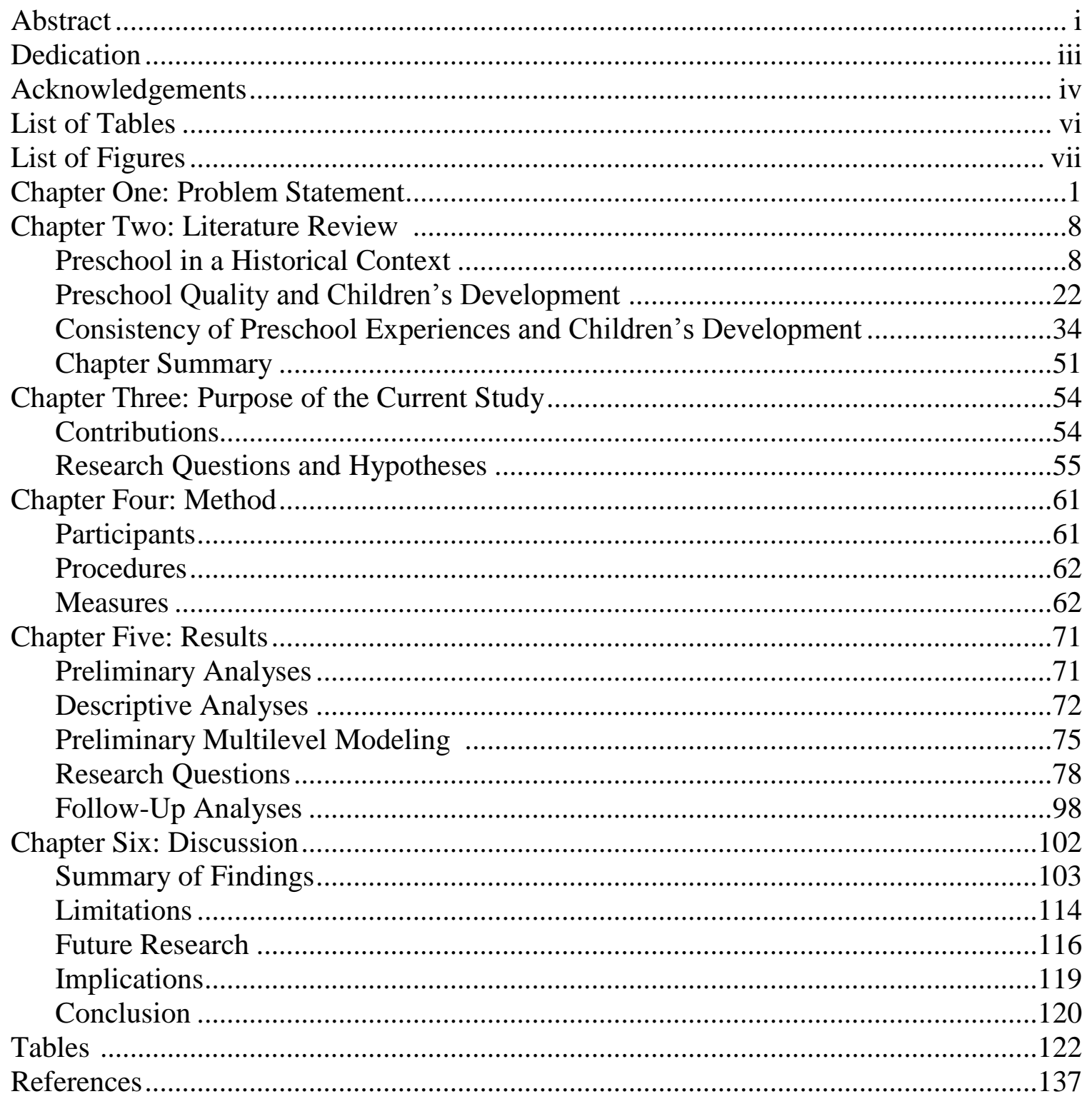




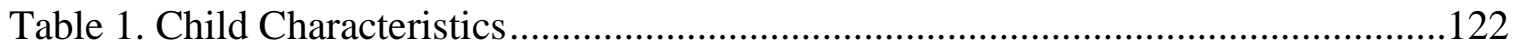

Table 2. Teacher Characteristics ................................................................................123

Table 3. Descriptive Statistics of Child- and Classroom-Level Variables .......................124

Table 4. Correlations Between Child Characteristics, Fall Cognitive and Social-Emotional Skills, Spring Cognitive and Social-Emotional Skills, Classroom Emotional Support, and Classroom Emotional

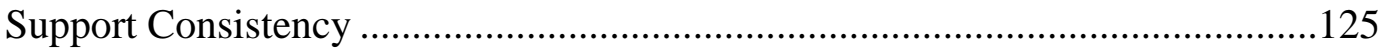

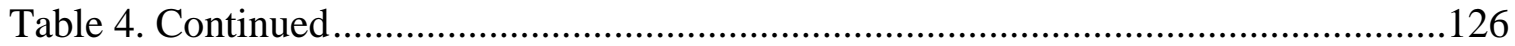

Table 5. Associations Between Fall Cognitive and Social-Emotional Skills and Child Characteristics

Table 6. Associations Between Spring Cognitive and Social-Emotional

Skills, Fall Cognitive and Social-Emotional Skills, and Child Characteristics.

Table 7. Associations Between Spring Cognitive and Social-Emotional Skills, Fall Cognitive and Social-Emotional Skills, and Classroom Emotional Support

Table 8. Associations Between Spring Cognitive and Social-Emotional

Skills, Fall Cognitive and Social-Emotional Skills, Child Characteristics, and Classroom Emotional Support (Main Effects).

Table 9. Associations Between Spring Cognitive and Social-Emotional

Skills, Fall Cognitive and Social-Emotional Skills, Child

Characteristics, and Classroom Emotional Support (Main Effects and Cross-Level Interactions)

Table 10. Associations Between Spring Cognitive and Social-Emotional

Skills, Fall Cognitive and Social-Emotional Skills, and Classroom Emotional Support

Table 11. Associations Between Spring Cognitive and Social-Emotional

Skills, Fall Cognitive and Social-Emotional Skills, Child Characteristics, and Classroom Emotional Support Consistency (Main Effects)

Table 12. Associations Between Spring Cognitive and Social-Emotional

Skills, Fall Cognitive and Social-Emotional Skills, Child Characteristics, and Classroom Emotional Support Consistency (Main Effects and Cross-Level Interactions)

Table 13. Associations Between Spring Cognitive and Social-Emotional Skills, Fall Cognitive and Social-Emotional Skills, Child Characteristics, Classroom Emotional Support, and Classroom Emotional Support Consistency .....

Table 14. Associations Between Spring Cognitive and Social-Emotional Skills, Fall Cognitive and Social-Emotional Skills, Child Characteristics, and Classroom Group Membership 
Figure 1. Emotional Support and Emotional Support Consistency

Figure 2. Effect Size Estimates for Child Characteristics in

Predicting Fall Cognitive and Social-Emotional Scores

Figure 3. ELL Status x Emotional Support Consistency on

TOPEL-DV Scores

Figure 4. Effect Size Estimates for Child Characteristics, Mean Emotional

Support, and Emotional Support Consistency in Predicting Spring

Cognitive and Social-Emotional Scores .95

Figure 5. Groups Resulting from Median Splits Characteristics

Figure 6. Direction of Associations Between Child Characteristics and

Fall Academic and Social-Emotional Skills 104

Figure 7. Direction of Associations Between Child Characteristics and Development of Academic and Social-Emotional Skills

Figure 8. Classroom Groups Resulting From Median Splits of

Emotional Support and Emotional Support Consistency..... 


\section{Chapter One: Problem Statement}

In his 2013 State of the Union address President Barrack Obama made early childhood education a national priority, calling on Congress to "expand access to highquality preschool to every child in America" (The White House, 2013). The White House asserted that "fewer than three in 10 four-year-olds are enrolled in high-quality programs" which it defined as programs with well-trained and well-paid teachers, low teacher-child ratios, rigorous curricula, and services related to health and program evaluation (The White House, 2013). This awareness of the benefits of access to preschool ${ }^{1}$ programs combined with vague definitions of "high quality" mirrors a decades-old question in early childhood education practice and policy, one that is the central focus of the current study: Which aspects of early childhood education matter most when preparing young children cognitively, socially, and emotionally for school readiness and later achievement?

Development in early learning programs must be thought of as encompassing and affecting all aspects of young children's lives. Their patterns of social-emotional and cognitive growth are of particular interest to researchers, especially in light of the predictive power growth in each area has in terms of academic and social-emotional outcomes measured during elementary school and beyond (e.g., Duncan et al., 2007; La Paro \& Pianta, 2000). In fact, for many years it was assumed that, by simply providing

\footnotetext{
${ }^{1}$ In this text, "pre-K" refers specifically to those state-funded programs serving only four-year-olds, while "preschool" and "early childhood education" refer to a wider range of formal, classroom-based learning opportunities available to three- and four-year-olds.
} 
access to early childhood education programs, policy makers and educators could positively influence children's development prior to their entry into the formal education system. A handful of well-researched and well-publicized early pilot programs supporting this belief by describing a connection between children's early learning experiences and outcomes later in life (e.g., Campbell et al., 2008; Campbell et al., 2012; Reynolds, Temple, Robertson, \& Mann, 2001; Reynolds, Temple, White, Ou, \& Robertson, 2011; Schweinhart et al., 2005).

Based on economists' way of framing results and influenced by a body of research by James Heckman, policymakers, politicians, and some researchers quantify the value of preschool programs as a ratio of "financial benefits to society" as compared to the initial investment for each child, an argument that has reached the highest levels of government (e.g., Heckman, n.d.). In December of 2104, the White House Summit on Early Education Investment reduced the argument for expanding preschool programs to just such a ratio: $\$ 8.60$ returned to society for every $\$ 1$ spent on early childhood education (The White House, 2014). However, there is a strong push to include objective measures of program quality into this "preschool to outcomes" equation.

Within the last decade multiple lines of research have made strong connections between the quality of children's experiences in early childhood education programs and their academic and social-emotional outcomes, both concurrently and at later time points. Researchers in fields as diverse as education, medicine, neuroscience, and developmental psychology concur with these findings to such an extent that an open letter urging policymakers to make funding decisions based on the full body of early childhood 
education research, specifically those studies which focus on program quality, has been signed by hundreds of researchers including 60 founding signatories from universities and research institutes across the country (National Institute for Early Education Research [NIEER], 2014). This response reflects researchers' interest in the variety of components that make up early childhood education programs including the physical setting, materials, resources, curriculum, teacher-child ratios, salaries, children's involvement with materials and resources, and relationships between children and teachers. These last two components - what children play with and how they are taught directly affect how children learn. They have been the subject of recent research on relations between early childhood education programs and children's development. How to most accurately define and measure the quality of the behaviors and patterns involved in teaching is a currently-evolving area of research and the focus of this study.

Traditionally, it has been assumed that the quality of teacher/child interactions remains relatively constant over time and thus a single mean-level data point created from multiple observations during the school year has been used in analyses. Recently, however, researchers have questioned whether this is the most accurate representation of the quality of children's overall experiences in the classroom and have started investigating the importance of consistency in defining the quality of classroom interactions (Curby, Brock, \& Hamre, 2013; Curby et al., 2011; Zinsser, Bailey, Curby, Denham, \& Bassett, 2013). Including time (in the form of consistency) as a crucial part of children's experiences is logical but has not been well explored in research on the impact of early childhood education. 
The effect of the basic level of quality cannot be ignored in the quest to understand consistency. A teacher who consistently responds in ways that hinder development and inhibit children's ability to learn (what most would consider low quality) cannot be said to be inherently equal to a teacher who consistently responds to children in ways which affirm their needs, take into consideration their goals, and provide the support they require, although the two teachers may be statistically similar on one aspect of quality. Borrowing from attachment and parenting theory, sensitive responsiveness is used here to define the behavior of those teachers who repeatedly and promptly respond to children's bids for attention in appropriate ways, thus exhibiting both high quality and consistency in their interactions (Bell \& Salter Ainsworth, 1972; Bornstein, Tamis-LeMonda, Hahn, \& Haynes, 2008; Schaffer \& Emerson, 1964). According to Bornstein et al. (2008) this type of responsiveness supports developmental outcomes of value to parents and teachers including social-emotional and cognitive skills. Similar to the expansion of the definition of quality through the inclusion of consistency in relation to teacher/child interactions, the unique characteristics each child brings to their classroom must be understood to clarify for whom specific program components might matter most. Commonly referred to as risk factors, characteristics such as household income, gender, race, ethnicity, and age, and child-level skills such as behavioral self-regulation and English Language proficiency, stand in as markers for children's cumulative prior experiences. The fact that a particular group of children may typically be unable to participate in a robust series of beneficial interactions repeated over time in early childhood due to factors out of their control is often reflected in these easily- 
identifiable characteristics.

Research has consistently linked these socioeconomic and behavioral risk factors with both lower academic and social-emotional skill levels during early childhood and more pronounced rates of development across the school year, given the benefit highquality educational environments (e.g., Brooks-Gunn \& Markman, 2005; Burchinal, Vandergrift, Pianta, \& Mashburn, 2010; Halle et al., 2009; Magnuson \& Waldfogel, 2005; Rimm-Kaufman, Curby, Grimm, Nathanson, \& Brock, 2009). It is theorized that teachers, one of the main components of high-quality settings, either purposefully or casually identify, assess, and intervene with children who enter preschool with skills that lag behind their peers. In addition, it is suggested that those children who need special support to reach their developmental goals are given extra attention and more intensive guidance by teachers who routinely engage in high quality teaching. It is important that these risk factors be included when conducting analyses of the impacts of quality and consistency on children's developmental outcomes so a more complete picture of the relations between the predictors and outcomes can be created.

Grounding the research on the impact of early childhood education programs on children's growth are a number of developmental theories, each of which addresses key areas of development and the influence of children's experiences. On their own the ecological systems theory (Bronfenbrenner, 1979; Bronfenbrenner \& Morris, 2006), bioecological model of development (including the chronosystem) (Bronfenbrenner \& Ceci, 1994; Bronfenbrenner \& Morris, 1998; 2006), and attachment theory (Bowlby, 1973; Ainsworth, 1979) each describe the mechanisms which influence development. 
It is only by combining these theories while simultaneously expanding the definition of quality to include consistently high quality that the mechanisms through which early childhood education programs affect development can be fully understood. This study draws on a multi-faceted definition of quality, the characteristics of children in classrooms, the theoretical underpinnings of both the bioecological model of development and attachment theory, and the importance of time as a part of children's experiences to help answer the big question: Which aspects of early childhood education matter most when preparing young children cognitively, socially, and emotionally for school readiness and later achievement?

Each of the areas previously discussed - the stages of children's development, why access to early childhood education programs matters, the importance of multiple aspects of quality when predicting children's developmental outcomes, the inclusion of sensitive responsivity in defining a high quality/high consistency classroom, the effect of children's individual behavioral, social, and risk factors on outcomes, and the theories addressing connecting these components - will be addressed in the following chapters.

Specifically, Chapter Two, will a) describe the history of early childhood education in the United States, summarize research on the question of whether preschool programs "work" in terms of child development, and outline questions that remain on how best to study preschool effectiveness; b) provide definitions of children's development and preschool quality, describe theoretical connections between the two, and discuss prior research in this area; and c) describe the theories of and prior research on consistency as it relates to teacher/child interactions and young children's 
development in preschool settings.

Chapter Three describes the research questions and hypotheses of the current study, proposing that a) children's socioeconomic and behavioral risk factors will negatively predict their cognitive and social-emotional skills at preschool entry; b) children with these risk factors will show greater improvements in their development across the school year; c) more emotionally supportive preschool classrooms will have a stronger benefit for children's development than less emotionally supportive classrooms; d) more emotionally supportive preschool classrooms will have a stronger benefit for children's development among children who experience greater risk compared to children who experience less risk; e) preschool classrooms with more consistent levels of emotional support will have a stronger benefit for children's development than classrooms with less consistent levels of emotional support; f) preschool classrooms with more consistent levels of emotional support will have a stronger benefit for children's development among children who experience greater risk compared to children who experience less risk; and e) when analyzed with mean emotional support and child risk factors, emotional support consistency will contribute to predicting development.

Chapter Four describes the methods through which these hypotheses were tested, including the participants, procedures, and measures that were used. Chapter Five describes the preliminary and descriptive analyses that were used as well as the multilevel modeling used for each of the research questions. Chapter Six summarizes key findings, discusses the implications of this study, suggests areas for future research, and describes this study's limitations. 


\section{Chapter Two: Literature Review}

Chapter One identified the components of development, early childhood education, and theory which are of interest when investigating relations between children's classroom experiences and their later outcomes. This chapter provides an indepth historical perspective on preschool in America and expands upon the issues of development, quality, consistency, and theory identified in the previous chapter.

The first section, Preschool in a Historical Context, describes the history of early childhood education in the United States, research on the effects of preschool on child outcomes, and the active ingredients which form the basis of this study. The second section, Preschool Quality and Children's Development, describes children's development and explains how quality in preschool settings is defined and measured, examines the theoretical connections development and quality, and summarizes prior research in this area. The final section, Consistency of Preschool Experiences and Children's Development, contains additional definitions and theory regarding time as a variable of interest and provides an in-depth summary of research on the link between the consistency of teachers' emotional support and young children's development of cognitive and social-emotional skills across the school year.

\section{Preschool in a Historical Context}

Creation and Expansion of Preschool. Preschool in America has gone through several phases since its introduction in the 1850s. This section provides information about a) the early days when preschool was primarily a social service provided by activists to poor urban, children and families, b) the subsequent development and 
expansion of federal and state Head Start programs designed to address the school readiness gap attributed to poverty, and finally, c) preschool programs in the current era when quality of care is being scrutinized at the same time funding and opportunities for young children are diminishing.

Early days. The seeds of modern-day preschool came to America with German immigrants in the middle of the 19th century as "kindergarten". The most popular kindergarten curricula used play as a teaching medium and included games and songs designed to foster social connections amongst the children (Beatty, 1995; More Muelle, 2005). They followed a model created by Freidrich Froebel and were based on the idea that children from three to seven years old should go to school to play instead of learn skills. The idea of "play as learning" for young children increased in popularity across the country during the early decades of the $20^{\text {th }}$ century. At the same time preschool programs expanded to provide services to mothers and families in need. The Progressive movement of the 1920 s and 30s began to embrace social reforms, including settlement houses and comprehensive preschool programs, as something to which poor families and children were entitled and which ought to be provided as part of society's obligation to support all of its members (More Muelle, 2005).

Enrollment in free early education programs was soon limited to four- and fiveyear-olds and services to families were eliminated despite the best intentions of early providers and policy makers who recognized the value of social services and education for young children. These restrictions came midway through the $20^{\text {th }}$ century as kindergarten became integrated into the public education system and the curriculum 
became more standardized, focusing on academic and school readiness skills (More Muelle, 2005). The care and education of children younger than five eventually reverted to families or individual programs until by 1960 only $10 \%$ of all three- and four-year olds were participating in any kind of classroom-based education programs (O'Brien \& Dervarics, 2007).

A series of technological developments and President Lyndon Johnson's War on Poverty pushed Congress to create federally-funded educational opportunities for lowincome children prior to kindergarten. When Russia launched the Sputnik space craft in 1957 America's attention was suddenly turned to education as a whole and young children in particular. Educators and politicians reacted to this technological advancement by calling for programs that would prepare students for later academic and career success, especially in science-related fields, and thereby guarantee America's continued status as a world leader (More Muelle, 2013; Bracey, 2007). At the same time, television news reports delivered images of the devastating effects of poverty on children into homes across America, pointing out the failures of the education system and bringing the issue into the "collective conscience of the nation" in a way that had never been done before (Mashburn, 2014, p. 271). Finally, in 1964 President Johnson launched the War on Poverty, an array of social reforms meant to address the disparity in education, health, and economic opportunities faced by low-income families as compared to more financially secure families. Government programs began ramping up in response to internal and external pressures on the education system, most notably with Project Head Start. 
Head Start. Head Start, now the single largest provider of preschool education in the U.S., was created in 1965 as an eight-week half-day summer preschool program for low-income and disabled children. It was meant to both prepare the children for school and address the needs of families with young children living in poverty. The Office of Child Development in the U.S. Department of Health, Education, and Welfare created the program to provide comprehensive services that addressed almost every aspect of impoverished children's lives, including their cognitive, social-emotional, psychological, nutritional, and health needs (Administration for Children and Families, n.d.). Head Start was seen as a way to reduce the persistent achievement gap between disadvantaged children and their more privileged peers in terms of school readiness and later achievement (Mashburn, 2014). By the end of the 1970s Head Start offered year-round classes to three- and four-year-olds in 21 states and its federal grant budget exceeded \$1 billion annually by 1984 (Administration for Children and Families, n.d.). However, millions of eligible children were being left out due to lack of funding and further investments were needed in preschool.

For several reasons individual states and families started investing more heavily in public and private preschool programs during the last decades of the $20^{\text {th }}$ century. First, the women's liberation movement of the 1970s and welfare reforms in the 1990s each resulted in more mothers entering the workforce and more children needing care outside the home. Women with preschool-aged children increasingly sought center-based care due to either necessity or choice. By $200060 \%$ of mothers with children younger than six were employed outside the home (Dunifon \& Gill, 2013). Second, scientific research 
began suggesting there were links between early childhood experiences and concurrent and subsequent brain development (National Research Council and Institute of Medicine, 2000), and a trio of pilot preschool programs from the 1960s and 1970s began suggesting positive links between early education and later achievement and economic benefits to society (O’Brien \& Dervarics, 2007). Third, cognizant of the increasing demand and aware that federal Head Start funding was insufficient to enroll a majority of low-income students, states began creating their own programs to serve low-income children. All of these factors combined to first create a demand for more educational opportunities and subsequently grow the ranks of young children participating in early care and education programs. By 2000 over $60 \%$ of all four year olds attended some type of classroom-based programs and 37 states had some type of publicly-funded preschool program, most of which focused on at-risk children (Aud et al., 2013; Barnett et al., 2014).

Twenty-first century. In the past two decades there has been an increase in preschool enrollment, a decline in state and federal funding, and a new focus on the link between the quality of early education programs and school readiness and later achievement and social skills. Currently, approximately 3.8 million children under age five and $66 \%$ of four-year-olds spent at least part of their time in center-based care every week (Child Care Aware of America [CCAA], 2013; Kena et al., 2014). Only three states and the District of Columbia have created new state-funded programs for four-year-olds in the last 20 years and state spending per child in all states has declined $20 \%$ from an average of over $\$ 5,000$ per child per year in 2002 to barely $\$ 4,000$ per child per year in 2013 (Barnett et al., 2014). Moreover, parents assume almost $60 \%$ of the cost of child 
care in the United States with rates ranging from an average of $\$ 3,700$ per child per year for family home care in Mississippi to over $\$ 12,000$ per child per year for center-based care in Massachusetts in 2012 (CCAA, 2013). Few states offer access to universal preschool (Georgia and Oklahoma are the notable exceptions, offering free high-quality programs to all eligible children) and President Obama's recent focus on creating new high quality early childhood education programs has not yet resulted in any additional allocation of funds or new government programs, leaving a sustained gap between available enrollment and needed capacity. Studies suggests that the quality of statefunded preschool programs has declined on certain indicators while research continues to demonstrate a link between the quality of children's early experiences and their later success in many areas, including school readiness, social-emotional development, and academic achievement (Barnett, 2014; Burchinal et al., 2010; Howes et al., 2008; Mashburn et al., 2008).

Summary. Classroom-based educational opportunities for young children have been part of the American landscape for over 150 years, often with a focus on providing school readiness opportunities for impoverished children in urban settings. Many preschool programs in the 1800 s and early 1900 s were run by charitable organizations and local governments. Widespread federally-funded preschool programs were created in the 1960s and laid the groundwork for states to design and implement their own publically-funded programs. Currently almost two-thirds of all four-year-olds in America attend some type of early education program. Total expenditures from all sources on these programs is estimated at over $\$ 35$ billion dollars per year. Recently, providing high- 
quality care has become the focus of those who were previously primarily concerned only with providing access to care.

History demonstrates that preschool programs are perceived by parents, policymakers, and politicians as instrumental in preparing young children for entry into, and success in, the K-12 school system, especially for children who face risk factors such as poverty. The following section describes a trio of model preschool programs and a large scale meta-analysis that indicate the potential impact of early childhood education programs on children, families, and society and which many cite as evidence of the quality and effectiveness of preschool.

Does Preschool Work? Researchers have been drawing links between sustained participation in comprehensive, high-quality early childhood education programs and later outcomes for many years. Much of the focus has been on three highly publicized programs: The High/Scope Perry Preschool Project, the Abecedarian Project, and the Chicago Child-Parent Centers Program. Each of these programs provided comprehensive classroom-based educational opportunities for economically disadvantaged children, the majority of whom were African-American, and was evaluated in terms of short- and long-term effectiveness in areas such as school readiness and social skills as well as economic benefits to society. In addition, a large number of less well-known early childhood interventions have also been evaluated over the past 50 years, creating a database of important information regarding the broader relationships between preschool enrollment and later cognitive and social-emotional development. Each of the three pilot programs and the findings from a meta-analytic review are discussed in this sub-section. 
High/Scope Perry Preschool Project. The High/Scope Perry Preschool Project was a randomized controlled study carried out between 1962 and 1967 in Ypsilanti, Michigan. One hundred and twenty three African-American children were randomly assigned to either a high-quality, comprehensive preschool program or no early childhood intervention. Fifty-eight students were assigned to the treatment group and 65 were assigned to the control group. All of the children were assessed as having a high risk of school failure due to demographic risk factors such as poverty, single-parent households, and low maternal education. The children who were assigned to the treatment group received up to two years of early care and education comprised of 2.5 hours per day of classroom-based interactive academic instruction during the school year and a weekly 1.5 hour home visit from a member of the teaching staff. All of the teachers had a Master's degree and had completed training in child development. Teacher/child ratios in the classroom were 5 or 6:1 (Muennig, Schweinhart, Montie, \& Neidell, 2009; Schweinhart, Montie, Xiang, Barnett, Belfield, \& Nores, 2005).

Participants in the study were subsequently assessed as adults at several time points on indicators such as educational attainment, earning potential, family relationships, health, delinquency and involvement with social services and the judicial system, and return on investment. Results from the Age 27 and Age 40 follow-ups suggest links between early childhood education and positive long-term benefits for participants, their families, and society (Muennig et al., 2009; Schweinhart et al., 2005). Participants in the intervention later reported more positive attitudes toward their own children's schooling, less use of social services over time, greater rates of employment 
and higher earning potential, fewer arrests and involvement in crime, and more positive health and relationship behaviors as compared to those in the control condition (Muennig et al., 2009; Schweinhart et al., 2005). Perhaps the most cited results of the Perry Preschool Project, as well as the following studies, are the cost-benefit analyses and returns on public investment. Analysts estimated the return in Year 2000 dollars to be almost $\$ 250,000$ per person on an initial investment of just over $\$ 15,000$ per treatment child, or roughly $\$ 16.00$ for every dollar invested (Muennig et al., 2009; Schweinhart et al., 2005).

Abecedarian Project. The Abecedarian Project was a randomized controlled trial of an intensive early childhood education program which took place between 1972 and 1985 in North Carolina. Children were selected for inclusion in the project based on risk factors such as low parental education, low family income, parental marital status, and indications of learning problems. One hundred and eleven at-risk children (98\% AfricanAmerican) were assigned to either a full-time, full-year, high-quality, intensive researchbased early education program from infancy through kindergarten or a control condition where similar care was not provided. Children were re-randomized at kindergarten entry with the new group treatment children receiving support services through third grade (Campbell et al., 2008; Campbell et al., 2012).

The results of an early follow-up study indicated that children who participated in any of the treatment conditions of the Abecedarian Project exhibited higher levels of language, cognitive, social-emotional, and gross and fine motor skills from infancy through the preschool years (Campbell et al., 2012). Subsequent studies suggest that the 
relationship between the high-quality, intensive early childhood education program and later positive outcomes continued for many years. At Age 21 individuals in the treatment condition, as compared to control children, had completed more years of college, years at a skilled job, or both, had fewer episodes of depression and fewer drug use issues, and fewer of them became parents while teenagers. The trend toward higher levels of educational attainment continued with treatment individuals obtaining more years of education at Age 30 as compared to the control group. The economic benefit to society was limited by the large initial investment in each child and the overall scope of the intervention (infancy to third grade) but each dollar invested was still estimated to return between two and four dollars to society (Campbell et al., 2008; Campbell et al., 2012).

\section{Chicago Child-Parent Center Program. The Chicago Child-Parent Center}

Program is the second-oldest federally funded preschool program and has been in operation since 1967, starting with four sites and expanding to 25 sites offering comprehensive half-day educational programs and family-support services to low-income three- and four-year-olds. The Chicago Longitudinal Study which evaluated the effectiveness of the program was begun in 1986 and eventually included 1536 children (93\% African-American) in a variety of experimental conditions including up to two years of early care and intervention services continuing through third grade. Parental involvement is a key component of the program with parents expected to participate in both parent education activities and their child's classroom. A comparison group comprised of children from similar circumstances who were not enrolled in the Chicago Child-Parent Centers (but who had the opportunity to enroll in other early childhood 
programs available to low-income children such as Head Start) served as a control group (Reynolds et al., 2001; Reynolds et al., 2011; University of Minnesota, 2014).

Findings from the Chicago Longitudinal Study indicate a similar relationships between the intensive early childhood education provided by the Chicago Parent-Child Center Program and later school and career achievement. At Age 26 treatment participants had greater educational achievement (highest grade completed), greater income and socioeconomic status, and lower rates of crimes committed as compared to control participants (Reynolds et al., 2011). The return per dollar invested was estimated to be between seven and ten dollars per person at age 21 depending on the treatment condition(s) to which they were assigned (Reynolds et al., 2001). By age 26 these benefits to society had been somewhat reduced but were still between two and seven dollars per person as compared to individuals in the control group (Reynolds et al., 2011).

Effects of Preschool. Complimentary to the three pilot programs described previously, Camilli, Vargas, Ryan, and Barnett (2010) conducted a wide-ranging metaanalysis of 123 quantitative studies of early childhood interventions which met a series of conditions including requirements that the programs under review be center based, educationally directed, and focused on improving children's cognitive skills, and that the studies include a comparison group in the form of a control or alternative treatment. Results of the original studies were required to have been reported after 1960 and programs serving only special needs children were excluded. Results of the programs were compared in terms of children's school progress, cognitive achievement (including IQ tests, and reading, math, and verbal skills) and social-emotional development 
measured at any of three time points - end of treatment, short term (from ages five to ten), or long term (after age ten).

Camilli et al. (2010) found significant effects across the 123 programs in all of the outcome domains. The largest effects were found in relation to cognitive outcomes with smaller effects observed for the social-emotional and school progress indicators. These results expand upon and lend additional support to the argument advanced by advocates of the three pilot programs previously described - that preschool programs provide real and lasting benefits to children in many important areas.

Summary. Results of the Perry Preschool, Abecedarian, and Chicago ChildParents Centers studies and the Camilli et al. (2010) meta-analysis provide support for early childhood education programs as a positive influence on indicators of children's development such as school readiness, later achievement, education and career attainment, as well as financial benefits to taxpayers and governments. These results help bolster support for future investments in early childhood education at a time when federal and state governments are faced with justifying expansion or even continuation of multibillion-dollar preschool programs and families are faced with increasing financial burdens in order to pay for preschool. However, the knowledge that preschool can be, in general, an effective way of increasing children's social and cognitive skills and is related to a host of later outcomes does not address more specific questions about what features and experiences in preschool settings produce the greatest impacts. The next sub-section discusses questions for future research and the importance of time as a variable in understanding the quality of preschool classrooms. 
Active Ingredients. Evidence suggests that a handful of comprehensive, longterm, high-quality preschool programs, with ongoing support services for families, which serve low-income African-American children may impact future outcomes, and that preschool in general may be beneficial to children's development. But what is it in particular about early education experiences and settings that makes a difference in children's lives on outcomes of interest to parents, educators, and policy makers? Which parts of model programs can be translated to preschools serving families across the country and thus improve school readiness and later achievement? How can policymakers structure and implement programs in ways that maximize the benefits of preschool for the largest number of children? In short, to reiterate the question overarching this study, which aspects of early childhood education matter most when preparing young children cognitively, socially, and emotionally for school readiness and later achievement?

Over the years, numerous research studies have focused on almost every aspect of preschool programs in efforts to understand how the structuring and implementation of preschool can produce the greatest impact on children's school readiness and later achievement. Everything from the physical setting of classrooms, teacher-child ratios, and teacher qualifications to children's interactions with their teachers and peers has been studied, with the majority of findings converging on the importance of high-quality interactions aimed at providing children with emotional support, developmentally appropriate instructional support, and well-managed classrooms in predicting later cognitive and social-emotional development (Camilli, 2010; NIEER, 2014). 
However, the element of time in any meaningful form has been missing from many previous analyses. Instead, researchers have taken periodic "snapshots" of what children experience in the classroom - most often through a small number of observations conducted during the academic year - and evaluated the influence of the variables observed at a level meant to represent the typical level (i.e., the mean). To create a more accurate and useful model of what children are experiencing across time, time itself must be included in a way which reflects what is actually happening in classrooms. Just as one child, one teacher, or one aspect of a curriculum cannot be examined in isolation when the goal is a clear picture of preschool environments that provide widespread and long-lived benefits, events of one day should not be expected to represent an entire year in preschool.

This necessitates moving away from a mean-level view of teacher-child interactions, classroom organization, and quality of instruction, investigating what amount of variability (or consistency) exists within each of these important aspects of classroom life over time, and understanding the impact of that variability (or consistency) on children's development, school readiness, and later achievement. In addition, the components of sensitive responsiveness (promptness, contingency, and appropriateness) must be considered when assessing the utility of teachers' interactions over time (Bornstein, 2008). One cannot assert that consistency at any level of quality is sufficient to meet children's needs, or that a consistently harsh teacher imparts the same benefits to young children's development as a consistently attentive and accessible teacher.

Summary. Preschool in America has evolved from a social service provided by 
charitable organizations as way of fulfilling their obligation to the poor to a publicallyfunded initiative meant to counteract the effects of poverty on young children as well as a multi-billion-dollar-a-year business funded by parents, local, state and federal governments as well as faith-based organizations. A few well-publicized pilot projects suggest that preschool enrollment is related to later achievement and school readiness, and a large meta-analysis showed an overall link between early childhood care and later beneficial outcomes. The next section discusses the active ingredients of preschool quality and provides definitions, theories, and prior research addressing the link between the quality of preschool programs and children's development of cognitive and socialemotional skills.

\section{Preschool Quality and Children's Development}

This section defines the constructs necessary to understand children's development in the preschool context, provides two theoretical frameworks for understanding the mechanisms of development and learning as they relate to preschool classrooms, and describes prior research on preschool quality and children's development.

Definitions. Defining development. By definition, participation in preschool programs is limited to the few years prior to kindergarten entry. However, this is only a small fraction of a child's potential lifetime and any concurrent or future impacts of preschool must be considered in the context of the developmental processes and stages through which children proceed. Patterns of constancy and change over the lifetime can be categorized by the processes of development within which they take place - 
biological, cognitive, and social-emotional.

Biological, or physical, developmental processes involve changes in a person's brain and body, including the nervous system and muscles, sensory capabilities, and needs for food, drink, and sleep. Cognitive developmental processes refer to changes in a person's intellectual abilities including language, learning, memory, problem solving, and intelligence. Social-emotional developmental processes encompass how a person's relationships and interactions with others grow and change over the lifetime as well as changes in emotions and personality (Santrock, 2011). Each of these developmental processes is dependent upon and intertwined with the others and each continues to occur across the lifespan from conception to death.

Researchers often describe the lifespan in terms of periods of development ranging from the prenatal period to late adulthood (Santrock, 2011). This study focuses on the period of early childhood, commonly defined as starting about two years of age and reaching until children are approximately six years old (Santrock, 2011), and the cognitive and social-emotional developmental processes which take place within this period in the context of the preschool environment.

Defining Preschool quality. Looking back through the history of preschool in the United States as well as the Abecedarian, Chicago Parent-Child, and Perry Preschool studies and the Camilli et al. (2010) meta-analysis, one is able to deduce that enrollment in a preschool program generally has a positive impact on children's development and is related to school readiness and later achievement. But what specifically about the environments within which children learn makes the greatest difference? What are the 
most important aspects of preschool classrooms for predicting the outcomes of physical, cognitive, and social-emotional developmental processes? In other words, how is quality conceptualized and measured in the preschool context?

There is a vast literature base reflecting research on the nature of high-quality preschool and the ways in which it has been measured. Aspects such as teacher/child ratios, health and safety measures, children's interactions with peers and teachers, and the education and training of the teachers have all been investigated (Vandell \& Wolfe, 2000). Measures of quality are typically divided into structural quality, which addresses characteristics of the physical environment and those aspects of care that can be regulated by policy, and process quality, which attempts to measure children's direct experiences in the classroom: how they are taught by teachers, peers, and the environment (Vandell \& Wolfe, 2000).

Structural quality. Each year the National Institute for Early Education Research (NIEER) publishes a report on state-funded pre-K programs' adherence to "10 researchbased quality standards benchmarks" (Barnett et al., 2014, p. 10). The NIEER standards against which state programs are compared include measures of teachers' education and training, inclusion of comprehensive learning standards in the curriculum, teacher-child ratios and class size, and services offered by the programs including meals and referrals (Barnett et al., 2014). Professional organizations such as the American Academy of Pediatrics and the American Public Health Association also publish similar guidelines which address aspects of child care which can be easily identified, quantified, and regulated by governmental policies. 
However, many researchers agree that these indicators of structural quality often play a more distal role in children's developmental processes than the experiences they have on a daily basis, described next as process quality.

Process quality. Process quality refers to the "range of features within (preschool) settings that children directly experience on a daily basis" (Mashburn, 2014, p. 274). In everyday terms this is the important work of teaching: how teachers and children engage in learning opportunities, how the learning space is set up, how teachers and children use the spaces available to them, how and what types of conversations or periods of instruction are carried out, how emotions, opinions, and social encounters are expressed. Do teachers actively listen to students or do they appear uninterested? Do they expand on children's thoughts and support their view of the world? How does a teacher react to conflict or a student's distress? To what degree are the children allowed to choose freely and engage in long periods of uninterrupted play? The list of teaching activities or behaviors is endless but is typically narrowed to a few key aspects that can assessed through raters' observations of the spaces, supplies and materials, activities, interactions, and/or routines children experience across a range of settings in the preschool context (Mashburn, 2014; Vandell \& Wolfe, 2000).

Several instruments including the Classroom Assessment and Scoring System Pre-K (CLASS; Pianta, La Paro, \& Hamre, 2008), the Early Childhood Environment Rating Scale - Revised (ECERS-R; Harms, Clifford, \& Cryer, 2005), the Early Language and Literacy Classroom Observation (ELLCO; Smith, Brady, \& Anastasopoulos, 2008) and the Caregiver Interaction Scale (Arnett, 1998) are typically used to assess the process 
quality of classrooms. These focus on discrete observable dimensions of the teaching practice including how warmly and respectfully teachers and students interact, how instances of misbehavior occur and are managed, the amount of supervision and encouragement provided by teachers and peers, the availability of, and access to, learning materials in different areas of the classroom, children's writing and language activities, and the type and quality of spaces and furnishings available to children. The current study uses the CLASS as a measure of process quality in preschool classrooms with particular attention paid to the quality of emotional support present in the classroom environment.

Defining outcomes. Integral to understanding the results of interactions between developmental processes and preschool quality and consistency is defining which outcomes are of interest and how they are measured. This section addresses cognitive and social-emotional outcomes as they relate to optimal development in preschool, subsequent school readiness, and later school achievement and social interactions. The third domain of developmental processes, physical or biological development, is not addressed in the current study due to lack of participant data in this area.

Cognitive outcomes in research on preschool effectiveness and school readiness are generally defined in terms of academic or pre-academic skills. Early math and language and literacy are the most commonly assessed skills both during and after preschool. Direct assessments of preschool children's language skills may include measures of receptive vocabulary (Dunn \& Dunn, 2007); literacy skills may include print knowledge, definitional vocabulary, and phonological awareness (Lonigan, Wagner, Torgeson, \& Rashotte, 2007); and early math skills may include numbering skills, 
number-comparison facility, and numeral literacy (Ginsburg \& Baroody, 2003). Later measures of language, literacy, and math reflect similar constructs in an increasingly complex and age-appropriate manner.

Information about young children's social-emotional adjustment in preschool classrooms is most often acquired through the use of teacher reports. Areas such as task orientation, behavior control, assertiveness, and peer social skills (Perkins \& Hightower, 2002) are commonly rated by a teacher who knows the child well and who can offer insight into their social-emotional skills and behaviors. Typically, measures of socialemotional development include items asking teachers to rate children compared to others the same age.

Summary. By breaking down what happens in the preschool classroom and understanding the work of teachers we are able to lay the groundwork required to create a theoretical link among the constructs. The next sub-section describes two theoretical perspectives for understanding the relationship between the quality of what happens in the preschool classroom and children's development.

Theoretical Perspectives. The ecological theories of development (Bronfenbrenner, 1979; Bronfenbrenner \& Morris, 2006) provide a framework through which the processes of developmental change in early childhood can be further understood as they relate to children's experiences of quality in the preschool classroom and later outcomes. The ecological theories of development were first described in terms of four environmental systems and were eventually expanded to include two propositions related to the mechanisms through which the systems are theorized to act on 
developmental processes. This sub-section describes each of the theories and their relationship to understanding children's development in preschool settings.

Ecological Systems Theory. Bronfenbrenner (1979) described four systems within which developmental processes theoretically take place - the microsystem, mesosystem, exosystem, and macrosystem. The microsystem, as applied to a four-yearold preschool student, is comprised of the activities, roles, and relationships in which the child engages in a preschool classroom and related settings (Bronfenbrenner, 1979). The people, objects, routines, and interactions which directly influence a child and which the child helps shape through patterns of experience define the microsystem. Examples of experiences within a child's microsystem are conversing with a peer in a preschool classroom or wrestling with an older brother at home.

The mesosystem recognizes the importance of relationships between two or more microsystems in which the preschool student is actively involved (Bronfenbrenner, 1979). In this situation, the child belongs to both the home and school microsystems and is thus influenced by interactions between his parents and teachers. How often his teacher emails his mother may eventually influence the child's social development, although he is not directly involved in their interactions.

More distant from the child than the mesosystem, the exosystem consists of settings in which the child does not actively take part but by which she is nevertheless affected (Bronfenbrenner, 1979). The classic example of a mesosystem is a parent's workplace, where decisions about schedules will impact the child's classroom routine when she is picked up later than usual. Similarly, decisions made by preschool program 
administrators about what to serve for meals take place outside of the child's immediate setting (the preschool classroom) but may affect her experiences at home if she does not receive adequate nutrition during the day.

Finally, and most distally, the cultural, societal, and economic systems within which the child lives make up the macrosystem. The macrosystem influences the child's development through the norms, attitudes, and ideologies that are transmitted by those both close and more distal to her everyday life (Bronfenbrenner, 1979). A child who grows up in a town in a small Northern European country will have a vastly different experience prior to starting school than a child who is born in a large, impoverished South American city at the same time.

Ecological Systems Theory steps through a series of contexts and settings which Bronfenbrenner theorized influence the developing child. It defines the ways in which a child's development may be impacted by everything from the relationship she shares with her teacher to the prevailing religious and moral environments of the country in which she lives. Over time Bronfenbrenner refined his theory to include information about the magnitude of influence of each system, recognizing that there were discrepancies between his original intent and the way the theory was being operationalized in research (Mashburn, 2014).

Bioecological Model of Development. The Bioecological Model of Development (Bronfenbrenner \& Ceci, 1994; Bronfenbrenner \& Morris, 1998; 2006) builds on Ecological Systems Theory through the introduction of proximal processes as the engine of development and the mechanism through which aspects of the microsystem impact 
development and discusses the potential for moderation of influences by several factors. The first proposition of the Bioecological Model states that development takes place through proximal processes, defined as direct interactions between the developing child and the persons, objects, and symbols in his or her immediate environment that occur regularly, are sustained, and which increase in complexity over time (Bronfenbrenner \& Morris, 1998; 2006). Proximal processes are the repeated, reciprocal interactions in which children engage that in turn affect their development, everything from listening to a story being read aloud many times to practicing how to tie shoes and button shirt buttons and observing and describing the weather throughout the year. Or, on the other side of the spectrum, proximal processes can involve conversing primarily with adults with a limited vocabulary, eating a nutrient-poor diet, or avoiding appropriate social interactions with peers. The occurrence, repetition, and increasing complexity of proximal processes are all important factors when considering their benefits to development and are central to the current study.

The second proposition of the Bioecological Model states that the impact of proximal processes on development varies systematically, or is moderated, as a function of the person and the environment (Bronfenbrenner \& Morris, 1998; 2006). For example, although the majority of children in preschool classes memorize the alphabet, how they acquire this skill is greatly affected by both their individual characteristics and characteristics of the environments in which they are learning. A child with a physical impairment, such as hearing loss, will learn very differently than a child who hears normally. A classroom with many opportunities for children to interact with text through 
songs, books, posters, puzzles, and writing materials will provide different learning opportunities than a classroom with a scarcity of books and few periods of organized teacher-directed instruction. In this example, a hearing-impaired child in a classroom void of specialized learning opportunities will have a very different language outcome than a child with normal hearing in a text-rich environment.

Summary. The mechanism through which children's environments influence their development was framed theoretically first by the Ecological Model of Development and later by the addition of two propositions addressing 1) interactions between the child and his environment and 2) the role the person himself plays in moderating the influence of his environment. Identifying which aspects of preschool settings - which interactions, teaching styles, relationships, settings, routines, individuals, and materials - are most relevant when the goal is children's optimal development has been the subject of many years of research. This research will be described in detail in the next sub-section.

Quality to Outcomes. Researchers have sought to understand how structural and process quality relate to outcomes of interest for many years. Most studies have focused on cognitive and social-emotional development as the goal of preschool programs with the aim of reducing the achievement gap and providing a more positive achievement trajectory at kindergarten entry. Despite the apparent simplicity of the questions regarding associations between quality and outcomes, the results of a vast amount of research over the past thirty-five years are less than clear. This section describes findings related to the interactions among structural quality, process quality, and cognitive and 
social-emotional outcomes.

Structural quality and outcomes. The relationship between structural quality and children's development during preschool has been found to vary according to the time period in which the studies were conducted (Mashburn, 2014). Results of research from the 1980s and 1990s generally support the conclusion that features of childcare settings such as teacher education and training, teacher-child ratios, class sizes, and curriculum type are related to children's development of cognitive and social-emotional skills (Mashburn, 2014; National Institute for Child Health and Human Development [NICHD], 1999; Vandell \& Wolfe, 2000). In contrast, more recent large-scale studies have found no effect of structural quality on the same outcomes (Early et al., 2007; Howes et al., 2008; Mashburn, 2008). The most plausible explanation for this shift is the changing role of government funding and regulatory oversight in relation to the programs involved in the studies. In the 1980s and 1990s the programs surveyed were less likely to have received public funding and oversight from governmental agencies, thus allowing a wider range in variability across programs than is possible in the current era. Today the majority of programs studied receive government funding and are therefore required to more closely adhere to quality standard benchmarks resulting in less variance in structural quality (Mashburn, 2014).

Process quality and outcomes. An extensive body of literature examining numerous indicators of process quality and multiple measures of development and school readiness has consistently found that preschool process quality positively predicts children's cognitive and social-emotional development prior to kindergarten entry (e.g., 
Burchinal et al., 2010; Curby et al, 2011; Howes et al., 2008; Mashburn et al., 2008; Molfese, et al., 2012; NICHD, 2002; Peisner-Feinberg \& Burchinal, 1997; RimmKaufman et al., 2009). This is a partial answer to the big question: How teachers and children engage with one another in the classroom matters when it comes to preparing children cognitively, socially, and emotionally for kindergarten and later achievement.

The Bioecological Model of Development (Bronfenbrenner \& Morris, 1998; 2006) suggests that the physical and social resources (social interactions) immediately available to children in classrooms are closely related to concurrent and subsequent development. Assessments of process quality build on this association by considering how "in-tune" the classroom environment, mainly comprised of teachers and peers, is with individual children's needs. For example, raters using the CLASS consider to what extent teachers challenge students' receptive vocabulary skills by using a variety of words and advanced vocabulary while at the same time remaining sensitive toward students' current level of understanding. The alignment of those aspects of teaching defined as process quality (including but not limited to peer interactions and children's use of materials) and children's developmental needs in a preschool context ensures that the resources made available to children are designed to foster their development.

One of the most widely-used assessments of the quality of classroom interactions is the Classroom Assessment and Scoring System - Pre-K (Pianta et al., 2008). The CLASS is comprised of three domains, Emotional Support, Classroom Organization, and Instructional Support, each of which assesses specific aspects of the preschool classroom experience (Pianta et al., 2008). One of the most important predictors has been higher 
ratings of teachers on the Emotional Support dimensions, which capture how teachers help children develop positive relationships, enjoyment in learning, comfort in the classroom, and appropriate levels of independence, have been positively related to young children's social competence, lower problem behaviors, and higher levels of academic achievement (Hamre \& Pianta, 2005; Howes et al., 2008; Mashburn, 2008; National Center on Quality Teaching and Learning, 2012).

Summary. Structural and process quality in preschool settings have both been linked to children's development of cognitive and social-emotional skills and competencies. The largest and most consistent effects have been found when examining those aspects of process quality which are aligned with children's developmental needs interactions between children, teachers, and peers, instructional processes and routines, and supplies, materials and space available to children - in terms of school readiness outcomes. The CLASS is widely used to assess these aspects of the classroom and provide information on the quality of children's environments.

Summary. This section has detailed the definitions, theoretical perspectives, and prior research necessary to create a picture of how the mechanisms of cognitive and social-emotional development and various aspects of preschool settings converge to predict and explain school readiness outcomes. The next section provides definitions, theories, and prior research addressing the link between the consistency of preschool experiences and children's development of cognitive and social-emotional skills.

\section{Consistency of Preschool Experiences and Children's Development.}

Like the rest of the world, teachers, children, and the preschool classroom 
environment exist in a dynamic state of change. From one day to the next the growth possible in a preschool classroom is almost palpable: one child has learned to identify a new letter while another can finally climb to the top of the climbing wall, a new teacher joined the team last week and is slowly getting used to the children's routines, the use of descriptive words and probing questions by the four-year-olds is driving a sudden interest in creative writing about wild animals. Recognizing that change is constantly occurring is an important step toward understanding the value of consistency in certain specific aspects of how teachers teach.

Definitions. Defining consistency. Consistency, while often referenced in research literature on children's development in home and early education contexts, is rarely clearly defined by those who use it. Oxford Dictionaries (2014) offers a definition that fits the context of preschool caregiving as "the achievement of a level of performance that does not vary greatly in quality over time." This is a good start but certainly not thorough enough for this study.

First, it is important to distinguish consistency, as maintenance of a level of responsiveness, from sameness or rigidity. Optimally, teachers' consistency does not take the form of responding in the same way to every child in every situation. Instead, the hallmark of sensitive consistency in the classroom is offering an appropriate level of support in various situations, with various children, at various times. For instance, a teacher who has a consistently kind and sensitive manner of interacting with children may offer one child a warm smile during a quiet moment and later provide another child with a high-five after he finished running an obstacle course on the playground. Both 
instances reflect the teacher's emotional connectedness with her students while at the same time being appropriate to the dynamic nature of the classroom.

Second, consistency must include all of the elements of sensitive responsiveness (promptness, appropriateness, and contingency) to be considered beneficial to children's development (Bornstein, 2008). A teacher who always replies with rudeness, sarcasm, or harsh language cannot be lumped together with a teacher who regularly treats her students with respect, seeks their input when making plans, and listens eagerly to their words.

Third, teachers and children in preschool classrooms tend to spend a vast amount time together, up to ten or twelve hours a day in some situations. The way in which a teacher's behavior varies during the course of a day can have immediate impacts on the children who share the space with her. Imagine you are a child in a classroom where, in the morning, a teacher speaks softly, reacts calmly, and engages warmly. Then by lunchtime she is distant, uninterested, and cool and she finally ends the day either yelling at the children or actively ignoring them. This instability, or lack of consistency, directly affects how children feel which in turn dictates what they do and how they learn. This within-day variability is a more-present reality to children then changes distributed across the school year.

The theoretical mechanisms through which consistency is related to children's development have been addressed through the addition of time in Bronfenbrenner and Morris's Bioecological Model of Development, described in the next sub-section.

Theoretical Perspectives. The Chronosystem. Bronfenbrenner and Morris 
(2006) summarized the results of studies examining the connection between household stability over time and children's development and distilled the findings to suggest a corollary to the Bioecological Model of Development: the chronosystem. This addition states that the "degree of stability, consistency, and predictability over time in any element of the systems constituting the ecology of human development is critical for the effective operation of the system in question" (pp. 820, emphasis added). Time in relation to children in preschool programs can be analyzed at three separate but interconnected levels. The macrochronological level (macro-time) can been seen in the political and social climate influencing preschool funding, the program structures of any particular preschool classroom, governmental policy requirements such as teacher training, and even regulations describing the number of square feet allotted per classroom per child. This level of time is often too distal from students to draw any meaningful conclusions about immediate impacts on their learning.

On the level of the individual child micro-time consists of the infinite variety of moment-to-moment interactions in which a particular child takes part, each of which is unique from every other interaction. For example, engaging in a conversation with a teacher and then turning to eat a few bites of snack make up two separate microchronological events. This level of time is often difficult to capture in ways that are meaningful in a research context.

Bridging the gap between an individual child's unique momentary experiences and the overarching historical period within which a child finds himself is the mesochronological time system. Meso-time spans hours, days, and weeks and is the 
concept of time within which the current study is grounded (Tudge, Mokrova, Hatfield, \& Karnik, 2009). The variations observed in teachers' behaviors within an individual day are privileged in the analysis and are theorized to make the most difference in how children engage with their learning environment, especially their teacher.

Most central to this study is Bronfenbrenner \& Morris's (2006) assertion that “proximal processes cannot function effectively in environments that are unstable and unpredictable across space and time" (p. 820). The chronosystems theory hypothesizes children's learn and development in preschool settings depends not only on the type or quality of any individual proximal process, but also on how those processes occur in meso-time. Whether proximal processes are predictable and repeated across time, settings, and people or take place in isolated episodes of time and are not repeated or sustained makes a difference. A child cannot learn to read in one day with no prior exposure to books, conversations, phonics, and a whole list of other necessary proximal processes. A child must be taught in a series of small steps that occur regularly over the course of many weeks, months, and years.

Attachment Theory. One of the central concepts of Attachment Theory is the internal working model: the mental representation a child develops of her primary caregiver (usually the mother) that is created based on prior experience and which influences how events are perceived and helps predict future behaviors (Bowlby, 1973). The internal working model is constructed through "continual transactions with the world of persons and objects" (Bretherton, 1985, p. 11) and becomes increasingly complex over time as a child accumulates experiences. When a child has a secure working model the 
caregiver is seen as responsive and accessible as a general rule. Because of this secure working model, the child is able to create a secure attachment with the attachment figure, most often but not always the mother. (Skinner, Kindermann, Roeser, Mashburn, Steele, \& Smith, in prep.). In contrast, a child develops an ambivalent insecure or avoidant insecure attachment with his primary caregiver if his bids for attention are not consistently met with an appropriate response.

In the mother/child relationship a secure attachment facilitates the child's exploration in ways that promote learning and continued healthy development. Children who have a secure attachment are better able to interact with peers and solve problems as well as self-direct and more eagerly explore their world (Skinner et al., in prep.). They see the world through a lens where their needs have been met in a consistent manner and they trust that this will continue to be the case as they grow and venture further from their secure base.

Research suggests that preschool children can form attachment-like bonds with their teachers that mirror the types of attachment seen between caregivers and children (Birch \& Ladd, 1997; Howes \& Ritchie, 1999). In preschool settings a child with a secure attachment-like bond with his teacher typically exhibits the same types of behaviors that characterize a secure mother-child attachment, including keeping track of and using the teacher as secure base from which to explore, seeking comfort and reassurance from the teacher, and observing and interpreting the teacher's facial expressions and emotions (Pianta, Nimetz, \& Bennett, 1997). Ainsworth (1979) suggests that children who feel secure display more intense interest in exploring, are more enthusiastic in problem- 
solving, and have longer periods of exploration. In both the family and preschool classroom context securely-attached children are also characterized as exhibiting more curiosity and being more likely to engage in self-directed activities instead of relying on an adult, although they are willing and able to solicit help when needed (Ainsworth, 1979; Skinner et al., in prep).

Preschool exploration and problem-solving can take many forms, the majority of which are conducive to the cognitive and social-emotional development and school readiness outcomes previously discussed. For example, a child who enters preschool with a secure working model and who is able to create an secure attachment-like bond with her teacher by virtue of the teachers' sensitive responsiveness can spend more time working on a puzzle before getting frustrated or venture a little further into her imagination through dramatic play with peers before mentally or physically returning to check in with her teacher.

Summary. The convergence of constructs from the Bioecological Model of Development and Attachment Theory results in a more robust model of the mechanisms through which children learn and develop than either theory provides alone: Higher quality and more consistently supportive classroom environments are related to better school readiness outcomes through the influence of a particular pattern of proximal processes in which any unique child engages over time. In classrooms with teachers who are predictable, helpful, kind, and approachable children feel supported in ways which allow them to venture into learning opportunities that help promote the highest possible level of cognitive and social-emotional knowledge and skills. The next sub-section 
summarizes prior research on the impact of consistency in children's environments on their cognitive and social-emotional development.

Consistency to Outcomes. Traditionally, the quality of classroom interactions has been treated as a static variable with any variance attributed to measurement error from various sources (Mashburn, 2014; Pianta et al., 2008). Teachers have been assumed to exhibit a typical level of emotional support that remains relatively constant across observations and time periods, thus justifying the creation of a single-number variable (e.g., Burchinal et al., 2010; Mashburn et al., 2008). However, recent research suggests that the variability in observer ratings of teachers' emotional support within and across days is itself a valuable source of information when considering children's cognitive and social-emotional outcomes, both in conjunction with average levels of emotional support and on its own (Brock \& Curby, 2014; Curby et al., 2013; Curby et al., 2011; Zinsser et al., 2013). This section summarizes prior research on the link between consistency in children's environments, both in the home and in school settings, and their development, as well as potential child-level moderators of these relations.

Family literature. Researchers interested in the relations between consistency of caregiving and child outcomes first focused on the role of responsive parenting (reactions to children's bids for attention in day-to-day interactions that are prompt, appropriate, and contingent) in young children's lives. Landry, Smith, Swank, Assel, and Vellet (2001) examined the relations between mothers' levels sensitive responsiveness (dichotomized into high and low) during their child's infancy and again in toddlerhood/preschool. They used these patterns (high in infancy/high in preschool, high in infancy/low in preschool, 
etc.) to predict children's cognitive development at 54 months. Children whose mothers exhibited a high-high pattern of responsiveness showed the most beneficial growth pattern on cognitive outcomes while the absence of responsive parenting (low-low pattern of responsiveness) predicted significantly slower rates of cognitive growth. Mixed patterns of responsiveness predicted growth patterns between the two consistent patterns. These results highlight the importance of mothers' continuing to provide a high level of consistent support over the first several years in order to meet children's ongoing cognitive needs (Landry et al., 2001). As expected, a low-low pattern which indicated a sustained lack of sensitive parenting predicted the poorest developmental outcomes, suggesting that both the typical level (mean) and consistency (pattern) of responsiveness are important when predicting children's development.

The families who took part in Landry et al.'s 2001 study were followed for an additional four years with mothers' responsiveness assessed again when children were six and eight years old (Landry, Smith, \& Swank, 2003). Mothers' early patterns of responsiveness (infancy to preschool) continued to predict more optimal cognitive and social development for children at eight years of age, even when later parenting was controlled. This pair of studies suggests that consistency in caregivers' patterns of sensitive responsiveness during the first four years has the potential to make a difference in children's cognitive development during the early years and continues to have an impact well into their formal schooling years.

Summary. Research suggests responsiveness in mothers' caregiving from early infancy through preschool influences children's cognitive development through first 
grade with early experiences and increasing sensitivity having the greatest effect on later achievement (Landry et al., 2001; Landry et al., 2003). Recent research on consistency has grown to include the preschool environment, including the quality of teacher care, and children's cognitive and social-emotional development. This line of classroomfocused research will be discussed in detail in the following sub-section.

Classroom literature. A recent line of research is investigating the importance of consistency of high-quality care as a necessary condition for children to develop a beneficial attachment-like bond with a caregiver which in turn provides them with support for optimal learning and development.

A study conducted by Wood (2007) provides a theoretical bridge between children's attachment within the family, as described in the previous section, and their academic competence during preschool. Woods suggests that children's internal working model - operationalized as how secure and trusting they were assessed to be by their mother at age three - was predictive of their social-emotional skills in preschool. Most importantly, Wood theorizes that children who lack a secure base either at home or in the classroom may not feel comfortable enough to fully partake in exploring their environment as part of the learning process. In addition, an insecure attachment with a mother may help "set the stage for heightened anxiety" which in turn can directly interfere with the proximal processes involved in children's learning (Wood, 207; pp 235).

Starting with a broad view of the preschool environment as the number of teachers and rooms that children may experience through the course of a typical day 
Clasien de Shipper, Van IJsendoorn, and Tavecchio (2004) found that young children ( $n=186$, mean age $=18.6$ months) who experienced fewer changes in their environment and whose trusted teachers were more available fared better in terms of fewer problem behaviors and better adjustment to the classroom. Specifically, when one or more trusted caregiver was regularly available when needed (sample item from assessment: "When this child is upset, a trusted caregiver takes care of him/her" [Clasien de Shipper, et al. (2004), p. 14.) children were perceived as being more comfortable and at ease in the preschool setting. Although this study relied on teacher ratings of both their own availability and children's well-being it serves as an introduction to the potential importance of consistency in predicting children's success in preschool.

Using the same measurement instruments as this study Curby and colleagues (2013) directly examined the degree to which the consistency of teachers' scores on the emotional support domain of the CLASS predicted children's cognitive and socialemotional development above and beyond mean levels of classroom emotional support using a large, nationally representative sample of children in early childhood education settings (child $n$ varied by outcome between 1,758 and 2,439; classroom $n=693$ ). The researchers theorized that consistency of emotional support in the classroom would be related to children's development through the same mechanisms described in this study, including a secure attachment-like bond with the teacher and the accumulation of supportive social interactions over time used as a basis for exploration and learning.

Children were assessed in the fall and spring of their preschool year on measures of receptive and expressive vocabulary, rhyming, applied problems, and letter naming. 
They were also rated by teachers using a measure of social competence and problem behaviors during the fall of their kindergarten year. Results indicate that the consistency of emotional support, calculated in a multi-step process that privileges within-day variability while considering experiences across the year, was predictive of children's development. In some cases consistency of emotional support was found to be predictive of children's development above and beyond mean levels of emotional support. When consistency of emotional support was entered into multi-level models without mean emotional support it was found to be a statistically significant predictor of development on all five academic and both social-emotional outcomes. When combined with mean emotional support, consistency continued to be a significant predictor of three language outcomes (expressive vocabulary, rhyming, and letter naming) and social competence as rated by kindergarten teachers whereas mean emotional support did not predict any of the outcomes. Children in classrooms where teachers exhibited higher levels of emotional support consistency had "superior achievement gains and displayed more social competence the following year" (Curby et al., 2013, pp. 303) when compared with children who had experienced less consistent emotional support in interactions with caregivers over the preschool year. This study did not consider the level at which variability occurred, focusing instead on lack of variability across the board.

The teacher-related changes children experience on a day-to-day basis in the preschool classroom can influence how they behave and how comfortable they feel in those spaces (Clasien de Shipper et al., 2004). The consistency of teachers' emotional support in preschool classrooms, conceptually very similar to aspects of sensitive 
responsiveness in parenting, has been found to be predictive of children's cognitive and social-emotional outcomes (Curby et al., 2013). Wood (2007) theorizes that this connection is due to children's ability to form secure attachment-like relationships with their caregivers which then allow them to more confidently explore their surroundings and thus engage in the proximal processes necessary for optimal learning and growth.

On the classroom level the consistency of teacher emotional support in conjunction with teachers' mean level of emotional support has been theoretically and analytically linked to children's developmental outcomes. The unique characteristics children bring with them to preschool should also be considered as part of future analyses to create a more nuanced picture of the preschool environment. This potential source of moderation is discussed in the next section.

Potential moderators. Until this point much of the research on the role of consistency in predicting child outcomes has ignored the characteristics of children such as self-regulation skills, family socioeconomic status, race, ethnicity, gender, English Language Learner status, and age. These characteristics have generally been interpreted in educational research as risk factors: those individual variables which may inhibit a child's ability to develop cognitive and social-emotional skills at an optimal rate. They act as stand-ins for children's "social addresses" or those factors outside of a child's control that may influence their ability to consistently and progressively partake in a particular set of proximal processes (learning environments and interactions) that are most beneficial for their development. A child who is raised in a severely economicallydisadvantaged situation may not have had access to a diverse array of toys, games, or 
books and because of this will enter preschool with fewer skills.

Brock and Curby (2014) suggest in their latest publication on consistency that child characteristics should be considered in future research on teachers' emotional support consistency as a way of getting a more fully-developed understanding of for whom this indication of classroom quality matters the most. The role of socioeconomic and behavioral characteristics as potential moderators of children's development in the preschool context can be separated into two outcomes: cognitive, or academic, achievement and social-emotional skills. Each of these is important for predicting children's school readiness and success as they progress through elementary school and beyond, with early math scores being particularly indicative of later academic achievement (Duncan at al., 2007; Claessens, Duncan, \& Engel, 2009).

Self-regulation. Self-regulation in early childhood is widely recognized as a critical component of school readiness, a significant predictor of children's social development and academic ability, and a child-level characteristic that has implications for both cognitive and social-emotional outcomes throughout elementary school and beyond (Blair \& Diamond, 2008; Brock, Rimm-Kaufman, Nathanson, \& Grimm, 2009; Howse, Calkins, Anastopoulos, Keane, \& Shelton, 2003; McClelland, Cameron, McDonald Connor, Farris, Jewkes, \& Morrison, 2007; Moffitt et al., 2011; Morrison, Ponitz, \& McClelland, 2010). Children with lower levels of self-regulation skills are more likely to enter school with more behavioral challenges and greater barriers to optimal development. Teacher ratings of children's ability to focus on school-related tasks at the beginning of the preschool year were used in this study as the first risk factor. 
Scores on the self-regulation measure were used to create two groups of children. Those children who scored more than one standard deviation below the mean were identified as having low self-regulation skills while all others were identified as not having low selfregulation skills.

Socioeconomic status. Socioeconomic status has consistently been one of the strongest predictors of children's academic achievement from a very early age (Halle et al., 2009; Reardon, 2011). Young children from low-income households transition into the formal education system with a greater probability of having limited experience with environments and interactions (proximal processes) meant to promote optimal cognitive and social-emotional development. As a result, they tend to enter the school system with significantly fewer academic skills, a gap in achievement which remains stubbornly persistent as children progress through school (Reardon, 2011; Stipek \& Ryan, 1997). In addition, the reported rate of behavioral issues in preschool settings for low-income children is five to ten times that of children from higher socioeconomic status families (30\% as compared to $3-6 \%$ ) and low-income children are significantly less likely to receive positive behavioral ratings from their caregivers as young as nine months old (Halle et al., 2009; Qi \& Kaiser, 2003). Free or reduced-price lunch status (“free/reduced lunch") was used as a proxy for family socioeconomic status in this study, with children who qualified for free or reduced-price lunches designated as higher risk than children who did not qualify for these income-based benefits.

Race and ethnicity. Due to a wide variety of social, economic, cultural, and contextual factors which influence their early development, members of African- 
American and Hispanic minority groups tend to enter first grade with reading and math skills up to one half of a standard deviation behind their Caucasian peers (Burchinal et al., 2011). This well-documented achievement gap has been measured with children as young as three years old and is clearly evident by the time children enter kindergarten (Burchinal et al., 2011). The racial/ethnic achievement gap persists and continues to widen as children progress through school, impacting academic achievement and graduation rates. Both race (African-American) and ethnicity (Hispanic) were used as separate child-level risk factors in this study, with children identified as AfricanAmerican or Hispanic designated as facing more risk than their peers of other races or ethnicities.

Gender. The effects of gender differences tend to be most visible in early education settings when examining behavioral or social skills, although there is some evidence of differences in pre-academic skills (Matthews, Ponitz, \& Morrison, 2009; Zill $\&$ West, 2001). Areas of performance where disparities can be attributed to gender include communication, paying attention, maintaining an appropriate level of physical activity in the classroom, cooperative friendship-building behaviors, following directions, focusing, and inhibitory control (Matthews et al., 2009; Zill \& West, 2001). Boys were designated as higher risk than girls in this study.

English Language Learner. Children who do not speak English as a first language face unique challenges in terms of school readiness, later academic achievement, and high school graduation rates, with differences on both cognitive and social-emotional measures showing up as early as nine and 24 months (Center for Public 
Education, 2007; Halle et al., 2009). English Language Learners were categorized as facing more risk than their peers in this study.

Age. Developmental theory suggests that children who are younger than their peers have less-well-developed cognitive and social-emotional skills than their older peers (Santrock, 2011). Zill and West (2001) found that children's age was associated with differences in virtually every area of kindergarten development, including academic knowledge, social skills, and behavior. Children's age was mean-centered to aid in interpreting the results of the regression equations.

Not all children enter early childhood education settings with the same level of cognitive and social-emotional skills and not all children develop subsequent new skills at the same rate. Some of the differences in where children start and how quickly they grow can be attributed to individual level characteristics which occur as a result of their “social address" including self-regulation skills, family socioeconomic state, race/ethnicity, gender, English Language Learner status, and relative age (Burchinal et al., 2010; Mashburn, 2008; Montes, Hightower, Brugger, Moustafa, 2005). In some ways, these child characteristics can serve as starting points for teachers who are in-tune with their students.

A sensitive and skilled teacher can recognize a child who enters the classroom lacking a particular skill because of no prior opportunity to practice that skill. She can then purposefully engage in creating learning new opportunities for that child. For instance, a teacher sees that a four-year-old girl does not know how to properly hold a book (spine on the right, title at the top) and is able to deduce that it is because she has 
had little prior exposure to books. The teacher can then work more intensely with the student by guiding her, modeling the right way to hold a book, and encouraging her inclusion in a peer reading group. This type of directed teaching can help children who start further behind catch up to their peers, which is understood statistically as developing at a greater rate.

Summary. Children's attachment to parental caregivers, primarily the mother, was first described theoretically in the 1960s and 1970s (Ainsworth, 1979; Bowlby, 1969; 1973; Bretherton, 1985). At that time sensitivity was described as a hallmark of a responsive mother: one who engaged in prompt, appropriate, and contingent reactions to her child's bids for attention which in turn promoted the development of a secure attachment and thereby facilitated optimal cognitive and social-emotional growth in her child (Ainsworth, 1979). Prior research in the family context has found that patterns of responsiveness in caregivers' interactions with infants and toddlers are predictive of children's cognitive and social-emotional development through elementary school (Landry et al., 2001; Landry et al., 2003). Recently, studies examining relations between the consistency of teachers' emotional support in school classrooms and children's school readiness have suggested similar results in the classroom context (Brock \& Curby, 2014; Curby et al., 2013; Zinsser et al., 2013). Future work remains to be done in understanding the implications of individual characteristics as moderators of the relationship between classroom emotional support and children's development.

\section{Chapter Summary.}

The narrative describing the creation and expansion of preschool provides a 
historical perspective on the shifting priorities of funders of preschool programs - local, state, and federal agencies as well as faith-based organization and parents - and concludes with the current era where preschool programs across the country receive billions of dollars per year in private and public funds and are increasingly being held accountable for preparing children for Kindergarten. Crucial to defining and assessing compliance with standard benchmarks of quality is first defining the developmental processes and needs of young children within theoretical frameworks that provide mechanisms for understanding how those indicators of quality impact learning and development. The bioecological theories of development, and in particular proximal processes, offer a perspective on interpreting how the quality of children's experiences in the classroom affects their development of cognitive and social-emotional skills and competencies.

The focus of research examining these relationships has also evolved over time. Initially quality was primarily defined and assessed in terms of those structural aspects of preschool programs which could be regulated by government agencies. More current research tends to assess the act of teaching - those indicators of quality which are directly experienced by children on a day-to-day basis and which are aligned with the Bioecological Theory of Development. Findings from numerous studies suggest that the classroom environment is a key predictor of children's school readiness, as well as later achievement and social skills.

Broad measures of the quality of classroom interactions, represented in this study by the Emotional Support domain of the CLASS, are still open to further refinement as a 
way to more accurately predict children's outcomes. Considering the variability involved in teacher/child interactions with a focus on within-day variability adds the dimension of time to assessments of quality, a dimension which is theoretically aligned with the constructs of both the Bioecological Theories of Development and Attachment Theory. These theories suggest that it is not enough to rely on a single-number variable as an indicator of the quality of classroom interactions across when children experience, and are affected by, changes in teachers' behaviors both during the course of a single day and across the year. 


\section{Chapter Three: Purpose of the Current Study}

The current study addressed questions on the influence of the quality of teachers' emotional support when interacting with students, the influence of variations in that level of quality, and the characteristics with which children enter the preschool classroom. It considered where children start based on their previous experiences, how these starting places affect where they end up in terms of school readiness, and what part teachers can play in mitigating any risks that may attach themselves to children's upbringings.

\section{Contributions}

The results of this study have the potential to make three contributions to our current understanding of the relationships among children's risk factors, quality and consistency of experiences in preschool classrooms, and school readiness outcomes, each of which will be discussed in the next sub-sections.

Refining the definition of classroom quality. Up until now research on classroom quality has focused on either what is in the classroom at one particular point (structural quality) or what is happening in the classroom at one particular point (process quality). This study goes beyond the traditional momentary view of what is inevitably a dynamic environment and integrates the relatively stability (or lack thereof) of teaching practices in preschool classrooms as a predictor of children's development. This study also does preliminary work in building a more useful definition of consistency, one which necessarily includes quality, by grouping classrooms based on information from both variables and using this composite identity in predicting development.

Self-regulation as More Than a Predictor. Low self-regulation is a well- 
established predictor of an increased probability that children will struggle both academically and socially in early education settings and the K-12 system. This study casts children's teacher-rated self-regulation skill at preschool entry in a different light by considering it as especially important for both mean emotional support and emotional support consistency on cognitive and social-emotional development. This line of inquiry goes towards helping to identify children for whom emotional support quality and consistency in the preschool context matters most and for whom it can make the biggest difference.

For Whom Does Emotional Support Matter Most? Finally, this study examines not only the classroom contexts which promote optimal cognitive and socialemotional development but will also identify the students for whom this pattern of highquality teaching matters most. In addition to children who enter preschool with low levels of self-regulation, this study will determine if there are differential effects of teachers' behaviors on children who are poor, younger, from ethnic and racial minority groups, male, or English Language Learners.

\section{Research Questions and Hypotheses}

Based on the definitions, theories, and prior research described in the previous chapters this study addresses the research questions detailed in this subsection.

Research Question One: A) Are children's socioeconomic and behavioral risk factors related to their cognitive and social-emotional skills at preschool entry?

Hypothesis One: A) This question investigates whether a relationship exists between children's risk factors and their skills at preschool entry. Numerous studies have 
shown that children from ethnic and racial minority groups, who are economically disadvantaged, and who are English Language Learners enter school with skill levels significantly behind their peers (Burchinal et al., 2011; Center for Public Education, 2007; Halle et al., 2009; Reardon, 2011). In addition, developmental science theorizes that children who are relatively younger than their peers will also have less developed cognitive and social-emotional skills (Santrock, 2011) and early gender differences in favor of girls have been found on measures of self-regulation and social skills, skills related to both social-emotional and cognitive outcomes (Matthews et al., 2009; Zill \& West, 2001). Children who experience these types of risk factors typically are not as likely to have experienced the proximal processes required to enter school with a fullydeveloped set of skills. For these reasons, it is hypothesized that children's socioeconomic and behavioral risk factors are associated with lower scores on all of the cognitive and social-emotional measures at preschool entry.

Research Question One: B) Are children's socioeconomic and behavioral risk factors at preschool entry related to their development of cognitive and socialemotional skills over the preschool year?

Hypothesis One: B) This question seeks to understand the ways in which children develop across the year based on the risk factors with which they enter preschool. Previous studies offer some conflicting evidence on the associations between children's individual and family risk factors and the development of cognitive and socialemotional competencies over the preschool year, although most large-scale studies indicate that preschool gains are larger for children with more risk factors (e.g., Brooks- 
Gunn \& Markman, 2005; Burchinal et al., 2010; Magnuson \& Waldfogel, 2005; RimmKaufman et al., 2009).

Based on prior research and theory and considering the schools, participants, and curriculum involved in this study, it is hypothesized that students who have lower teacher-reported self-regulation skills, or who are African-American, male, younger, English Language Learners, or from families with lower incomes will experience more pronounced cognitive and social-emotional development during the school year than their peers with fewer behavioral, social, and economic risk factors.

\section{Research Question Two: A) Is the mean level of emotional support in the} preschool classroom related to children's development of cognitive and socialemotional skills over the preschool year?

Hypothesis Two: A) The level of teachers' emotional support in preschool settings has consistently been found to be an indicator of children's skills development, particularly on measures of social-emotional functioning (Burchinal, Howes, Pianta, Bryant, Early, Clifford, \& Barbarin, 2008; Curby et al., 2009; Mashburn et al., 2008). The ways in which teachers engage in teaching behaviors such as creating a positive learning environment and connecting emotionally with their students are expected to impact how children learn. It is hypothesized that preschool classrooms with higher levels of emotional support will have a stronger benefit for children's development than classrooms with lower levels of emotional support.

Research Question Two: B) Do children's risk factors moderate the impact of teachers' mean emotional support in the preschool classroom in predicting 


\section{children's development of cognitive and social-emotional skills over the preschool year?}

Hypothesis Two: B) Findings from previous research indicate that children's risk factors act as a moderator on the impact of preschool quality (Burchinal et al., 2010; Mashburn, 2008; Montes et al., 2005). Based on evidence that higher-risk children benefit more from higher levels of classroom support, it is hypothesized that more emotionally supportive preschool classrooms will have a stronger benefit for children's development among children who experience greater risk compared to children who experience less risk. This question investigates whether the average level of emotional support with which teachers react to their students matters more in terms of development for those children who enter preschool with higher risk as compared to children with lower risk.

Research Question Three: A) Is the consistency of emotional support in the preschool classroom related to children's development of cognitive and socialemotional skills over the preschool year?

Hypothesis Three: A) Because previous research has shown that the consistency of emotional support in the preschool classroom is related to children's achievement (Brock \& Curby, 2014; Curby et al, 2013; Zinsser et al., 2013), it is predicted that preschool classrooms with more consistent levels of emotional support will have a stronger benefit for children's development than classrooms with less consistent levels of emotional support. Research question 3A seeks to isolate the impact of consistency of teachers' behavior on the average child's school readiness. 
Research Question Three: B) Do children's risk factors moderate the impact of teachers' emotional support consistency in the preschool classroom in predicting children's development of cognitive and social-emotional skills over the preschool year?

Hypothesis Three: B) It is expected that children who experience greater behavioral, social, and economic risks will benefit more from consistency in the preschool classroom than their peers who experience lower risk. Consistency, as seen through the lenses of proximal processes and working models, would seem to provide higher-needs children with more benefits as they develop emotional, social, and cognitive skills in the classroom (Montes et al., 2005). For this reason, it is hypothesized that preschool classrooms with more consistent within-day levels of emotional support will have a stronger benefit for children's development among children who experience greater risk compared to children who experience less risk.

Research Question Four: Are children's risk factors, the mean level of emotional support, and emotional support consistency in the preschool classroom related to children's development of cognitive and social-emotional skills over the preschool year?

Hypothesis Four: This question is a preliminary investigation of the impact of emotional support and emotional support consistency on children's school readiness while at the same time taking into consideration the level at which children enter the preschool classroom. Based on previous research on relations between and among each of the components it is hypothesized that children's risk factors, mean level of emotional 
support, and emotional support consistency will each positively predict spring scores on each of the outcomes measures when controlling for fall scores. 


\section{Chapter Four: Method}

Data for this study were collected by AppleTree Institute for Education Innovation as part of their implementation and evaluation of an evidence-based, highquality early childhood education instructional approach (Every Child Ready) in public charter preschools in the Washington, DC metropolitan area (AppleTree, 2014).

\section{Participants}

Participants were 95 teaching staff members and 593 children in 31 classrooms from five full-day, free, public charter preschool programs. The preschools serve children who experience high levels of social and economic risks. More specifically, $79 \%$ of the children $(n=466)$ qualified for free or reduced lunches and $21 \%(n=127)$ did not receive free/reduced lunch benefits. Eighty-three percent $(n=492)$ of children were Black/African-American, $14 \%(n=83)$ were White, 3\% $(n=18)$ were Hispanic, $2 \%(n=$ 10) were Asian, $1 \%(n=3)$ were Native Hawaiian/Pacific Islander, and $1 \%(n=4)$ were American Indian/Alaskan. Ten percent $(n=60)$ of the children were English Language Learners and 90\% $(n=533)$ were proficient in English. The sample was $51 \%$ female $(n=$ $302)$ and $49 \%$ male $(n=291)$. Children ranged in age from 2 years 11 months to 4 years 11 months $(M=3$ years 10 months). These child characteristics are displayed in Table 1 on Page 122.

The 31 classrooms and children in the sample were divided among five campuses. There were 170 children in eight classrooms at Campus One, 64 children in three classrooms at Campus Two, 166 children in eight classrooms at Campus Three, 175 children in eight classrooms at Campus Four, and 84 children in four classrooms at 
Campus Five. Classroom enrollment ranged from 19 to 23 students per classroom $(M=$ 21.26; $S D=1.03$ ) across all campuses.

The sample included 95 teaching staff members in 31 classrooms. Teaching staff positions included Teacher $(n=42)$, Assistant Teacher $(n=29)$, Teaching Fellow $(n=$ 18), School Aide $(n=4)$, and Special Education Coordinator $(n=2)$. The teaching staff was $7.4 \%$ male $(n=7)$ and $92.6 \%$ female $(n=88)$. The median age of the staff was 25 years old, with a median of four years of experience in the early care and education field. In 80 percent of the classrooms there were two or more teaching staff members in the classroom for at least 8 hours per day. Most of the teaching staff $(76.8 \%, n=73)$ held at least a bachelor's degree. These teacher characteristics are shown in Table 2 on Page 123.

\section{Procedures}

One cohort of students and teaching staff from the 2012-2013 academic year were included in this study. Children's cognitive and social-emotional outcomes were assessed by independent assessors at the beginning and end of the academic year using three different measures. Lead teachers also provided reports of children's social-emotional and behavioral skills in the classroom at the beginning and end of the preschool year. The quality of classroom interactions was assessed at three time points during the year (fall, winter, and spring) by trained independent assessors using the Classroom Scoring and Assessment System - PreK (Pianta et al., 2008).

\section{Measures}

\section{Child Characteristics.}

Socioeconomic risk. Several demographic characteristics of the children and their 
families were collected at the time of initial school enrollment from a parent survey. These data include the children's age, gender, free/reduced lunch status, race and ethnicity, and English Language Learner status. Free/reduced lunch status was converted to a dichotomous variable indicating whether the family was below $185 \%$ of the 2012 federal poverty guidelines for the family size (Department of Health and Human Services, 2012). Each of the risk factors except age were entered as dichotomous variables with the reference groups being the low-risk children (female, non-Hispanic, non-African American, English language proficient, and high self-regulation). Age was mean centered.

Behavioral risk. The Task Orientation subscale of the Teacher-Child Relationship Scale was selected as a measure of children's self-regulation at the beginning of the school year. This subscale assesses children's attention as well as their ability to complete tasks and follow directions on school-related tasks. According the measure's authors, students who score below the $15^{\text {th }}$ percentile, or approximately one standard deviation below the mean, on any subscale are considered to be at risk in that area (Montes et al., 2005).

Cognitive Outcomes. The assessments were conducted by contracted, trained independent assessors each of whom held a bachelor's degree in early childhood education or a related field and had previous experience working with children. Different assessors assessed children at the baseline and outcome time points to minimize potential bias.

Students' early language and literacy skills were assessed at the beginning and 
end of the school year using a measure of receptive vocabulary (PPVT) and a measure of early language and literacy (TOPEL).

Peabody Picture Vocabulary Test-4. The Peabody Picture Vocabulary Test, Fourth Edition (PPVT-4; Dunn \& Dunn, 2007) is a measure of receptive vocabulary for standard American English. During the assessment children were shown four pictures and asked to point to the one that best represents the word spoken by the assessor. Normreferenced scores were created by comparing individual children's scores to a normative sample of children in the same six-month age range from a sample of 3,450 individuals from two years six months to 81 years of age (Dunn \& Dunn, 2013). The PPVT-4 has been found to exhibit very high test-retest reliability (correlations between 0.92 and 0.96), split-half reliability (correlations of 0.94 and 0.95 ), and alternate-form reliability (correlations of 0.87 and 0.93) (Community-University Partnership for the Study of Children, Youth, and Families, 2011; Dunn \& Dunn, 2013).

Test of Preschool Early Literacy. The Test of Early Preschool Literacy (TOPEL; Lonigan et al., 2007) is a norm-referenced measure of young children's emergent literacy that comprises three subscales: print knowledge, definitional vocabulary, and phonological awareness. The TOPEL has been found to have two-week test-retest reliability coefficients from 0.81 to 0.89 (Wilson \& Lonigan, 2009). Convergent validity with other measures of similar constructs has been shown to be good (0.59 to 0.77$)$. The TOPEL has also been predictive of reading skills in kindergarten and first grade (as reported in Wilson \& Lonigan, 2009).

Student's early math skills were assessed at the beginning and end of the school 
year using a measure of early mathematical ability.

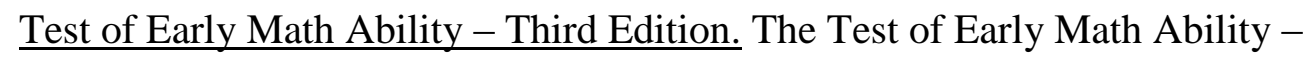
Third Edition (TEMA-3; Ginsburg \& Baroody, 2003) is a norm-referenced measure assessing children's mathematical conceptual understanding and skills including numbering skills, number-comparison facility, and numeral literacy. The tool is comprised of 72 items which assess knowledge of concepts such as numbers, comparisons, addition, subtraction, multiplication, and division (Molfese et al., 2012). It is designed to be used with children from three years to eight years 11 months of age. The two-week test-retest reliability is reported to be 0.82 (Molfese et al., 2012) and internal consistency reliability coefficients were found to be above 0.92 (Pro-Ed, 2012). In previous samples children's responses were scored on a record form and raw scores were transformed to Math Ability scores (Mean $=100, \mathrm{SD}=15$ ).

Lead teachers reported on their perception of children's social-emotional adjustment, including problem behaviors and competencies, at the beginning and end of the school year.

Social-Emotional Outcome. Teacher-Child Rating Scale Version 2.1. The Teacher-Child Rating Scale Version 2.1 (T-CRS; Perkins \& Hightower, 2002) is a 32item rating scale of teacher's perceptions of children's social-emotional and academic adjustment. Teachers provided ratings on how much they agree each item describes the child on a five-point Likert-type scale ranging from $1=$ Strongly disagree to $5=$ Strongly agree. Examples of items include "Has difficulty following directions", "Makes friends easily", and "Nervous, frightened, tense". 
The T-CRS comprises four subscales: task orientation, behavior control, assertiveness, and peer social skills. Each subscale contains four positively-worded items ("Completes schoolwork") and four negatively-worded items ("Has poor concentration, limited attention span"). Negative items were reverse coded for analysis. The Task Orientation domain assesses children's attention and ability to complete tasks and follow directions. Behavior Control measures children's tolerance for frustration, ability to cope with and adapt to limitations, and aggressive or noncompliant behavior. The Assertiveness subscale includes items assessing confidence, leadership, and skill in dealing with challenging social situations. Peer Social Skills assesses a child's likeability, skill in creating and maintaining friendships, and style of interacting with others. The test-retest reliability for 10 to 20 weeks reported by the publishers of the scale ranged from .61 to .91 (McCabe \& Marshall, 2006). Cronbach's alpha coefficients for the four subscales in two studies ranged from 0.84 to 0.94 (McCabe \& Marshall, 2006; Montes et al., 2005). A composite score was created by combining the scores on each of the four subscales.

Teacher Emotional Support. The quality of classroom interactions between the teaching staff and the students was assessed at three time points (fall, winter, and spring). Each time point consisted of two days of live observations with four 15-minute cycles of observation per day for a total of 24 separate observations across the year. The observations were conducted by trained independent observers during normal school hours.

The Classroom Assessment Scoring System - Pre-K (Pianta et al., 2008) is an 
observational measure that assesses teacher-child interactions that support children's learning and development (Hamre, Goffin, \& Kraft-Sayre, 2009). It assesses three domains of process quality in classrooms: Emotional Support, Classroom Organization, and Instructional Support (Hamre et al., 2009). Of particular interest in this study is the Emotional Support domain which reflects the degree to which teachers engage in practices that impact children's sense of a warm, sensitive, and responsive environment. The Emotional Support domain captures the processes through which teachers help children create positive relationships with others, develop a fondness for learning, find comfort in interactions within the classroom, and attain developmentally appropriate levels of independence (National Center on Quality Teaching and Learning, 2012). The Emotional Support domain comprises four dimensions: Positive Climate, Negative Climate, Teacher Sensitivity, and Regard for Student Perspective.

Positive climate refers to the "emotional connection between the teacher and students and among students and the warmth, respect, and enjoyment communicated by verbal and nonverbal interactions" (Pianta et al., 2008, p. 23). Classrooms that receive high scores on this dimension are characterized by teachers and children who are in close physical proximity with one another, who show positive emotions such as smiling and laughing, who communicate positively both verbally and physically, and who engage in calm and respectful interactions (Pianta et al., 2008).

Negative climate reflects the "level of expressed negativity such as anger, hostility, or aggression exhibited by teachers and/or students in the classroom" (Pianta et al., 2008, p. 3). Classrooms where negative affect, punitive control, sarcasm or disrespect, 
or severe negativity are evident are scored higher on the Negative Climate dimension. This includes behaviors such as anger or irritability from the teacher, aggression amongst peers, yelling or threatening on the part of the teacher, repeated teasing or humiliation, bullying, victimization, or any type of physical punishment (Pianta et al., 2008). The scores for this dimension are reversed in analysis to reflect lower scores being more beneficial for children's development.

Teacher sensitivity captures the "teacher's awareness of and responsivity to students' academic and emotional needs" (Pianta et al., 2008, p. 32). This dimension focuses on assessing the degree to which teachers are aware of and responsive to children's need for attention and individual support, as well as teachers' ability to help address and resolve problems, with higher scores indicated more sensitivity and awareness. This dimension also rates how comfortable the children appear to be in interacting with the teacher in terms of seeking support, participating in classroom activities, and sharing ideas (Pianta et al., 2008).

Regard for student perspectives encompasses the "degree to which the teacher's interactions with student and classroom activities place an emphasis on students' interests, motivations, and points of view and encourage student responsibility and autonomy" (Pianta et al., 2008, p. 38). A higher score on this dimension reflects a teacher who demonstrates flexibility and student focus in planning and carrying out activities, who allows students to make choices and lead activities, discussions, and conversations, and who provides freedom of movement and expression during activities (Pianta et al., 2008). 
Mean emotional support. The mean emotional support score was computed by first reverse-scoring Negative Climate (subtracting the assigned score from eight), combining the scores for each of the four dimensions (Positive Climate, reversed Negative Climate, Teacher Sensitivity, and Regard for Student Perspectives), and finally dividing this sum by four. This yielded a domain-level emotional support mean score that was entered as a variable for each observational time point.

Emotional support consistency. The repeated assessment of classroom environments over time aligns with the construct of meso-time from the bioecological model of development (Bronfenbrenner and Morris, 2006). A broader sense of teachers' usual teaching style can be operationalized as emotional support consistency by considering how teachers and children interact over longer intervals (several hours to a whole day) in the context of the school year.

A measure of consistency of emotional support which privileges within-day variation for each classroom was computed in several steps following the process described by Curby et al. (2013). First, the amount of variability (variances) in each teachers' emotional support scores for each day of observation (fall, winter, and spring) was computed, using the eight observations per day. Second, the mean of the three within-day variances for each classroom was computed by taking the average of the three variances. Third, the square root of the mean variances was calculated to convert them to standard deviations. Finally, the sign for this variable was then be reversed to reflect consistency. This multi-step process produced a variable in standard deviation units that was used as a classroom-level predictor. A classroom may have ended up with an 
emotional support consistency rating of -0.89 which indicates that the emotional support ratings varied by $0.89 \mathrm{SD}$. In the end, less-negative emotional support consistency scores reflect a narrower range in scores. 


\section{Chapter Five: Results}

\section{Preliminary Analyses}

All data analyses were performed using R version 3.0.2 (R Core Team, 2013) statistical computing software. Preliminary analyses and visual inspection of the data were conducted prior to addressing the research questions. To start, the data were assessed to ensure they met the assumptions of linear regression and multilevel modeling. The linearity of the relationships between the predictors and variables was examined through the use of partial residual plots. Box plots, histograms, P-P plots, and Q-Q plots were used to check for outliers and confirm the normality of the error and observation distributions. All preliminary inspections and analyses indicated that the data and errors were approximately normally distributed with few influential outliers.

Age and baseline scores on the academic and social-emotional measures were centered according to their respective grand means, while free/reduced lunch status, English Language Learner status, gender, ethnicity, race, and self-regulation skills were entered as categorical predictors. Both of the level two predictors (mean emotional support and emotional support consistency) were also mean centered to aid in the interpretation of regression coefficients.

Due to concerns about the multicollinearity of mean emotional support and emotional support consistency $(r=0.72)$ the variance inflation factor was computed to assess multicollinearity in the models that contained both level-two variables. The results of these tests indicate that all of the variance inflation factors were relatively low (VIF < 10), suggesting no excessive correlation between any of the variables. 
The potential impact of classrooms being clustered within the five campuses was examined by computing the intraclass correlation coefficients for each child-level outcomes based on campus membership. The ICCs for each of the child-level outcomes ranged from $r=0.01$ to $r=0.04$, indicating no statistically significant difference in scores based on campus, thus there was no need to enter campus as a level three variable in the multi-level analyses.

\section{Descriptive Analyses}

Means, standard deviations, minimums, maximums, and standard errors were computed for each of the child-level and classroom-level variables. These descriptive statistics are shown in Table 3 on Page 124.

Compared to age-adjusted nationally-representative samples $(\mathrm{M}=100, \mathrm{SD}=15)$ the children who participated in this study scores somewhat lower than average on the fall TEMA $(\mathrm{M}=89.19, \mathrm{SD}=12.51)$, fall PPVT $(97.56, \mathrm{SD}=16.86)$, fall TOPEL-DV $(\mathrm{M}$ $=90.83, \mathrm{SD}=16.36)$, and fall TOPEL-PA $(\mathrm{M}=91.21, \mathrm{SD}=15.46)$. However, these deficits had been overcome in the post-test scores and in some cases spring scores were above the norm-referenced mean: TEMA $(M=100.17, \mathrm{SD}=16.18)$, PPVT $(M=104.48$, $\mathrm{SD}=14.60)$, TOPEL-DV $(\mathrm{M}=99.49, \mathrm{SD}=12.76)$, TOPEL-PA $(\mathrm{M}=103.17, \mathrm{SD}=$ 16.59).

The classroom-level variables were emotional support $(\mathrm{M}=5.79, \mathrm{SD}=0.38)$ and emotional support consistency $(\mathrm{M}=-0.63, \mathrm{SD}=0.19)$. It is important to note that although all values of emotional support consistency are negative, those values that are less negative (i.e., closer to zero) represent greater consistency in emotional support 
scores across the year. For example, an emotional support consistency score of -0.43 reflects more stability and less variability in emotional support scores across the school year than an emotional support consistency score of -1.10 . Figure 1 shows the relations between the two classroom-level variables.

\section{Figure 1.}

Mean Emotional Support and Emotional Support Consistency

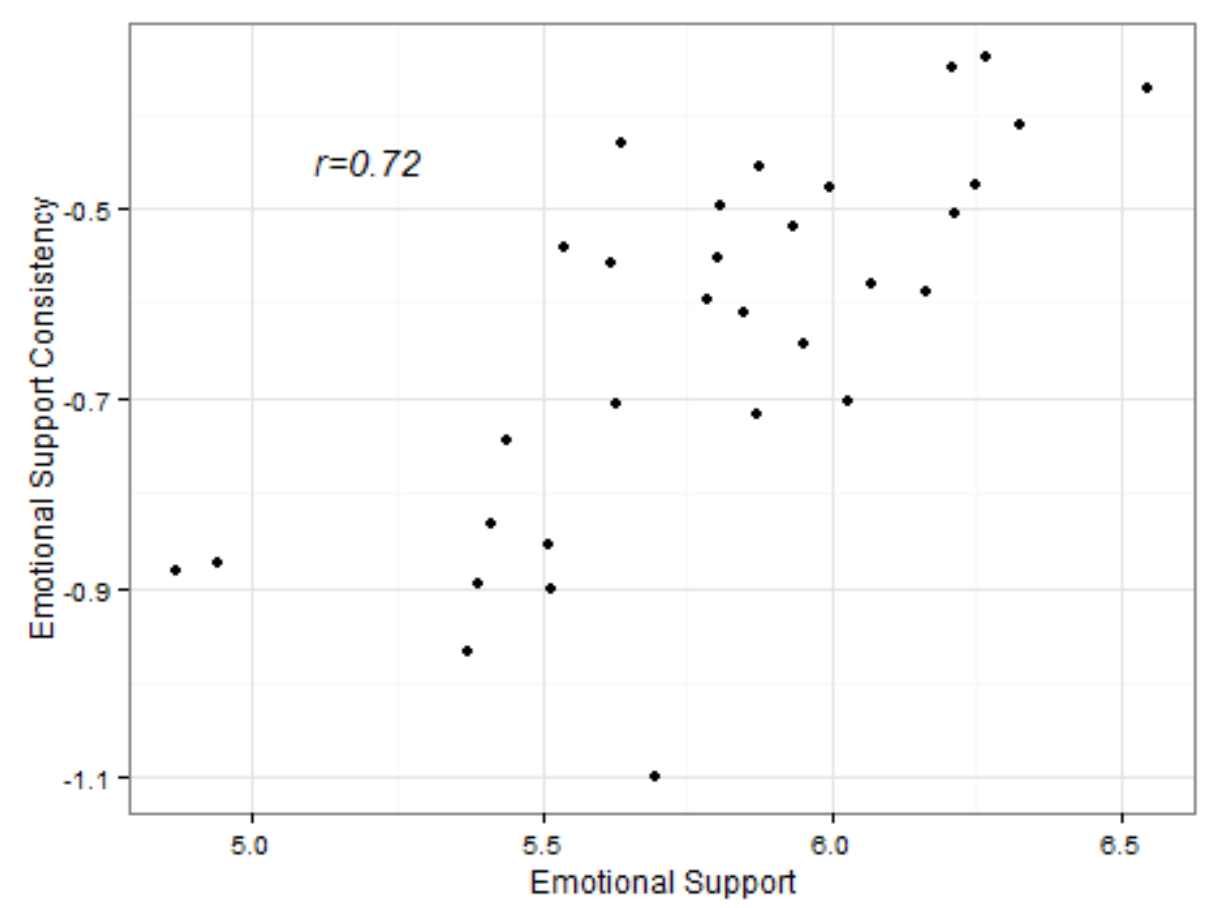

The second preliminary step involved computing the bivariate correlation coefficients among each of the child characteristics, baseline measures, and outcome measures to get an indication of the strength of the relationships between the variables. The correlations are presented in Table 4 on Page 124 and Page 125. The association between the baseline score and outcome score for each academic and social-emotional measure was moderate to strong, ranging from $r=0.47(p<.01)$ for the TOPEL-PK scores to $r=0.74(p<.01)$ for the PPVT scores, with all correlations statistically 
significant at the 0.05 level. The associations between the academic and social-emotional measures in general were all moderately to strongly positive (from $r=0.29, p<.01$ to $r=$ $0.74, p<.01)$, indicating that a child who scored higher on one of the academic or socialemotional measures was somewhat likely to score higher on another measure.

The correlations between child demographic characteristics and academic and social-emotional measures ranged from $r=-0.28(p<.01)$ to $r=0.293(p<.01)$, indicating weak associations between all of the child demographic characteristics and the academic and social-emotional scores in both fall and spring. Free/reduced lunch status was consistently negatively correlated with scores on all of the academic and socialemotional measures in both fall and spring. Ethnicity was not significantly correlated with any of the academic or social-emotional measures at either time point. There was a moderate negative correlation $(r=-0.51, p<.01)$ between race and English Language Learner status, with other associations between child demographic characteristics ranging from $r=-0.18(p<0.1)$ (race and ethnicity) to $r=0.42(p<.01)$ (race and free/reduced lunch status). Gender was not statistically significantly correlated with any of the other child demographic characteristics. Age, free/reduced lunch status, ethnicity, race, and English Language learner status had statistically significant correlations with at least one other demographic characteristic.

The correlation between teachers' emotional support mean and emotional support consistency $(r=0.72, p<.01)$ indicates that teaching staff who were rated as high in emotional support were are also likely to exhibit high stability in their level of emotional support. 
There were no systematic relationships between teachers' average level or consistency of emotional support and children's scores on academic and social-emotional measures at either time point. Most correlations were non-significant and/or less than $r=$ 0.15. There was a similar lack of pattern in the correlations between mean level of emotional support or consistency of teacher emotional support and child and family characteristics, indicating that children were not selected into classrooms in any systematic manner based on risk factors.

\section{Preliminary Multilevel Modeling}

Multilevel modeling was used to address several of the research questions due to the structure of the data and the nature of the research questions (Raudenbush \& Bryk, 2002). Because this project focuses on how differences both between individuals (childlevel variables) and between classrooms (mean emotional support and consistency of emotional support) are related to children's development of academic and socialemotional skills, it was necessary to account for the nesting of children within classrooms. To ensure that the multilevel analysis framework was suitable for the data, preliminary tests were run to assess the how much variance in outcome scores was attributable to classroom membership.

First, a series of one-way analysis of covariance (ANCOVAs) was run to determine if there were significant differences in the outcome measures attributable to classroom membership while controlling for baseline scores. Next, the intraclass correlation coefficients - which indicate how much variance in scores is due to classroom membership - were extracted from the intercepts-only linear mixed effects models. 
Norm-referenced scores were used for the TEMA, PPVT, and each of the TOPEL subtests. A composite of the four T-CRS subtests was used. In general, ICCs greater than 0.1 indicate enough group-dependency in outcomes to warrant the use of a multilevel modeling framework.

TEMA. An ANCOVA was run to assess the difference in TEMA spring scores attributable to classroom membership, while taking fall scores into consideration. The results $(F(525)=14834.38, p<.001)$ indicate significant differences in children's spring TEMA scores across classrooms. The ICC for differences in spring TEMA scores from the intercepts-only model was 0.096 , indicating that $9.6 \%$ of the variance in spring TEMA scores while controlling for fall scores was attributable to classroom membership.

TOPEL-PK. An ANCOVA was run to assess the difference in TOPEL-PK spring scores attributable to classroom membership, while taking fall scores into consideration. The results $(F(525)=11484.80, p<.001)$ indicate significant differences in children's spring TOPEL-PK scores across classrooms. The ICC for differences in spring TOPELPK scores was 0.226 , indicating that $22.6 \%$ of the variance in spring TOPEL-PK scores while controlling for fall scores was attributable to classroom membership.

TOPEL-PA. An ANCOVA was run to assess the difference in TOPEL-PA spring scores attributable to classroom membership, while taking fall scores into consideration. The results $(F(522)=12176.66, p<.001)$ indicate significant differences in children's spring TOPEL-PA scores across classrooms. The ICC for spring TOPEL-PA was 0.093, indicating that $9.3 \%$ of the variance in spring TOPEL-PA scores while controlling for fall scores was attributable to classroom membership. 
TOPEL-DV. An ANCOVA was run to assess the difference in TOPEL-DV spring scores attributable to classroom membership, while taking fall scores into consideration. The results $(F(525)=17411.00, p<.001)$ indicate significant differences in children's spring TOPEL-DV scores across classrooms. The ICC for spring TOPELDV scores while controlling for fall scores was 0.152 , indicating that $15.2 \%$ of the variance in spring TOPEL-DV scores while controlling for fall scores was attributable to classroom membership.

PPVT. An ANCOVA was run to assess the difference in PPVT spring scores attributable to classroom membership, while taking fall scores into consideration. The results $(F(525)=31783.71, p<.001)$ indicate significant differences in children's spring PPVT scores across classrooms. The ICC for spring PPVT scores while controlling for fall scores was 0.058 , indicating that $5.8 \%$ of the variance in spring PPVT scores while controlling for fall scores was attributable to classroom membership.

T-CRS. An ANCOVA was run to assess the difference in T-CRS scores attributable to classroom membership, while taking fall scores into consideration. The results $(F(477)=5847.66, p<.001)$ indicate significant differences in children's spring T-CRS scores across classrooms. The ICC for spring T-CRS was 0.219 , indicating that $21.9 \%$ of the variance in spring T-CRS scores was attributable to classroom membership.

The decision was made to fit all multi-level data using random intercepts/fixed slopes models. This decision was based on several preliminary model-fit comparisons indicating only non-significant differences between random intercepts/fixed slope and random intercepts/random slopes models. Additionally, it was assumed that the effect of 
each child characteristic on the predictor/outcome slope did not vary among classrooms.

\section{Research Questions}

\section{Research Question One: A) Are children's socioeconomic and behavioral risk factors related to their cognitive and social-emotional skills at preschool entry?}

It was predicted that children's risk factors (those students who have lower teacher-reported self-regulation skills at the beginning of the year, or who are AfricanAmerican, male, younger, Hispanic, English Language Learners, or from families with lower income) would be associated with lower baseline scores on all of the academic and social-emotional measures.

Multiple linear regression equations were used to address this research question, with one equation for each child-level measure. Children's socioeconomic and behavioral risk factors were entered as predictors of baseline scores on each of the cognitive and social-emotional measures. Norm-referenced scores were used for the TEMA, PPVT, and each of the TOPEL subtests. A composite of the four T-CRS subtests was used at both time points. Age in months was mean-centered to aid in interpreting results for each of the regressions. Results for Research Question 1A are presented in Table 5 on Page 127.

TEMA. Fall TEMA scores were significantly negatively predicted by male gender $(b=-2.333, p=.029)$, free/reduced lunch eligibility $(b=-8.493, p<.001$.$) , and$ low self-regulation $(b=-7.734, p<.001)$ when controlling for all other child characteristics. Age in months significantly positively predicted fall TEMA scores $(b=$ $0.243, p=.015)$ when controlling for all other child characteristics. Ethnicity, race, and ELL status did not uniquely predict fall TEMA scores. 
PPVT. Fall PPVT scores were significantly negatively predicted by free/reduced lunch eligibility $(b=-9.194, p<.001)$, ELL status $(b=-16.075, p<.001)$, and low selfregulation $(b=-11.870, p<.001)$ when controlling for all other child characteristics. Gender, age, ethnicity, and race did not uniquely predict fall PPVT scores.

TOPEL-DV. Fall TOPEL-DV scores were significantly negatively predicted by free/reduced lunch eligibility $(b=-8.81, p<.001)$, ELL status $(b=-14.27, p<.001)$, and low self-regulation $(b=-11.50, p<.001)$ when controlling for all other child characteristics. Age in months $(b=0.68, p<.001)$ significantly positively predicted fall TOPEL-DV scores when controlling for all other child characteristics. Gender, ethnicity, and race did not uniquely predict fall TOPEL-DV scores.

TOPEL-PK. Fall TOPEL-PK scores were significantly negatively predicted by male gender $(b=-5.14, p=0.001)$, free/reduced lunch eligibility $(b=-11.95, p<.001)$, and low self-regulation $(b=-6.85, p<.001)$ when controlling for all other child characteristics. Age in months $(b=0.49, p<.001)$ significantly positively predicted fall TOPEL-PK scores when controlling for all other child characteristics. Ethnicity, race, and ELL status did not uniquely predict fall TOPEL-PK scores.

TOPEL-PA. Fall TOPEL-PA scores were significantly negatively predicted by male gender $(b=-3.60, p=0.003)$, free/reduced lunch eligibility $(b=-5.46, p=0.001)$, ELL status $(b=-8.60, p=0.001)$, and low self-regulation $(b=-11.31, p<.001)$ when controlling for all other child characteristics. Age in months $(b=0.33, p=0.004)$ significantly positively predicted fall TOPEL-PA scores when controlling for all other child characteristics. Ethnicity and race did not uniquely predict fall TOPEL-PA scores. 
T-CRS. Fall T-CRS scores were significantly negatively predicted by male gender $(b=-6.810, p<.001)$, free/reduced lunch status $(b=-5.806, p=0.003)$, and low self-regulation $(b=-36.318, p<.001)$ when controlling for all other child characteristics. Age in months $(b=0.624, p<.001)$ significantly positively predicted fall T-CRS scores when controlling for all other child characteristic. Ethnicity, race, and ELL status did not uniquely predict fall T-CRS scores.

The effect size estimates for each child characteristic in predicting scores on fall cognitive and social-emotional measures are presented in Figure 2.

Figure 2.

Effect Size Estimates for Child Characteristics in Predicting Fall Cognitive and Social-Emotional Scores

\begin{tabular}{|l|cccccc|}
\cline { 2 - 7 } \multicolumn{1}{c|}{} & \multicolumn{5}{c|}{ Fall Scores } \\
\cline { 2 - 7 } & $\begin{array}{c}\text { Early } \\
\text { Math }\end{array}$ & $\begin{array}{c}\text { Receptive } \\
\text { Vocabulary }\end{array}$ & $\begin{array}{c}\text { Definitional } \\
\text { Vocabulary }\end{array}$ & $\begin{array}{c}\text { Print } \\
\text { Knowledge }\end{array}$ & $\begin{array}{c}\text { Phonological } \\
\text { Awareness }\end{array}$ & $\begin{array}{c}\text { Social- } \\
\text { Emotional } \\
\text { Adjustment }\end{array}$ \\
\hline Male & -0.18 & & & -0.28 & -0.23 & -0.30 \\
Age & 0.02 & & 0.04 & 0.03 & 0.02 & 0.03 \\
F/R Lunch & -0.68 & -0.55 & -0.54 & -0.66 & -0.35 & -0.25 \\
Af. Am. & & & & & -0.25 & \\
ELL & & -0.95 & -0.87 & -0.29 & -0.56 & -0.24 \\
Low SR & -0.62 & -0.70 & -0.70 & -0.38 & -0.73 & -1.59 \\
\hline
\end{tabular}

Note . Af. Am. $=$ African American; ELL $=$ English Language Learner; F/R Lunch $=$ Free/reduced lunch eligible; Low $\mathrm{SR}=$ low self-regulation. Green cells indicate a significant favorable impact $(\mathrm{p} \leq$ $0.10)$; blue cells indicate a significant unfavorable impact $(\mathrm{p} \leq 0.10)$; blank cells indicate a nonsignificant impact. The effect size for each categorical predictor (male, Hispanic, free/reduced lunch eligibility, African American, English Language Learner, and low self-regulation) is the regression coefficient for each predictor divided by the standard deviation of the outcome, indicating the magnitude of the difference between the reference group and the named group. The effect size for the continuous predictor (age in months) is the regression coefficient divided by the standard deviation for the outcome measure, indicating the magnitude of the difference for each one-month increase in age.

Research Question One: B) Are children's socioeconomic and behavioral risk factors at preschool entry related to their development of cognitive and socialemotional skills over the preschool year? 
It was hypothesized that, when controlling for baseline scores on each measure, each of the risk factors would positively predict development over the year.

These analyses were conducted in two steps. First, matched pairs t-tests were run to evaluate whether the difference between fall and spring scores on each of the childlevel academic and social-emotional measures was statistically different than zero. Second, a series of multilevel models were tested with the socioeconomic and behavioral risk factors entered as predictors of spring scores on each of the academic and socialemotional measures, and fall scores entered as control variables. Age was mean-centered to aid in interpreting results for each of the regressions. Norm-referenced scores were used for the TEMA, PPVT, and each of the TOPEL subtests. A composite of the four TCRS subtests was used at both time points. The results of the regression equations are presented in Table 6 on Page 128.

TEMA. A matched pairs t-test indicated a significant difference $(t(556)=21.332$, $p<.001)$ in children's fall scores $(\mathrm{M}=89.19, \mathrm{SD}=12.51)$ and spring scores $(\mathrm{M}=$ $100.17, \mathrm{SD}=16.19)$ on the TEMA.

When controlling for fall TEMA scores $(b=0.776, p<.001)$, age in months $(b=$ $-0.280, p=.010)$, African American race $(b=-3.724, p=.030)$, and low self-regulation $(b=-7.095, p<.001)$ significantly negatively predicted spring TEMA scores. Gender, ethnicity, free/reduced lunch eligibility, and ELL status did not uniquely predict spring TEMA scores.

PPVT. A matched pairs t-test indicated a significant difference $(t(556)=6.01, p$ $<.001)$ in children's fall scores $(\mathrm{M}=97.56, \mathrm{SD}=16.86)$ and spring scores $(\mathrm{M}=104.48$, 
$\mathrm{SD}=14.60)$ on the PPVT.

When controlling for fall PPVT scores $(b=0.569, p<.001)$ spring PPVT scores were significantly negatively predicted by low self-regulation $(b=-5.363, p<.001)$.

Gender, age in months, ethnicity, free/reduced lunch eligibility, race, and ELL status did not uniquely predict spring PPVT scores.

TOPEL-DV. A matched pairs t-test indicated a significant difference $(t(556)=$ $16.60, \mathrm{p}<.001)$ in children's fall scores $(\mathrm{M}=90.83, \mathrm{SD}=16.36)$ and spring scores $(\mathrm{M}=$ 99.45, SD $=12.76)$ on the TOPEL-DV.

When controlling for fall TOPEL-DV scores $(b=0.536, p<.001)$, spring PPVT scores were significantly negatively predicted by age in months $(b=-0.580, p<.001)$ and low self-regulation $(b=-3.957, p<.001)$.

TOPEL-PK. A matched pairs t-test indicated a significant difference $(t(556)=$ $13.63, \mathrm{p}<.001)$ in children's fall scores $(\mathrm{M}=106.13, \mathrm{SD}=18.14)$ and spring scores $(\mathrm{M}$ $=115.98, \mathrm{SD}=13.02)$ on the TOPEL-PK.

When controlling for fall TOPEL-PK scores $(b=0.323, p<.001)$, spring TOPEL-DV scores were significantly negatively predicted by male gender $(b=-2.677, p$ $=.003)$, age in months $(b=-0.768, p<.001)$, and low self-regulation $(b=-6.610, p<$ .001). Ethnicity, free/reduced lunch status, race, and ELL status did not uniquely predict spring TOPEL-PK scores.

TOPEL-PA. A matched pairs t-test indicated a significant difference $(t(553)=$ $18.96, \mathrm{p}<.001)$ in children's fall scores $(\mathrm{M}=91.21, \mathrm{SD}=15.46)$ and spring scores $(\mathrm{M}=$ 103.47, SD = 16.59) on the TOPEL-PA. 
When controlling for fall TOPEL-PA scores $(b=0.451, p<.001)$, spring TOPEL-PA scores were significantly negatively predicted by low self-regulation $(b=-$ 9.147, $p<.001)$. Gender, age in months, ethnicity, free/reduced lunch eligibility, race, and ELL status did not uniquely predict spring TOPEL-PA scores.

T-CRS. A matched pairs t-test indicated a significant difference $(t(507)=7.87, \mathrm{p}$ $<.001)$ in children's fall scores $(\mathrm{M}=121.15, \mathrm{SD}=22.86)$ and spring scores $(\mathrm{M}=128.68$, $\mathrm{SD}=22.30)$ on the $\mathrm{T}-\mathrm{CRS}$.

When controlling for fall T-CRS scores $(b=0.431, p<.001)$ spring T-CRS scores were significantly negatively predicted by male gender $(b=-4.916, p=.008)$ and low self-regulation $(b=-9.160, p<.001)$. Age in months, ethnicity, free/reduced lunch eligibility, race, and ELL status did not uniquely predict spring T-CRS scores.

Research Question Two: A) Is the mean level of emotional support in the preschool classroom related to children's development of cognitive and socialemotional skills over the preschool year?

It was hypothesized that preschool classrooms with higher mean levels of emotional support would have a stronger benefit for children's development than classrooms with lower levels of emotional support.

A series of multilevel models were run to investigate the relationship between the mean level of teacher emotional support across the preschool year and spring scores on each of the academic and social-emotional measures, controlling for fall scores. These models included children's baseline scores as level-one control variables, mean teacher emotional support as a level-two variable, and children's spring scores on the specified 
academic or social-emotional measure as the outcome. Mean emotional support and fall scores were mean-centered to aid in interpreting the results of each regression equation. Norm-referenced scores were used for the TEMA, PPVT, and each of the TOPEL subtests. A composite of the four T-CRS subtests was used at both time points. The results of the regression equations are presented in Table 7 on Page 129.

TEMA. The multilevel model for this outcome indicated that, when controlling for fall TEMA scores $(b=0.85, p<.001)$, spring TEMA scores were not significantly predicted by mean emotional support.

PPVT. The multilevel model for this outcome indicated that, when controlling for fall PPVT scores $(b=0.62, p<.001)$, spring PPVT scores were significantly positively predicted $(b=3.28, p=.027)$ by mean emotional support.

TOPEL-DV. The multilevel model for this measure indicated that, when controlling for fall TOPEL-DV scores $(b=0.54, p<.001)$, mean emotional support did not uniquely predict spring TOPEL-DV scores.

TOPEL-PK. The multilevel model for this measure indicated that, when controlling for fall TOPEL-PK scores $(b=0.37, p<.001)$, mean emotional support did not uniquely predict spring TOPEL-PK scores.

TOPEL-PA. The multilevel model for this measure indicated that, when controlling for fall TOPEL-PA scores $(b=0.55, p<.001)$, mean emotional support $(b=$ 4.42, $p=0.064$ ) trended toward positively predicting spring TOPEL-PA scores.

T-CRS. The multilevel model for this measure indicated that, when controlling for fall T-CRS scores $(b=0.58, p<.001)$, mean emotional support did not uniquely 
predict spring T-CRS scores.

\section{Research Question Two: B) Do children's risk factors moderate the impact of teachers' emotional support in the preschool classroom in predicting children's development of cognitive and social-emotional skills over the preschool year?}

This question was addressed in two steps, by investigating 1) the relations among child risk factors and mean emotional support without cross-level interactions between the child-level variables and the classroom-level variable, and 2) the relations among child risk factors and mean emotional support with cross-level interactions between the child-level variables and the classroom-level variable.

It was hypothesized that child risk factors would negatively predict development, mean emotional support would positively predict development, and preschool classrooms with higher mean levels of emotional support would have a stronger benefit for children's development among children who experience greater risk compared to children who experience less risk.

Multilevel modeling was used to address this research question based on children being nested within classrooms. A series of models were run to investigate relations among the mean level of teacher emotional support across the preschool year, children's risk factors, and each developmental outcome. These models included children's baseline scores and risk factors as level-one variables, mean level of teacher emotional support as a level-two variable, and children's spring scores on the specified academic or socialemotional measure as the outcome. Age in months, mean emotional support, and fall scores were mean-centered to aid in interpreting results for each of the regressions. 
Norm-referenced scores were used for the TEMA, PPVT, and each of the TOPEL subtests. A composite of the four T-CRS subtests was used at both time points. The results of the regression equations without interactions are presented in Table 8 on Page 130 while the results of the regression equations with the cross-level interactions are presented in Table 9 on Page 131.

TEMA. Multilevel models indicate that, when controlling for fall TEMA scores $(b=0.78, p<.001)$, spring TEMA scores were significantly negatively predicted by age in months $(b=-0.31, p=.004)$, African American race $(b=-3.67, p=.033)$, and low self-regulation $(b=-7.04, p<.000)$. Mean emotional support, gender, ethnicity, free/reduced lunch eligibility, and ELL status were not uniquely predictive of spring TEMA scores. There were no statistically significant cross-level interactions between any of the child characteristics and mean emotional support in predicting spring TEMA scores.

PPVT. Multilevel models indicate that, when controlling for fall PPVT scores $(b$ $=0.57, p<.001$ ), spring PPVT scores were significantly positively predicted by mean emotional support $(b=3.36, p=0.023)$ and significantly negatively predicted by African American race $(b=-3.30, p=.027)$ and low self-regulation $(b=-5.25, p<.001)$. Gender, age in months, ethnicity, free/reduced lunch eligibility, and ELL status were not uniquely predictive of spring PPVT scores. There were no statistically significant crosslevel interactions between any of the child characteristics and mean emotional support in predicting spring PPVT scores.

TOPEL-DV. Multilevel modeling indicated that, when controlling for fall 
TOPEL-DV scores $(b=0.54, p<.001)$, spring TOPEL-DV scores were significantly negatively predicted by age in months $(b=-0.58, p<.001)$ and low self-regulation $(b=-$ 3.95, $p<.001)$. Mean emotional support, gender, ethnicity, free/reduced lunch eligibility, race and ELL status were not uniquely predictive of spring TOPEL-DV scores. The interaction between ELL status and mean emotional support $(b=7.76, p=0.059)$ trended toward positively predicting spring TOPEL-DV scores. There were no other statistically significant cross-level interactions between any of the child characteristics and mean emotional support in predicting spring TOPEL-DV scores.

TOPEL-PK. Multilevel modeling indicated that, when controlling for fall TOPEL-PK scores $(b=0.32, p<.001)$, spring TOPEL-PK scores were significantly negatively predicted by male gender $(b=-2.68, p=.003)$, age in months $(b=-0.77, p<$ $.001)$, and low self-regulation $(b=-6.60, p<.001)$. Mean emotional support, ethnicity, free/reduced lunch status, race, and ELL status were not uniquely predictive of spring TOPEL-PK scores. There were no statistically significant cross-level interactions between any of the child characteristics and mean emotional support in predicting spring TOPEL-PK scores.

TOPEL-PA. Multilevel modeling indicated that, when controlling for fall TOPEL-PA scores $(b=0.45, p<.001)$, spring TOPEL-PA scores were significantly negatively predicted by low self-regulation $(b=-9.04, p<.001)$. Mean emotional support $(b=4.60, p=0.053)$ trended toward positively predicting spring TOPEL-PA scores. Gender, age in months, ethnicity, free/lunch eligibility, race, and ELL status were not uniquely predictive of spring TOPEL-PA scores. There were no statistically 
significant cross-level interactions between any of the child characteristics and mean emotional support in predicting spring TOPEL-PA scores.

T-CRS. Multilevel modeling indicated that, when controlling for fall T-CRS scores $(b=0.43, p<.001)$, spring T-CRS scores were significantly negatively predicted by male gender $(b=-4.91, p=.001)$ and low self-regulation $(b=-9.21, p<.001)$. Free/reduced lunch eligibility $(b=-3.71, p=.063)$ trended toward negatively predicting spring T-CRS scores. Mean emotional support, age in months, ethnicity, race, and ELL status were not uniquely predictive of spring T-CRS scores. There were no statistically significant cross-level interactions between any of the child characteristics and mean emotional support in predicting spring T-CRS scores.

Research Question Three: A) Is the consistency of emotional support in the classroom related to children's development of cognitive and social-emotional skills over the preschool year?

It was hypothesized that preschool classrooms with more consistent levels of emotional support would have a stronger benefit for children's development than classrooms with less consistent levels of emotional support.

Multilevel modeling was used to address this research question based on children being nested within classrooms. A series of models were run to investigate the relationship between the consistency of teacher emotional support across the preschool year and each developmental outcome. These models included children's baseline scores as level-one control variables, consistency of teacher emotional support as a level-two variable, and children's spring scores on the specified academic or social-emotional 
measure as the outcome. Fall scores and emotional support consistency were meancentered to aid in interpreting the results of the regression equations. Norm-referenced scores were used for the TEMA, PPVT, and each of the TOPEL subtests. A composite of the four T-CRS subtests was used at both time points. The results of the regression equations are presented in Table 10 on Page 132.

TEMA. The multilevel model for this outcome indicated that, when controlling for fall TEMA scores $(b=0.85, p<.001)$, spring TEMA scores were significantly positively predicted by consistency of emotional support $(b=8.32, p=.040)$.

PPVT. The multilevel model for this outcome indicated that, when controlling for fall PPVT scores $(b=0.62, p<.001)$, spring PPVT scores were significantly positively predicted by emotional support consistency $(b=9.53, p<.001)$.

TOPEL-DV. The multilevel model for this measure indicated that, when controlling for fall TOPEL-DV scores $(b=0.54, p<.001)$, emotional support consistency did not uniquely predict spring TOPEL-DV scores.

TOPEL-PK. The multilevel model for this measure indicated that, when controlling for fall TOPEL-PK scores $(b=0.37, p<.001)$, emotional support consistency did not uniquely predict spring TOPEL-PK scores.

TOPEL-PA. The multilevel model for this measure indicated that, when controlling for fall TOPEL-PA scores $(b=0.55, p<.001)$, spring TOPEL-PA scores were significantly positively predicted by emotional support consistency $(b=13.59, p=$ $.002)$.

T-CRS. The multilevel model for this measure indicated that, when controlling 
for fall T-CRS scores $(b=0.58, p<.001)$, emotional support consistency did not uniquely predict spring T-CRS scores.

Research Question Three: B) Do children's risk factors moderate the impact of teachers' emotional support consistency in the preschool classroom in predicting children's development of cognitive and social-emotional skills over the preschool year?

This question was addressed in two steps, by investigating 1) the relations among child risk factors and emotional support consistency without cross-level interactions between the child-level variables and the classroom-level variable and 2) the relations among child risk factors and emotional support consistency with cross-level interactions between the child-level variables and the classroom-level variable.

It was hypothesized that child risk factors would negatively predict development, emotional support consistency would positively predict development, and preschool classrooms with higher mean levels of emotional support consistency would have a stronger benefit for children's development among children who experience greater risk compared to children who experience less risk.

Multilevel modeling was used to address this research question based on children being nested within classrooms. A series of models were run to investigate relations among emotional support consistency across the preschool year, children's risk factors, and each developmental outcome. These models included children's baseline scores and risk factors as level-one variables, teachers' emotional support consistency as a level-two variable, and children's spring scores on the specified academic or social-emotional 
measure as the outcome. Age in months, emotional support consistency, and fall scores were mean-centered to aid in interpreting results for each of the regressions. Normreferenced scores were used for the TEMA, PPVT, and each of the TOPEL subtests. A composite of the four T-CRS subtests was used at both time points. The results of the regression equations without interactions are presented in Table 11 on Page 133 while the results of the regression equations with the cross-level interactions are presented in Table 12 on Page 134.

TEMA. Multilevel models indicate that, when controlling for fall TEMA scores $(b=0.77, p<.001)$, spring TEMA scores were significantly negatively predicted by age in months $(b=-0.28, p=.007)$, African American race $(b=-3.64, p=.034)$, and low self-regulation $(b=-7.11, p<.000)$. Emotional support consistency $(b=6.94, p=.063)$ trended toward positively predicting spring TEMA scores. Gender, ethnicity, free/reduced lunch eligibility, and ELL status were not uniquely predictive of spring TEMA scores. There were no statistically significant cross-level interactions between any of the child characteristics and emotional support consistency in predicting spring TEMA scores.

PPVT. Multilevel models indicate that, when controlling for fall PPVT scores $(b$ $=0.57, p<.001)$, spring PPVT scores were significantly positively predicted by emotional support consistency $(b=9.06, p<.001)$ and significantly negatively predicted by African American race $(b=-3.23, p=.029)$ and low self-regulation $(b=-5.24, p<$ .001). Gender, age in months, ethnicity, free/reduced lunch eligibility, and ELL status were not uniquely predictive of spring PPVT scores. There were no statistically 
significant interactions between any of the child characteristics and emotional support consistency in predicting spring PPVT scores.

TOPEL-DV. Multilevel modeling indicated that, when controlling for fall TOPEL-DV scores $(b=0.54, p<.001)$, spring TOPEL-DV scores were significantly negatively predicted by age in months $(b=-0.58, p<.001)$ and low self-regulation $(b=-$ 3.97, $p<.001)$. Emotional support consistency, gender, ethnicity, free/reduced lunch eligibility, race and ELL status were not uniquely predictive of spring TOPEL-DV scores.

Controlling for all other child characteristics and fall scores, there was a significant interaction between ELL status and emotional support consistency $(b=16.78$, $p=0.025)$ in predicting spring TOPEL-DV scores. The interaction indicates that English Language Learners tended to benefit more from increased levels of emotional support consistency than their English-proficient peers in the same classroom in terms of spring TOPEL-DV scores. This is shown in the following equations which demonstrate the relationship between emotional support consistency (ESC) for ELL and English proficient students respectively, for a female, non-Hispanic, non-African American student of average age with average self-regulation skills who was not eligible for free/reduced lunch and who received the average score on the fall TOPEL-DV. See Figure 3 on Page 93 for a graphical representation of the interaction between ELL status and emotional support consistency.

English proficient student (at average age, with average fall score, low risk in all 
other categories):

TOPEL-DV $=99.528+1.917 * \mathrm{ESC}$

ELL student (at average age, with average fall score, low risk in all other areas):

TOPEL-DV $=99.572+18.587 *$ ESC

\section{Figure 3.}

ELL Status x Emotional Support Consistency on TOPEL-DV Scores

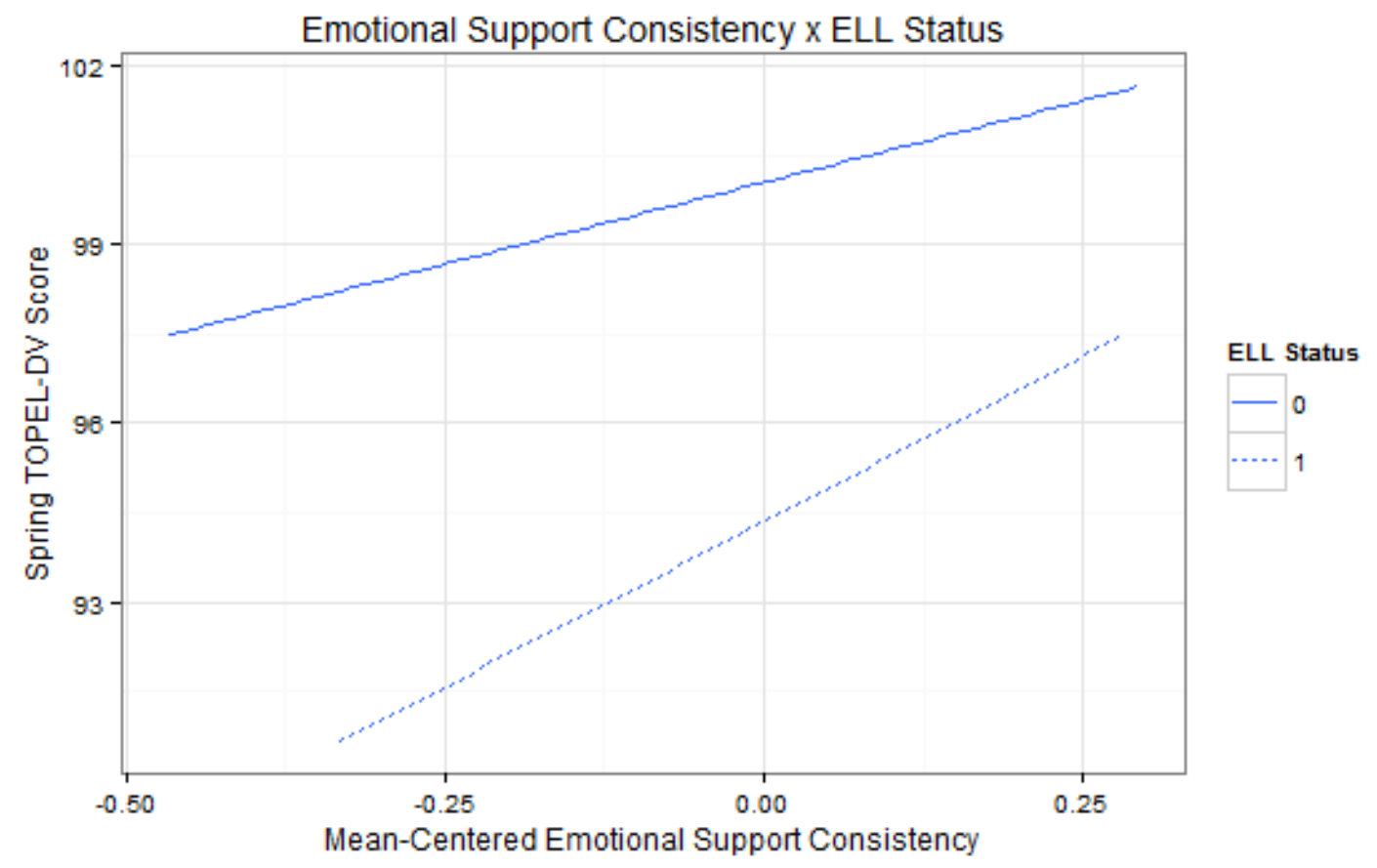

TOPEL-PK. Multilevel modeling indicated that, when controlling for fall TOPEL-PK scores $(b=0.32, p<.001)$, spring TOPEL-PK scores were significantly negatively predicted by male gender $(b=-2.65, p=.003)$, age in months $(b=-0.77, p<$ $.001)$, and low self-regulation $(b=-6.61, p<.001)$. Emotional support consistency, ethnicity, free/reduced lunch status, race, and ELL status were not uniquely predictive of 
spring TOPEL-PK scores. There were no statistically significant cross-level interactions between any of the child characteristics and mean emotional support in predicting spring TOPEL-PK scores.

TOPEL-PA. Multilevel modeling indicated that, when controlling for fall TOPEL-PA scores $(b=0.46, p<.001)$, spring TOPEL-PA scores were significantly positively predicted by emotional support consistency $(b=12.46, p=.004)$ and significantly negatively predicted by low self-regulation $(b=-9.09, p<.001)$. Gender, age in months, ethnicity, free/lunch eligibility, race, and ELL status were not uniquely predictive of spring TOPEL-PA scores. There were no statistically significant cross-level interactions between any of the child characteristics and emotional support consistency in predicting spring TOPEL-PA scores.

T-CRS. Multilevel modeling indicated that, when controlling for fall T-CRS scores $(b=0.43, p<.001)$, spring T-CRS scores were significantly negatively predicted by male gender $(b=-4.92, p=.001)$ and low self-regulation $(b=-9.16, p<.001)$. Free/reduced lunch eligibility $(b=-3.69, p=.065)$ trended toward negatively predicting spring T-CRS scores. Emotional support consistency, age in months, ethnicity, race, and ELL status were not uniquely predictive of spring T-CRS scores. There were no statistically significant cross-level interactions between any of the child characteristics and mean emotional support in predicting spring T-CRS scores.

The effect size estimates for child characteristics, emotional support, and emotional support consistency in predicting development of cognitive and socialemotional measures are presented in Figure 4 on Page 95. Effect sizes for emotional 
support and emotional support consistency are derived from models where each

classroom-level variable was entered separately in a block with the child characteristics,

not from the models where both classroom-level variables were entered simultaneously.

Figure 4.

Effect Size Estimates for Child Characteristics, Mean Emotional Support, and Emotional Support Consistency in Predicting Spring Cognitive and Social-Emotional Scores

\begin{tabular}{|c|c|c|c|c|c|c|}
\hline & \multicolumn{6}{|c|}{ Spring Scores } \\
\hline & $\begin{array}{l}\text { Early } \\
\text { Math }\end{array}$ & $\begin{array}{l}\text { Receptive } \\
\text { Vocabulary }\end{array}$ & $\begin{array}{l}\text { Definitional } \\
\text { Vocabulary }\end{array}$ & $\begin{array}{c}\text { Print } \\
\text { Knowledge }\end{array}$ & $\begin{array}{l}\text { Phonological } \\
\text { Awareness }\end{array}$ & $\begin{array}{c}\text { Social- } \\
\text { Emotional } \\
\text { Adjustment }\end{array}$ \\
\hline \multirow{6}{*}{$\begin{array}{l}\text { Male } \\
\text { Age } \\
\text { Af. Am. } \\
\text { Low SR } \\
\text { ES Mean } \\
\text { ES Consistency }\end{array}$} & & & & -0.20 & & -.22 \\
\hline & -0.02 & & -0.04 & -0.06 & & \\
\hline & -0.22 & -0.22 & & & & \\
\hline & -0.44 & -0.37 & -0.32 & -0.52 & -0.55 & -0.41 \\
\hline & & 0.09 & & & 0.11 & \\
\hline & 0.08 & 0.12 & & 0.09 & 0.15 & \\
\hline
\end{tabular}

Note . Af. Am. $=$ African American; ELL $=$ English Language Learner; F/R Lunch $=$ Free/reduced lunch eligible; Low SR = low self-regulation. ES = Emotional Support. Green cells indicate a significant favorable impact $(\mathrm{p} \leq 0.10)$; blue cells indicate a significant unfavorable impact $(\mathrm{p} \leq$ $0.10)$; blank cells indicate a nonsignificant impact. The effect size for each categorical predictor (male, Hispanic, free/reduced lunch eligibility, African American, English Language Learner, and low self-regulation) is the regression coefficient for each predictor divided by the standard deviation of the outcome, indicating the magnitude of the difference between the reference group and the named group. The effect size for the continuous predictor (age in months) is the regression coefficient divided by the standard deviation for the outcome measure, indicating the magnitude of the difference for each one-month increase in age..

\section{Research Question Four: Are children's risk factors, the mean level of}

emotional support, and emotional support consistency in the preschool classroom

related to children's development of cognitive and social-emotional skills over the preschool year?

It was hypothesized that children's risk factors, mean level of emotional support, and emotional support consistency would each positively predict spring scores on each of the outcomes measures when controlling for fall scores. 
Multilevel modeling was used to address this research question based on children being nested within classrooms. A series of models were run to investigate relations among mean emotional support and emotional support consistency across the preschool year, children's risk factors, and each developmental outcome. These models included children's baseline scores and risk factors as level-one variables, teachers' mean emotional support and emotional support consistency as level-two variables, and children's spring scores on the specified academic or social-emotional measure as the outcome. Age in months, mean emotional support, emotional support consistency, and fall scores were mean-centered to aid in interpreting results for each of the regressions. Norm-referenced scores were used for the TEMA, PPVT, and each of the TOPEL subtests. A composite of the four T-CRS subtests was used at both time points. The results of the regression equations are presented in Table 13 on Page 135.

TEMA. Multilevel models indicate that, when controlling for fall TEMA scores $(b=0.77, p<.001)$, spring TEMA scores were significantly negatively predicted by age in months $(b=-0.29, p=.008)$, African American race $(b=-3.64, p=.035)$, and low self-regulation $(b=-7.09, p<.000)$. Mean emotional support, emotional support consistency, gender, ethnicity, free/reduced lunch eligibility, and ELL status were not uniquely predictive of spring TEMA scores.

PPVT. Multilevel models indicate that, when controlling for fall PPVT scores $(b$ $=0.57, p<.001)$, spring PPVT scores were significantly positively predicted by emotional support consistency $(b=9.76, p=.007)$ and significantly negatively predicted by African American race $(b=-3.24, p=.029)$ and low self-regulation $(b=-5.45, p<$ 
.001). Mean emotional support, gender, age in months, ethnicity, free/reduced lunch eligibility, and ELL status were not uniquely predictive of spring PPVT scores.

TOPEL-DV. Multilevel modeling indicated that, when controlling for fall TOPEL-DV scores $(b=0.53, p<.001)$, spring TOPEL-DV scores were significantly negatively predicted by age in months $(b=-0.56, p<.001)$ and low self-regulation $(\mathrm{b}=-$ 4.04, $p<.001)$. Mean emotional support, emotional support consistency, gender, ethnicity, free/reduced lunch eligibility, race and ELL status were not uniquely predictive of spring TOPEL-DV scores.

TOPEL-PK. Multilevel modeling indicated that, when controlling for fall TOPEL-PK scores $(b=0.32, p<.001)$, spring TOPEL-PK scores were significantly positively predicted by emotional support consistency $(b=12.43, \mathrm{p}=.007)$ and significantly negatively predicted by male gender $(b=-2.55, p=.004)$, age in months $(b$ $=-0.72, p<.001)$, and low self-regulation $(b=-6.71, p<.001)$. Mean emotional support $(b=4.56, \mathrm{p}=.052)$ trended toward positively predicting spring TOPEL-PK scores. Ethnicity, free/reduced lunch status, race, and ELL status were not uniquely predictive of spring TOPEL-PK scores.

TOPEL-PA. Multilevel modeling indicated that, when controlling for fall TOPEL-PA scores $(b=0.46, p<.001)$, spring TOPEL-PA scores were significantly positively predicted by emotional support consistency $(b=13.38, \mathrm{p}=.028)$ and significantly negatively predicted by low self-regulation $(b=-9.10, p<.001)$. Mean emotional support, gender, age in months, ethnicity, free/lunch eligibility, race, and ELL status were not uniquely predictive of spring TOPEL-PA scores. 
T-CRS. Multilevel modeling indicated that, when controlling for fall T-CRS scores $(b=0.43, p<.001)$, spring T-CRS scores were significantly negatively predicted by male gender $(b=-4.89, p=.001)$ and low self-regulation $(b=-9.20, p<.001)$. Free/reduced lunch eligibility $(b=-3.64, p=.069)$ trended toward negatively predicting spring T-CRS scores. Mean emotional support, emotional support consistency, age in months, ethnicity, race, and ELL status were not uniquely predictive of spring T-CRS scores.

Follow-Up Analyses. To shed more light on the question of how mean emotional support and emotional support consistency work together in predicting children's school readiness, the classrooms in the sample were divided into four groups based on median splits for the emotional support (median=5.81) and emotional support consistency (median=-0.589) variables. See Figure 5 on Page 99 for a graphical representation of the four groups obtained when classrooms were divided at the median for each of the variables. Group 1 is the high emotional support/high consistency and acted as the reference group for comparisons. These results must be interpreted with a great deal of caution due to the small number of classrooms in each group (Group $1 n=10$ classroom [188 students]; Group $2 n=5$ classroom [101 students]; Group $3 n=5$ classroom [97 students]; Group 4 n= 11 classroom [207 students]).

Multilevel modeling was used in the follow-up analyses based on children being nested within classrooms. A series of models were run to investigate relations among classroom group membership, children's risk factors, and each developmental outcome. These models included children's baseline scores and risk factors as level-one variables, 
classroom group membership as a level-two variable, and children's spring scores on the specified academic or social-emotional measure as the outcome. Age in months and fall scores were mean-centered to aid in interpreting results for each of the regressions. Norm-referenced scores were used for the TEMA, PPVT, and each of the TOPEL subtests. A composite of the four T-CRS subtests was used at both time points. The results of the regression equations are presented in Table 14 on Page 136.

Figure 5.

Classroom Groups Resulting from Median Splits

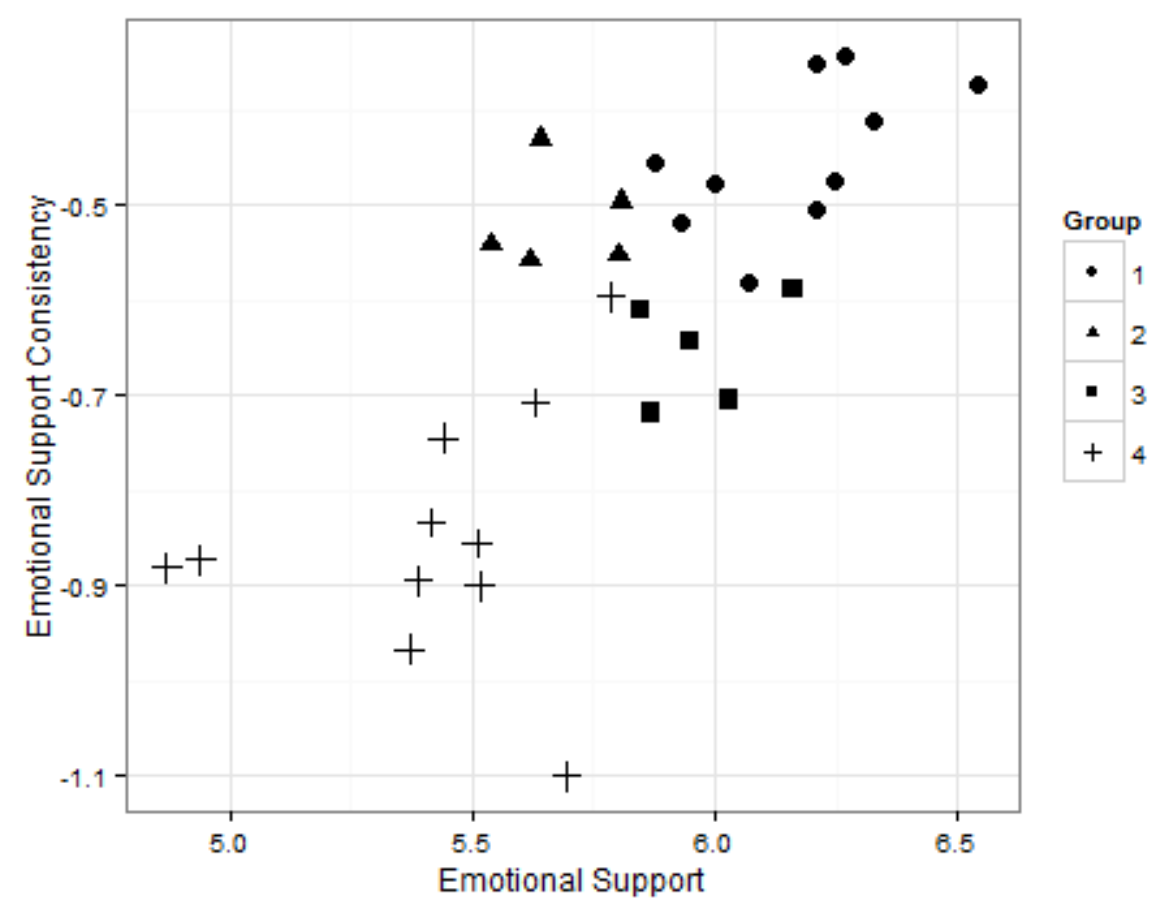

Results of the analyses indicate that, when considering fall scores and all child characteristics, no statistically significant difference exists between Group 1 (high emotional support/high consistency) and Group 2 (low emotional support/high consistency) for any of the outcomes. Male gender, age in months, African American 
race, and low self-regulation were also found to be statistically significant negative predictors of various outcomes, discussed below.

Specifically, multilevel modeling indicated that, when controlling for fall TEMA scores $(b=0.77, p<.001)$, spring TEMA scores were significantly negatively predicted by age in months $(b=-0.30, p=.007)$, African American race $(b=-3.47, p=.044)$, and low self-regulation skills $(b=-7.13, p<.001)$. In addition, membership in Group $3(b=$ $-4.33, p=0.051)$ and membership in Group $4(b=-3.77, p=0.036)$ were significantly predictive of fall scores. Gender, ethnicity, free/lunch eligibility, ELL status, and membership in Group 2 were not uniquely predictive of spring TEMA scores.

Multilevel modeling indicated that, when controlling for fall PPVT scores $(b=$ 0.57, $\mathrm{p}<.001$ ), spring PPVT scores were significantly negatively predicted by African American race $(b=-3.14, \mathrm{p}=0.036)$ and low self-regulation. In addition, membership in Group $4(b=-3.87, \mathrm{p}=0.003)$ was significantly negatively predictive of spring PPVT scores. Gender, age in months, ethnicity, free/reduced lunch status, ELL status, membership in Group 2, and membership in Group 3 were not uniquely predictive of spring PPVT scores.

Multilevel modeling indicated that, when controlling for fall TOPEL-DV scores $(b=0.53, \mathrm{p}<.001)$, spring TOPEL-DV scores were significantly negatively predicted by age in month $(b=-0.57, \mathrm{p}<.001)$ and low self-regulation skills $(b=-4.05, \mathrm{p}<.001)$. Gender, ethnicity, free/reduced lunch status, race, ELL status, and membership in Groups 2, 3, and 4 were not uniquely predictive of spring TOPEL-DV scores.

Multilevel modeling indicated that, when controlling for fall TOPEL-PK scores $(b$ 
$=0.32, \mathrm{p}<.001)$, spring TOPEL-PK scores were significantly negatively predicted by male gender $(b=-2.66, \mathrm{p}=.003)$, age in months $(b=-0.74, \mathrm{p}<.001)$, and low selfregulation scores $(b=-6.67, \mathrm{p}<.001)$. In addition, membership in Group $3(b=-4.35, \mathrm{p}$ $=0.015$ ) was significantly negatively predictive of spring TOPEL-PK scores. Ethnicity, free/reduced lunch status, race, ELL status, membership in Group 2, and membership in Group 4 were not uniquely predictive of spring TOPEL-DV scores.

Multilevel modeling indicated that, when controlling for fall TOPEL-PA scores $(b$ $=0.45, \mathrm{p}<.001)$, spring TOPEL-PA scores were significantly negatively predicted by low self-regulation skills $(b=-9.13, \mathrm{p}<.001)$ and membership in Group $4(b=-4.90, \mathrm{p}$ $=.022)$. Gender, age in months, ethnicity, free/reduced lunch status, race, ELL status, membership in Group 2, and membership in Group 3 were not uniquely predictive of spring TOPEL-PA scores.

Multilevel modeling indicated that, when controlling for fall T-CRS scores $(b=$ $0.43, \mathrm{p}<.001)$, spring T-CRS scores were significantly negatively predicted by male gender $(b=-4.97)$ and low self-regulation skills $(-9.28, \mathrm{p}<.001)$. Age in months, ethnicity, free/reduced lunch status, race, ELL status, and memberships in Groups 2, 3, and 4 did not uniquely predict spring T-CRS scores. 


\section{Chapter Six: Discussion}

The primary goal of this study was to investigate the relations among preschool children's socioeconomic and behavioral risk factors, classroom emotional support, the consistency of classroom emotional support, children's cognitive and social-emotional skills at preschool entry, and the development of children's cognitive and socialemotional skills across the school year. Unlike previous studies of emotional support consistency that have focused mainly on the role of classroom-level influences in understanding how young children develop math, language and literacy, and socialemotional skills during preschool (Brock \& Curby, 2014; Curby et al., 2013; Curby et al., 2011; Zinsser et al., 2013), this study included children's gender, age, race, ethnicity, socioeconomic status, English proficiency, and teacher-rated self-regulation skills as factors affecting children's development to create a more nuanced picture of the influences at play in preschool classrooms.

The results of this study confirm previous findings on the relations between several socioeconomic and behavioral risk factors and lower levels of early math, language and literacy, and social-emotional skills at preschool entry as well as less pronounced development of those same skills across the preschool year (e.g., BrooksGunn \& Markman, 2005; Burchinal et al., 2011; Halle et al., 2009; Howse et al., 2003; Magnuson \& Waldfogel, 2005; Rimm-Kaufman et al., 2009). However, the results run contrary to, among others, Mashburn and colleagues' (2008) findings regarding the effects of teachers' emotional support on children's development in that most child outcomes in this study were not associated with the quality of teachers' emotional 
support. The findings from this study also expand our knowledge surrounding the importance of teachers' ability to maintain a consistent level of emotional support across the course of a day. This indicator of classroom quality was found to be positively associated with children's development of early math, language, and literacy skills. This effect that was found to be especially important for English Language Learners in expressive vocabulary development.

\section{Summary of Findings}

Child Characteristics. Children who enter preschool with backgrounds that have not provided them with complex, ongoing, and progressive learning opportunities have been found to have less well-developed academic and social-emotional skills at the beginning of the year and less positive patterns of development during the school year when compared with their peers from more beneficial backgrounds. Factors such as low socioeconomic status, Hispanic ethnicity, African American race, English Language Learner status, male gender, and younger age have all been found to be related to skills deficits in fall and spring (e.g., Brooks-Gunn \& Markman, 2005; Burchinal et al., 2011; Halle et al., 2009; Howse et al., 2003; Magnuson \& Waldfogel, 2005; McClelland et al., 2007; Rimm-Kaufman et al., 2009). The results of this study align with these previous findings in that boys, comparatively younger children, children from lower income households, African American children, children identified as English Language Learners, and children with challenges relating to self-regulation all had lower scores on some or all of the measures in fall.

Figure 6 summarizes the direction of the associations between child 
characteristics and fall scores with the "minus" sign representing negative associations.

Figure 6.

Direction of Associations Between Child Characteristics and Fall Academic and Social-Emotional Skills

\begin{tabular}{|c|c|c|c|c|c|c|}
\hline & Math & $\begin{array}{l}\text { Receptive } \\
\text { Vocabulary }\end{array}$ & $\begin{array}{l}\text { Expressive } \\
\text { Vocabulary }\end{array}$ & $\begin{array}{c}\text { Print } \\
\text { Knowledge }\end{array}$ & $\begin{array}{c}\text { Phonological } \\
\text { Awareness }\end{array}$ & $\begin{array}{c}\text { Social- } \\
\text { Emotional } \\
\text { Adjustment }\end{array}$ \\
\hline Boys & & & & - & - & - \\
\hline Younger age & - & & - & - & - & - \\
\hline Low SES & - & - & - & - & - & - \\
\hline $\begin{array}{l}\text { African } \\
\text { American }\end{array}$ & & & & & - & \\
\hline ELL & & - & - & & - & \\
\hline $\begin{array}{l}\text { Low self- } \\
\text { regulation }\end{array}$ & - & - & - & - & - & - \\
\hline
\end{tabular}

One of the key indicators of young children's school readiness and later achievement is their ability to focus their attention, control their impulses, and interact with peers in ways that are socially acceptable. Children who have trouble regulating their behaviors in these areas have been found to do less well academically and socially in several prior studies of early childhood and elementary classrooms (Blair \& Diamond, 2008; Brock et al., 2009; Howse et al., 2003; McClelland et al., 2007; Moffitt et al., 2011; Morrison et al., 2010; Rimm-Kaufman et al., 2009). Many of previous studies have relied on complex, time-consuming direct assessments of children by outside observers to assess children's levels of self-regulation (e.g., the Head-Toes-Knees-Shoulders task [HTKS], the Pencil Tap task, and the Balance Beam task) (e.g., Brock et al., 2009; McClelland et al., 2007; Rimm-Kaufman et al., 2009). In contrast, this study relied solely 
on teachers' ratings of children's ability to focus on tasks in the classroom (a total of eight questions at the beginning of the year) as a way of predicting children's academic and social-emotional skill levels in fall and spring.

Similar to McClelland and colleagues' (2007) findings using the HTKS, this quick teacher assessment of children's ability to focus on and complete tasks was related to every measure at both time points in this study. In fall, the children who teachers rated as being better able to focus on their work generally scored about half a standard deviation higher than their peers on the math, language, and literacy measures. Putting this in concrete terms, a child who was identified as having below-average self-regulation skills scored, on average, almost twelve points lower (nearly three-quarters of a standard deviation) on a measure of expressive vocabulary in fall than his peers. This difference continued across the school year: In spring, this same child scored, on average, over three points lower on the same measure, or over one-third of a standard deviation lower than his peers with higher self-regulation skills.

Preschool teachers often spend a great deal of time with the children in their care and can quickly develop a sense of each child's strengths and limitations, as evidenced by the associations between teachers' ratings of children's task orientation and academic and social-emotional skills observed in this study. Using the scores from this quick, one-time, observational measure, preschool teachers can easily pinpoint students who need extra assistance in learning both how to focus their attention and in turn how to learn the academic and social-emotional skills necessary for school readiness and later achievement. 
Most likely due to the relatively small proportion of Hispanic students in this study (approximately three percent) there were no significant relations between ethnicity and any of the fall or spring measures of cognitive or social-emotional skill. In the group of children who participated in this study, English Language Learner status and Hispanic ethnicity represented two slightly-overlapping groups - less than twenty percent of the children who were English Language Learners were also Hispanic. This could be indicative of a diversity of first languages in the preschool classrooms which may have induced teachers to pay particular attention to making sure everyone was able to participate.

In fact, two highly recommended strategies for including ELL students in preschool classrooms are the use of explicit, systematic instruction in vocabulary and the provision of opportunities for children to engage in frequent conversations with assistance when needed and with ample feedback and encouragement (Colorin Colorado, 2015). These suggestions directly relate to the finding of this study that ELL children benefitted more from higher levels of emotional support consistency in developing definitional vocabulary skills than their English-proficient peers in the same classrooms. Teachers who were able to consistently engage in and model these conversations and interactions in turn demonstrated the type of consistency of emotional support measured in this study. This consistency may have benefited those children who felt disconnected from the classroom environment due to a language barrier by providing them with the direct, useful, and warm interactions and support they needed to quickly learn and apply new words, essentially outpacing their English-proficient peers. However, when the 
situation was reversed and the classroom environment provided less consistent conversations, interactions, or encouragement over the course of a day, English-proficient students were able to compensate in ways that their ELL peers were not, resulting in ELL students lagging behind in learning how to express themselves.

Children from families with limited incomes were found to have scores approximately one half of a standard deviation lower than their higher-income peers on the math, language, literacy, and social-emotional measures in fall. This association was in line with previous research. However, none of these differences were sustained through to spring, indicating that, in this case, a low socioeconomic background may have affected a child's early experiences but did not necessarily impact their ability to develop academic and social-emotional skills on par with their peers. In this case, there was neither a Matthew effect nor a compensatory effect for the low-income children across the preschool year.

The only associations that were sustained through spring for boys were those related to scores on print knowledge and levels of social-emotional adjustment, both of which remained negative and declined slightly in magnitude from fall to spring. The effect size for male gender when considering social-emotional development across the school year was small (0.22 SD) but significant, consistent with previous findings on gender-based differences in early social-emotional adjustment skills in the classroom environment (Matthews et al., 2009; Zill \& West, 2001).

When looking at age, the negative associations seen in fall related to comparatively young age were reversed by spring, with comparatively older children 
showing less positive development than their younger peers on early math, expressive vocabulary, and print knowledge. These differences were less than 0.10 SD per month of age at both time points. For example, a child who started the school year three months older than the mean age ( 3 years and 10 months) had, on average, a print knowledge score only 0.09 SD higher in fall than a child of mean age. In spring this difference reversed, with a child three months older than the mean developing skills, on average, 0.18 SD less positively than a child of mean age. Keeping in mind that the scores for the academic measures are norm-referenced, with age already included in the calculations for the final scores, these finding suggests that older children were not benefitting as much from the preschool program as their younger peers, although the differences were relatively small.

The negative association between phonological awareness scores in fall and African American race previously discussed was not evident in spring. Instead, African American children tended to have less positive development in early math and receptive vocabulary skills than their non-African American peers. This indicates that African American children were not learning these skills at the same rate as their peers, a potentially troubling confirmation of an early start to the race-based achievement gap often observed in early childhood education settings and the K-12 school system (Brooks-Gunn \& Markman, 2005; Halle et al., 2009; Magnuson \& Waldfogel, 2005).

Figure 7 on Page 117 summarizes the direction of the associations between child characteristics and spring scores with the "minus" sign representing negative associations and the "plus" sign representing positive associations. 
Figure 7.

Direction of Associations Between Child Characteristics and Development of Academic and SocialEmotional Skills

\begin{tabular}{l|cccccc}
\hline \multicolumn{2}{l}{ Math } & $\begin{array}{c}\text { Receptive } \\
\text { Vocabulary }\end{array}$ & $\begin{array}{c}\text { Expressive } \\
\text { Vocabulary }\end{array}$ & $\begin{array}{c}\text { Print } \\
\text { Knowledge }\end{array}$ & $\begin{array}{c}\text { Phonological } \\
\text { Awareness }\end{array}$ & $\begin{array}{c}\text { Social- } \\
\text { Emotional } \\
\text { Adjustment }\end{array}$ \\
\hline $\begin{array}{l}\text { Boys } \\
\text { Younger age }\end{array}$ & + & & & - & & - \\
$\begin{array}{l}\text { African } \\
\text { American }\end{array}$ & - & - & + & + & & - \\
$\begin{array}{l}\text { Low self- } \\
\text { regulation }\end{array}$ & - & - & - & - & - & \\
\hline $\begin{array}{l}\text { Note. The reference groups are girls, comparatively older children, non-African American children } \\
\text { (White, Asian, Indian, Native Hawaiian/Pacific Islander, and American Indian/Alaskan), and children }\end{array}$ \\
with higher teacher-rated self-regulation skills.
\end{tabular}

Emotional Support. Many large-scale studies have suggested a link between the quality of emotional support observed in classrooms and children's development of early academic and social-emotional skills (e.g., Burchinal et al., 2010; Curby et al, 2011; Howes et al., 2008; Mashburn et al., 2008; Molfese, et al., 2012; NICHD, 2002; PeisnerFeinberg \& Burchinal, 1997; Rimm-Kaufman et al., 2009). Contrary to these previous findings, the results of this study indicate either a very small or non-existent relationship between observers' ratings of classroom emotional support and children's outcomes. In models where child characteristics and emotional support were entered at the same time, emotional support was positively related only to children's development of expressive vocabulary and phonological awareness skills across the preschool year, and even then the effect sizes were quite small ( 0.09 and 0.11 , respectively). Even in models were emotional support was used as the only predictor of development, this same trend was observed and the effect sizes were even smaller (0.09 and 0.10). 
The lack of strong associations between emotional support and children's development may be related to the small number of classrooms participating in this study. With a sample size of only 31 classrooms, these findings may suffer from a lack of power to detect differences between classrooms.

Emotional Support Consistency. One of the underlying goals of this study was to investigate the role of emotional support consistency in young children's development of early academic and social-emotional skills and thereby expand the definition of what a "high quality" preschool classroom looks like when assessed by outside observers. Researchers, policy makers, and parents have increasingly narrowed their focused in search of those aspects of early childhood education that matter the most in preparing young children cognitively, socially, and emotionally for school readiness and later success. In the early days of large-scale preschool programs, providing access to any type of child care was considered sufficient, without regard to quality. Then, a series of studies pointed out the necessity of high-quality experiences - most often in the form of high quality emotional support - for children's optimal development (Burchinal et al., 2010; Curby et al, 2011; Howes et al., 2008; Mashburn et al., 2008; Molfese, et al., 2012; NICHD, 2002; Peisner-Feinberg \& Burchinal, 1997; Rimm-Kaufman et al., 2009). This study provides evidence that mean levels of quality still may not be enough when considering which aspects of preschool are most important for preparing young children for kindergarten. The stability of the classroom environment, in terms of the quality of emotional support observed throughout the course of a day, was found to be positively related to children's development of math, receptive vocabulary, print knowledge, and 
phonological awareness during the preschool year, similar to previous studies (Brock \& Curby, 2014; Curby et al., 2013; Curby et al., 2011; Zinsser et al., 2013). For example, spring receptive vocabulary scores for children in the classroom with the highest consistency score were, on average, nearly ten points, or over half of a standard deviation, higher than spring receptive vocabulary scores for children in the classroom with the lowest consistency score when fall scores and child characteristics were entered as control variables in both cases. Given that only 31 classrooms participated in this study, the magnitude of these relations, like those related to emotional support, may actually be understated. Lack of power to detect differences based on the limited sample size creates the need for future, larger studies of diverse groups of children in preschool classrooms.

However, the evidence that consistency of emotional support across the day is a better predictor of children's development than mean emotional support was reinforced when both emotional support and consistency were entered simultaneously with child characteristics in models predicting development. While emotional support was associated with development of print knowledge skills in this model (in the negative direction, something that runs counter to logic), consistency of emotional support was positively associated with skill development on every measure except early math. The effect sizes for emotional support consistency were small (from 0.08 to 0.15 ), again most likely due to the lack of power to detect differences between classrooms.

Grouping Classrooms. While it is possible to separately characterize the influence of mean emotional support and emotional support consistency, either alone or 
in the same equation, on children's development, the question naturally arises of how combining the two aspects of the classroom environment might improve upon what can be learned from each one. Creating a variable that reflects each classroom's unique combination of mean and stability for use in equations predicting children's development can help identify which type of classroom environment is most beneficial for children's development, school readiness, and later achievement. It seeks to answer the question the following question: Is a classroom with a high mean level of emotional support a "better" place for learning and growing than a one with high consistency, or must both be present to support optimal development?

To answer this question each of the classroom-level variables was split at the median to create four groups of classrooms. Group One was the reference group, comprised of those classrooms with both mean emotional support and emotional support consistency ratings above the median. Group Two was those classrooms with consistency ratings above the median and emotional support ratings below the median, Group Three consisted of classrooms with emotional support mean ratings above the median and consistency ratings below the median, and Group Four contained those classrooms with both mean emotional support and emotional support consistency ratings below the median. Figure 8 on Page 113 depicts the groups of classrooms that resulted from the median splits as described.

Results of the post hoc analyses suggest that it is the stability of emotional support across the preschool year that matters most in predicting many aspects of children's academic and social-emotional development. Across the board, classrooms in Group 2 
(below-median emotional support/above-median consistency) were not mathematically identifiably different than those classrooms in Group One (above median on both variables) in predicting development on any of the measures, while differences were detected for Groups Three and Four. This suggests that, under conditions of relatively high quality such as those observed in this study, the stability of emotional support matters more for children's development than the mean level. This finding must be interpreted with some caution, however, given the small number of classrooms in the study and the lack of wide-ranging variability in either the mean emotional support or consistency ratings. Case in point, the classroom with the lowest average emotional

Figure 8. Classroom Groups Resulting From Median Splits of Emotional Support and Emotional Support Consistency

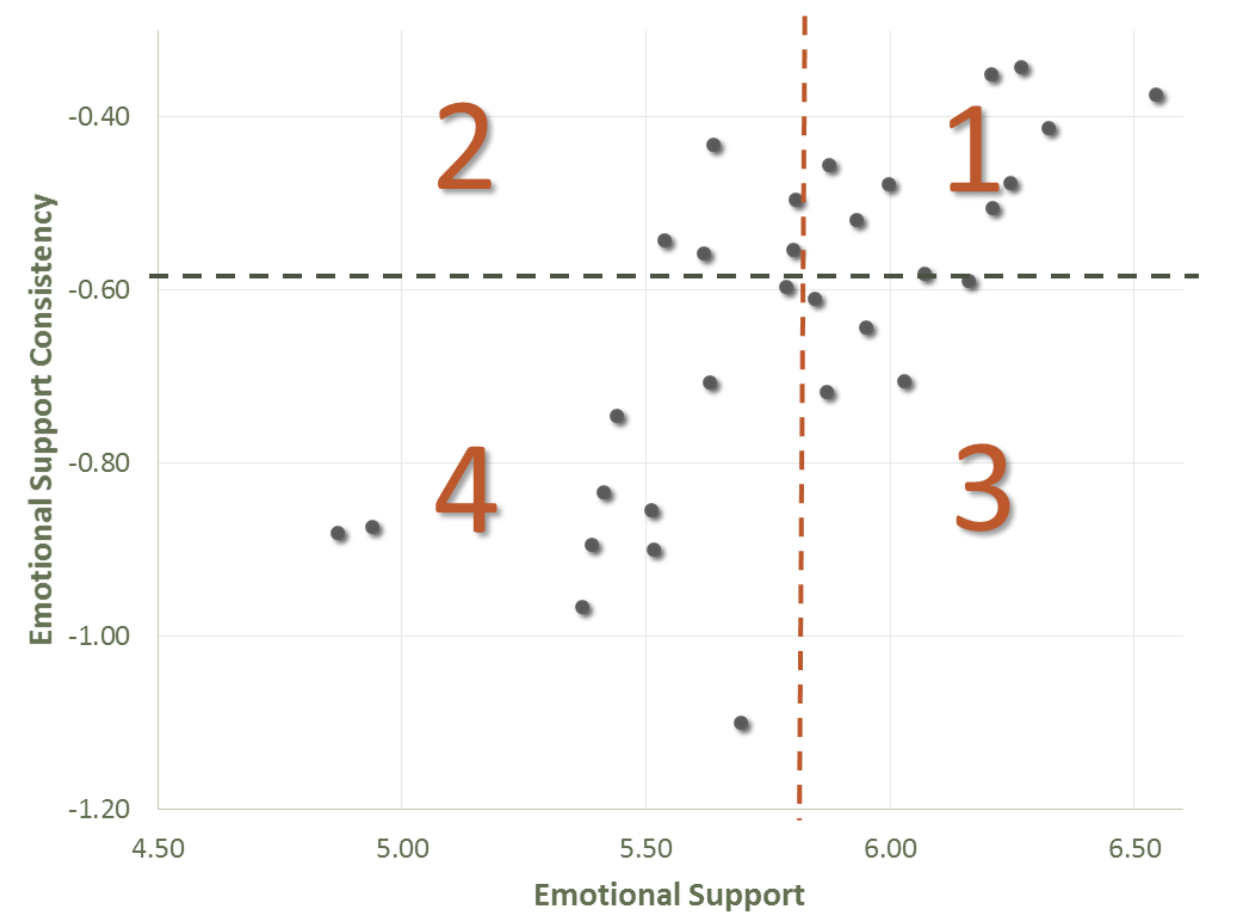

support was rated at 4.87 , just barely outside of the "high quality" range as defined by the authors of the instrument (Pianta et al., 2008). As one would hope, none of the 
classrooms in this study were observed to have the type of mean emotional support that would test whether truly low emotional support ratings (in the 1 to 3 range) would continue to have no separable role in predicting children's development.

\section{Limitations}

Sample. The students who participated in this study represent a population of interest to researchers in that a majority of the children are from urban, low-income, African-American families, a group which is at higher risk for entering kindergarten with lower levels of cognitive and social-emotional development. In addition, the students enrolled in the public charter schools which provided these data were chosen through a lottery system as part of a city-wide public school initiative providing free education to three- and four-year-olds in the city. This process is different than traditional enrollment where parental income acts to segregate children into different centers based on family resources.

The nature of the charter schools involved in this study are also a limitation. The curriculum in place at the five campuses focuses heavily on individual child assessments and creating person-centered learning experiences that address each child's strengths and challenges. As a result, findings from this sample may not generalize to other preschool environments that use a more traditional early learning curriculum.

Measures. The measures used in this study represent both strengths and limitations. First, the use of the CLASS as a measure of emotional support quality in preschool classrooms is a major strength. The CLASS is a well-documented tool that has been validated and used in numerous studies across a variety of preschool contexts. In 
addition, the availability of 24 CLASS observation cycles in all of the classrooms across the school year provides a wider range of data than has been used in most previous studies examining consistency and quality of emotional support as predictors of school readiness.

However, relying on the CLASS as a measure of consistency is also problematic in that it overestimates the consistency of experiences in the classroom. Because teachers are rated on their average level of emotional support over a series of twenty-minute cycles, the CLASS does not capture the full range of variability that children may experience on a minute-to-minute basis. This study is a step forward in understanding how consistency is related to outcomes using the instruments available at this time so this limitation was considered acceptable.

Another limitation in the study's measurement is the reliance on teacher reports of children's social and emotional adjustment in the classroom when the teachers are themselves being rated on the quality and consistency of their emotional support. The use of teacher reports introduces a potential source of bias that could be avoided through the use of neutral observer ratings. However, in this study any potential bias is reduced by virtue of trained raters observing the teaching team (two or three individuals) instead of just the lead teacher - the person responsible for completing the reports on students' social-emotional development - to assess the quality and consistency of emotional support in the classroom.

Analyses. Multi-level modeling as an analytical framework for teasing apart the differential influences of risk factors, quality, and consistency within classrooms is a 
strength of this study. Because the majority of children were nested within fixed classrooms for the duration of the school year, the multi-level modeling technique will more accurately partition the variance into both child- and classroom-level sources when analyzing school readiness outcomes. This provides valuable information that would not be available using traditional Ordinary Least Squares methodology.

\section{Future Research}

The CLASS has many attributes that recommend it to researchers as a welldeveloped measure of the quality of the classroom environment. There is also as a robust history of statistical relations between higher CLASS scores (in particular, the Emotional Support domain) and more positive child outcomes. And yet, there is still room for improvement in understanding exactly what the CLASS measures, how it can more accurately assess those aspects of the classroom that matter for children's development, and how CLASS scores might be more usefully and correctly interpreted when ratings are made of preschool classrooms. This section discusses a potential improvement on the CLASS as a measure of classroom interactions, an understated and often overlooked strength of the ratings resulting from CLASS observations in preschool environments, and the conflation of quality and consistency that inevitably occurs when researchers use the CLASS as a classroom-level predictor in this type of study.

First, the CLASS was created as a way of assessing classroom environments, teachers' behaviors, and the quality of classroom interactions. Raters using the CLASS are instructed to consider what everyone in the classroom is doing when assigning ratings. This global view of the classroom environment necessarily includes how children 
are behaving, the shared mood of everyone in the room, and the interplay between and amongst the teachers and children. When the CLASS is used as designed it is impossible to separate a teacher's emotional support from the demands and reactions of the children with whom she is interacting.

In a classroom where the children are well adjusted, even tempered, and eager to please, ratings on the Emotional Support domain may be drastically different than ratings in a classroom filled with children who are easily frustrated, tired, and stressed even if the same teacher is present in both situations. Some groups of children may be predominantly comprised of children who enter the classroom lacking the skills to support their peers or verbalize their needs in ways that are not disruptive. For example, young children with challenges related to self-regulation may have a hard time controlling their irritability, keeping their voice at an acceptable volume, or refraining from interrupting their peers in conversation or play. These child-level behaviors are then assigned to the teacher, according to the most common interpretation and use of the CLASS.

When the quality or consistency of emotional support is conceptualized as a classroom-level variable without adjustment for the impact of characteristics of the children in the classroom, the results may mask the influence of children in creating "teacher" ratings. In the future, measures that explicitly consider the role of child characteristics (e.g., age, self-regulation skill, ability to communicate in a language that is understood by peers and teachers) when aggregated as part of a classroom-level variable may be more reflective of teachers' true influence on the quality and consistency of the classroom environment. 
Secondly, in the classrooms where the observations for this study took place there were two or more teaching staff in the classroom at least eighty percent of the time. Again, according to instructions given to CLASS raters, everyone in the classroom must be included in any ratings assigned. What this means in terms of classrooms with more than one teacher is that the ability of those teachers to present the kind of "unified front" required to receive consistent scores across eight ratings during the course of one day and 24 ratings across the year may play an especially important part predicting children's development in the preschool context. Teachers who are able to work together in such a way that their combined and individual efforts result in scores in the "high" range (5 to 7 on a 7 point scale) may reflect a kind of stability not clearly communicated in studies using the CLASS in classrooms with more than one adult, as is typical for K-12 classrooms.

Finally, although the analysis of consistency of CLASS scores undertaken in this study indicates that stability in the classroom environment plays a key role in predicting children's development, the dependence of consistency on the mean is an area that deserves further exploration. Much like children and teachers jointly contribute to the classroom environment, mean and consistency of emotional support are linked in ways that make it difficult to differentiate them from one another in certain situations. Especially at high levels of quality, the amount of variability that can occur in emotional support scores is limited by the nature of the CLASS scale and is constrained to occurring in the negative direction. For example, a classroom with a mean emotional support score of 5.8 (the average in this study) can have variability in the positive direction no larger 
than 1.2 points due to the seven-point scale. The closer the ratings get to the ceiling, the more variability is necessarily constrained. Thus, the mean score for a classroom at the highest end of the scale already includes aspects of consistency in the ratings. The field of early childhood development would be well served by the development of a measure that clearly defines and measures the stability of classroom environments over distinct periods of time.

\section{Implications}

There are three important and intriguing implications of this study. First, one aspect of children's teacher-rated self-regulation skills at preschool entry consistently negatively predicted both fall scores and development on every measure used in this study. Those children whose scores on teacher-rated task orientation - their ability to focus on and complete school-related tasks - were just one standard deviation below the mean were at much greater risk for finishing preschool with deficits in all areas of learning. Based on this, it makes sense to equip teachers with the right tool to systematically assess children's self-regulation to help them identify and assist those children who face extra risk due to their inability to focus. The Task Orientation subscale of the T-CRS is a relatively simple and quick rating that teachers can complete based simply on what they have observed in the classroom. It requires no specialized training to complete and alleviates the need for complicated lab-based assessments administered by outside observers. Preschools would be well served to consider implementing use of the T-CRS as a means of helping teachers create optimal learning environments for every child. 
Second, English Language Learners typically face challenges in reaching the same level of vocabulary knowledge as their English-proficient peers. In addition, limited vocabulary skills in children beyond preschool are related to poorer outcomes in a variety of language and literacy skill areas (Vinco, 2013). The results of this study suggest that when young English Language Learners are learning what things are called and how to define them, they rely on teachers who are consistently respectful and kind and who place a high value on the contributions of children in the classroom (Colorin Colorado, 2015; Vinco, 2013). Teaching teams in preschool classrooms with English Language Learners would do well to remain vigilant with regards to the level of care and respect with which they treat their students across the course of a day. Young English Language Learners rely on days filled with interactions - both casual and instructional - that are warm, respectful, helpful, and which offer them opportunities to be heard and encouraged, even more so than their English-proficient peers.

And finally, emotional support consistency is both a concept and a variable that deserves continued attention in future research. The exploratory, post-hoc work done in this study indicates that, under conditions of relatively high overall quality, consistency of emotional support is an important factor in predicting children's success in preschool. More work remains to be done with larger classroom samples to further understand this effect and work towards clarifying how consistency (or lack thereof) and the average level of emotional support combine to influence children's development.

\section{Conclusion}

Preschool classrooms are active, emotional, dynamic settings. The children in the 
classroom progress through a series of routines, often interrupted by unexpected by moments of exuberance, sadness, or conflict, and nothing stays the same for very long. This study suggests that, in order for those children to develop fully and learn to the best of their ability, there must be a layer of high quality emotional stability underneath all of that change and growth. Teachers in preschool classroom must provide their care and instruction within a framework of sensitivity, warmth, compassion, and respect to create environments were children feel safe enough to venture into learning opportunities that result in optimal development. 
Tables

Table 1

Child Characteristics

\begin{tabular}{lcrr}
\hline & & $n$ & $\%$ \\
\hline Free/reduced lunch & & & \\
& Yes & 466 & 79 \\
& No & 127 & 21 \\
African American & & 492 & 83 \\
& Yes & 101 & 17 \\
& No & 18 & 3 \\
Hispanic & & 575 & 97 \\
& Yes & 60 & 10 \\
Eng. Lang. Learner & No & 533 & 90 \\
& Yes & & \\
Male & No & 291 & 49 \\
& & 302 & 51 \\
Self-regulation & Yes & & \\
& No & & \\
& High & 447 & 83 \\
\hline Age (months) & Low & & 17 \\
\hline & & Mean & $S D$ \\
\hline & & 45.71 & 6.40 \\
\hline
\end{tabular}


Table 2

Teacher Characteristics

\begin{tabular}{|c|c|c|c|}
\hline & & $n$ & $\%$ \\
\hline \multicolumn{4}{|l|}{ Gender } \\
\hline Female & & 88 & 93 \\
\hline Male & & 7 & 7 \\
\hline \multicolumn{4}{|l|}{ Position } \\
\hline Teacher & & 42 & 44 \\
\hline Assistant Teacher & & 29 & 31 \\
\hline Teaching Fellow & & 18 & 19 \\
\hline School Aide & & 4 & 4 \\
\hline \multicolumn{2}{|c|}{ Special Education Coordinator } & 2 & 2 \\
\hline & Min. & Median & Max. \\
\hline Age (years) & 21 & 25 & 56 \\
\hline Teaching experience (years) & 1 & 4 & 26 \\
\hline
\end{tabular}


Table 3

Child- and Classroom-Level Variables

\begin{tabular}{lrrrrrr}
\hline & $n$ & Mean & SD & Min. & Max. & SE \\
\hline Child Level & & & & & & \\
Fall TEMA $^{1}$ & 587 & 89.19 & 12.51 & 65.00 & 146.00 & 0.516 \\
Spring TEMA $^{1}$ & 562 & 100.17 & 16.18 & 62.00 & 146.00 & 0.683 \\
& & & & & & \\
Fall PPVT $^{1}$ & 586 & 97.56 & 16.86 & 20.00 & 140.00 & 0.697 \\
Spring PPVT $^{1}$ & 562 & 104.48 & 14.60 & 53.00 & 148.00 & 0.616 \\
& & & & & & \\
Fall TOPEL-DV $^{1}$ & 588 & 90.83 & 16.36 & 9.00 & 127.00 & 0.675 \\
Spring TOPEL-DV $^{1}$ & 562 & 99.49 & 12.76 & 54.00 & 127.00 & 0.538 \\
& & & & & & \\
Fall TOPEL-PK $^{1}$ & 588 & 106.13 & 18.14 & 74.00 & 145.00 & 0.748 \\
Spring TOPEL-PK $^{1}$ & 562 & 115.98 & 13.02 & 78.00 & 145.00 & 0.549 \\
& & & & & & \\
Fall TOPEL-PA $^{1}$ & 586 & 91.21 & 15.46 & 55.00 & 145.00 & 0.639 \\
Spring TOPEL-PA $^{1}$ & 561 & 103.17 & 16.59 & 57.00 & 138.00 & 0.701 \\
& & & & & & \\
Fall T-CRS $^{2}$ & 544 & 121.15 & 22.86 & 49.33 & 160.00 & 0.980 \\
Spring T-CRS $^{2}$ & 542 & 128.68 & 22.30 & 62.00 & 160.00 & 0.958 \\
Classroom Level $_{\text {Emotional Support }}$ & & & & & & \\
ES Consistency & 31 & 5.79 & 0.38 & 4.87 & 6.54 & 0.02 \\
& & -0.63 & 0.19 & -0.34 & -1.10 & 0.01 \\
\hline
\end{tabular}

Note. ${ }^{1}$ Norm-reference score. ${ }^{2}$ Composite raw score. ES $=$ Emotional Support. PPVT = Peabody Picture Vocabulary Test. T-CRS $=$ Teacher-Child Rating Scale. TEMA = Test of Early Math Ability. TOPEL-DV = Test of Preschool Early Literacy - Definitional Vocabulary. TOPEL-PA $=$ Test of Preschool Early Literacy - Phonological Awareness. TOPEL-PK = Test of Preschool Early Literacy - Print Knowledge. 


\section{Table 4}

Correlations Between Child Characteristics, Fall Cognitive and Social-Emotional Skills, Spring Cognitive and Social-Emotional Skills, Classroom Emotional Support, and Classroom Emotional Support Consistency

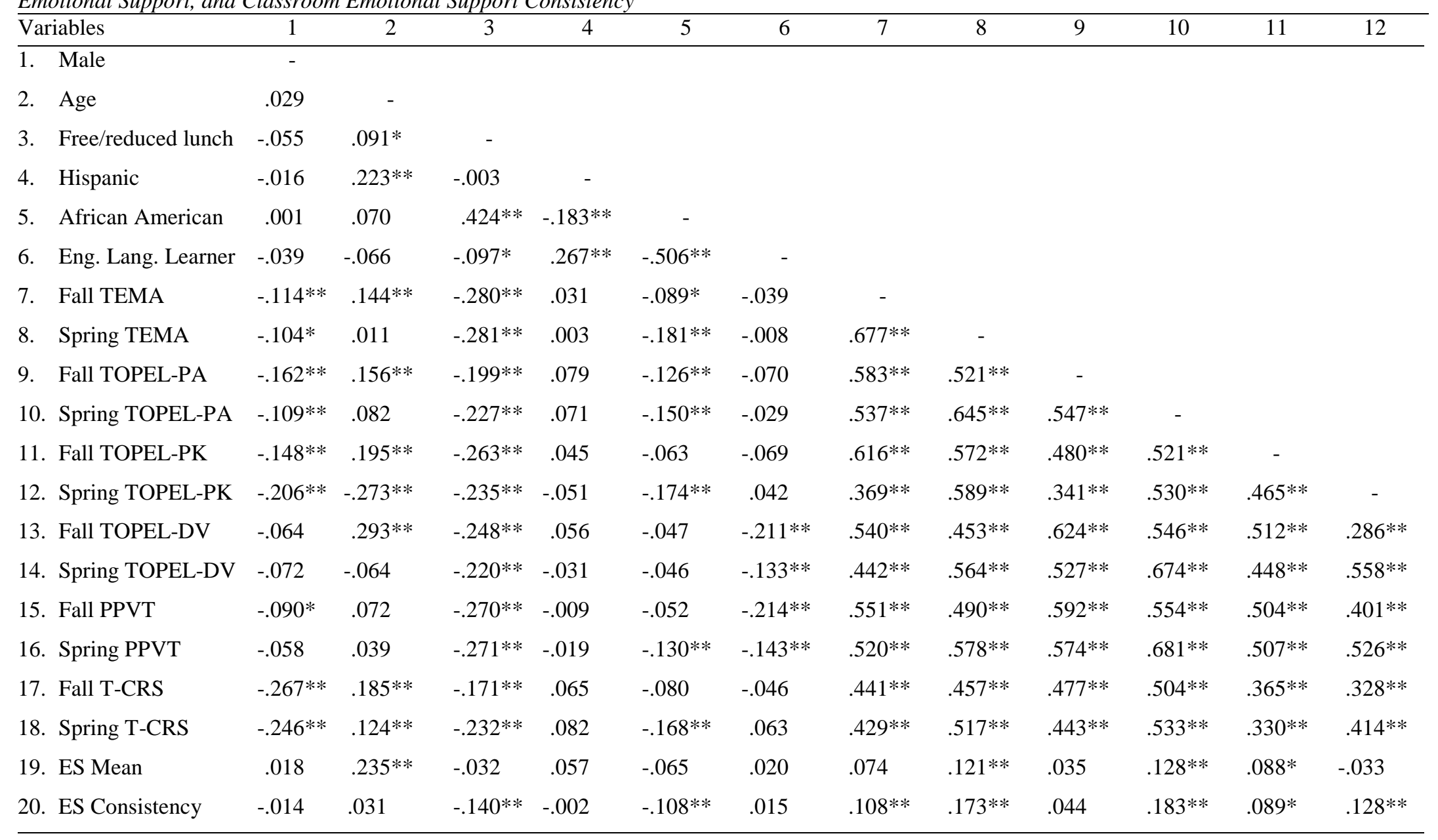




\section{Table 4}

Continued

Variables

13

14

15

16

$17 \quad 18$

13. Fall TOPEL-DV

14. Spring TOPEL-DV

15. Fall PPVT

$.663 * *$

15. Fall PPVT

$.721 * * .649 * *$

16. Spring PPVT

$.678 * * .744 * * .737 * *$

17. Fall T-CRS

$.482 * * .450 * * \quad .414 * *$

18. Spring T-CRS

$.418 * * .486 * * .372 * *$

$.099 * \quad .012$

.049

20. ES consistency

$.082 *$

$.090 * \quad .118 * \quad .211 * * \quad .005 \quad .029$

$.721 * *$

Note. ES = Emotional Support. PPVT = Peabody Picture Vocabulary Test. T-CRS = Teacher-Child Rating Scale. TEMA = Test of Early Math Ability. TOPEL-DV = Test of Preschool Early Literacy - Definitional Vocabulary. TOPEL-PA = Test of Preschool Early Literacy - Phonological Awareness. TOPEL-PK $=$ Test of Preschool Early Literacy - Print Knowledge. $*=p<.05 . * *=p<.01$. 


\section{Table 5}

Associations Between Fall Cognitive and Social-Emotional Skills and Child Characteristics

\begin{tabular}{|c|c|c|c|c|c|c|c|c|c|c|c|c|}
\hline & \multicolumn{2}{|c|}{ Fall TEMA $^{1}$} & \multicolumn{2}{|c|}{ Fall PPVT $^{1}$} & \multicolumn{2}{|c|}{ Fall TOPEL-DV ${ }^{1}$} & \multicolumn{2}{|c|}{ Fall TOPEL-PK } & \multicolumn{2}{|c|}{ Fall TOPEL-PA $^{1}$} & \multicolumn{2}{|c|}{ Fall T-CRS ${ }^{2}$} \\
\hline & $b$ & SE & $b$ & SE & $b$ & SE & $b$ & SE & $b$ & SE & $b$ & $\mathrm{SE}$ \\
\hline Intercept & $98.05 * * *$ & 1.70 & $111.68 * * *$ & 2.18 & $104.24 * * *$ & 1.02 & $118.65 * * *$ & 2.41 & $103.57 * * *$ & 2.01 & $136.53 * * *$ & 2.41 \\
\hline Male & $-2.23^{*}$ & 1.02 & -1.79 & 1.31 & -1.15 & 1.21 & $-5.14 * * *$ & 1.46 & $-3.62 * *$ & 1.22 & $-6.81 * * *$ & 1.40 \\
\hline Age (in months) ${ }^{3}$ & $0.24 *$ & 0.10 & 0.19 & 0.13 & $0.68 * * *$ & 0.12 & $0.49 * * *$ & 0.13 & $0.33 * *$ & 0.11 & $0.62 * * *$ & 0.15 \\
\hline Hispanic & -0.60 & 3.05 & 1.33 & 3.91 & 2.28 & 3.63 & 1.08 & 4.37 & 3.64 & 3.64 & -0.60 & 4.24 \\
\hline Free/reduced lunch & $-8.49 * * *$ & 1.40 & $-9.19 * * *$ & 1.79 & $-8.81 * * *$ & 1.66 & $-11.95 * * *$ & 2.00 & $-5.46 * * *$ & 1.67 & $-5.81 * *$ & 1.93 \\
\hline African American & 1.12 & 1.74 & -2.32 & 2.23 & -2.50 & 2.07 & 1.97 & 2.50 & $-3.91 \dagger$ & 2.08 & -0.59 & 2.41 \\
\hline ELL & -1.67 & 2.13 & $-16.08 * * *$ & 2.73 & $-14.27 * * *$ & 1.53 & $-5.27 * * *$ & 3.05 & $-8.60 * * *$ & 2.54 & $-5.50 \dagger$ & 2.96 \\
\hline Low self-regulation & $-7.73 * * *$ & 1.35 & $-11.87 * * *$ & 1.75 & $-11.50 * * *$ & 1.60 & $-6.85 * * *$ & 1.94 & $-11.31 * *$ & 1.61 & $-36.32 * * *$ & 1.86 \\
\hline
\end{tabular}

Note. ${ }^{1}$ Norm-reference score. ${ }^{2}$ Composite raw score. ${ }^{3}$ Mean-centered predictor. ELL=English Language Learner. PPVT $=$ Peabody Picture Vocabulary Test. T-CRS = Teacher-Child Rating Scale. TEMA = Test of Early Math Ability. TOPEL-DV = Test of Preschool Early Literacy - Definitional Vocabulary. TOPEL-PA = Test of Preschool Early Literacy - Phonological Awareness. TOPEL-PK = Test of Preschool Early Literacy - Print Knowledge. $\uparrow \mathrm{p} \leq .08$. $* \mathrm{p} \leq .05 . * * \mathrm{p} \leq .01 . * * * \mathrm{p} \leq .001$. 


\section{Table 6}

Associations Between Spring Cognitive and Social-Emotional Skills, Fall Cognitive and Social-Emotional Skills, and Child Characteristics

\begin{tabular}{|c|c|c|c|c|c|c|c|c|c|c|c|c|}
\hline & \multicolumn{2}{|c|}{ Fall TEMA $^{1}$} & \multicolumn{2}{|c|}{ Fall PPVT ${ }^{1}$} & \multicolumn{2}{|c|}{ Fall TOPEL-DV ${ }^{1}$} & \multicolumn{2}{|c|}{ Fall TOPEL-PK ${ }^{1}$} & \multicolumn{2}{|c|}{ Fall TOPEL-PA ${ }^{1}$} & \multicolumn{2}{|c|}{ Fall T-CRS ${ }^{2}$} \\
\hline & $b$ & SE & $b$ & SE & $b$ & SE & $b$ & SE & $b$ & SE & $b$ & SE \\
\hline Intercept & $106.50 * * *$ & 1.74 & $109.15 * * *$ & 1.49 & $99.63 * * *$ & 1.31 & $120.97 * * *$ & 1.52 & $109.20 * * *$ & 2.04 & $137.54 * * *$ & 2.79 \\
\hline Fall score ${ }^{3}$ & $0.78 * * *$ & 0.04 & $0.57 * * *$ & 0.03 & $0.54 * * *$ & 0.03 & $0.32 * * *$ & 0.03 & $0.45^{* * *}$ & 0.04 & $0.43 * * *$ & 0.04 \\
\hline Male & -0.53 & 1.00 & 0.48 & 0.87 & -0.14 & 0.77 & $-2.68 * *$ & 0.88 & -0.53 & 1.16 & $-4.92 * *$ & 1.46 \\
\hline Age (in months) ${ }^{3}$ & $-0.28 *$ & 0.11 & -0.06 & 0.09 & $-0.58 * * *$ & 0.07 & $-0.77 * * *$ & 0.09 & -0.09 & 0.13 & 0.18 & 0.19 \\
\hline Hispanic & -1.99 & 2.99 & -2.52 & 2.59 & -0.97 & 2.29 & -0.48 & 2.63 & 1.81 & 3.46 & -0.02 & 4.28 \\
\hline Free/reduced lunch & -1.86 & 1.41 & -0.88 & 1.21 & -0.66 & 1.08 & -0.37 & 1.24 & -2.49 & 1.60 & $-3.69 \dagger$ & 1.99 \\
\hline ELL & -0.90 & 2.10 & -1.73 & 1.88 & 0.48 & 1.66 & -0.53 & 1.85 & -2.05 & 2.46 & 4.21 & 3.01 \\
\hline Low self-regulation & $-7.10 * * *$ & 1.36 & $-5.36 * * *$ & 1.20 & $-3.96 * * *$ & 1.06 & $-6.61 * * *$ & 1.17 & $-9.15 * * *$ & 1.59 & $-9.16 * * *$ & 2.49 \\
\hline
\end{tabular}

Note. ${ }^{1}$ Norm-reference score. ${ }^{2}$ Composite raw score. ${ }^{3}$ Mean-centered predictor. ELL $=$ English Language Learner. PPVT $=$ Peabody Picture Vocabulary

Test. T-CRS $=$ Teacher-Child Rating Scale. TEMA $=$ Test of Early Math Ability. TOPEL-DV $=$ Test of Preschool Early Literacy - Definitional

Vocabulary. TOPEL-PA = Test of Preschool Early Literacy - Phonological Awareness. TOPEL-PK $=$ Test of Preschool Early Literacy - Print

Knowledge. $\dagger \mathrm{p} \leq .08 . * \mathrm{p} \leq .05 . * * \mathrm{p} \leq .01 . * * * \mathrm{p} \leq .001$ 
Table 7

Associations Between Spring Cognitive and Social-Emotional Skills, Fall Cognitive and Social-Emotional Skills, and Classroom Emotional Support

\begin{tabular}{|c|c|c|c|c|c|c|c|c|c|c|c|c|}
\hline & \multicolumn{2}{|c|}{ Spring TEMA ${ }^{1}$} & \multicolumn{2}{|c|}{ Spring PPVT ${ }^{1}$} & \multicolumn{2}{|c|}{$\begin{array}{c}\text { Spring } \\
\text { TOPEL-DV }^{1} \\
\end{array}$} & \multicolumn{2}{|c|}{$\begin{array}{c}\text { Spring } \\
\text { TOPEL-PK }{ }^{1}\end{array}$} & \multicolumn{2}{|c|}{$\begin{array}{c}\text { Spring } \\
\text { TOPEL-PA }^{1} \\
\end{array}$} & \multicolumn{2}{|c|}{ Spring T-CRS ${ }^{2}$} \\
\hline & $b$ & $\overline{\mathrm{SE}}$ & $b$ & $\overline{\mathrm{SE}}$ & $b$ & $\mathrm{SE}$ & $b$ & $\overline{\mathrm{SE}}$ & $b$ & $\mathrm{SE}$ & $b$ & $\mathrm{SE}$ \\
\hline Intercept & $99.93 * * *$ & 0.79 & $104.60 * * *$ & 0.53 & $99.67 * * *$ & 0.73 & $115.93 * * *$ & 1.05 & $103.51 * * *$ & 0.87 & $128.46 * * *$ & 1.66 \\
\hline Fall score ${ }^{3}$ & $0.85 * * *$ & 0.04 & $0.62 * * *$ & 0.02 & $0.54 * * *$ & 0.02 & $0.37 * * *$ & 0.03 & $0.55^{* * * *}$ & 0.04 & $0.58 * * *$ & 0.03 \\
\hline ES mean ${ }^{3}$ & 2.79 & 2.07 & $3.28 *$ & 1.40 & -2.20 & 1.93 & -3.06 & 2.76 & $4.42 \dagger$ & 2.30 & -0.80 & 4.33 \\
\hline
\end{tabular}

Note. ${ }^{1}$ Norm-reference score. ${ }^{2}$ Composite raw score. ${ }^{3}$ Mean-centered predictor. ES $=$ Emotional Support. PPVT $=$ Peabody Picture Vocabulary Test. TCRS $=$ Teacher-Child Rating Scale TEMA $=$ Test of Early Math Ability. TOPEL-DV = Test of Preschool Early Literacy - Definitional Vocabulary. TOPEL-PA = Test of Preschool Early Literacy - Phonological Awareness. TOPEL-PK = Test of Preschool Early Literacy - Print Knowledge. $\dagger \mathrm{p} \leq .08 . * \mathrm{p} \leq .05 . * * \mathrm{p} \leq .01 . * * * \mathrm{p} \leq .001$ 


\section{Table 8}

Associations Between Spring Cognitive and Social-Emotional Skills, Fall Cognitive and Social-Emotional Skills, Child Characteristics, and Classroom Emotional Support (Main Effects)

\begin{tabular}{|c|c|c|c|c|c|c|c|c|c|c|c|c|}
\hline & \multicolumn{2}{|c|}{ Spring TEMA ${ }^{1}$} & \multicolumn{2}{|c|}{ Spring PPVT $^{1}$} & \multicolumn{2}{|c|}{$\begin{array}{c}\text { Spring } \\
\text { TOPEL-DV }{ }^{1} \\
\end{array}$} & \multicolumn{2}{|c|}{$\begin{array}{c}\text { Spring } \\
\text { TOPEL-PK }^{1}\end{array}$} & \multicolumn{2}{|c|}{$\begin{array}{c}\text { Spring } \\
\text { TOPEL-PA }^{1}\end{array}$} & \multicolumn{2}{|c|}{ Spring T-CRS ${ }^{2}$} \\
\hline & $b$ & SE & $b$ & SE & $b$ & $\mathrm{SE}$ & $b$ & $\mathrm{SE}$ & $b$ & SE & $b$ & $\mathrm{SE}$ \\
\hline Intercept & $106.42 * * *$ & 1.72 & $109.01 * * *$ & 1.47 & $99.62 * * *$ & 1.31 & $120.96 * * *$ & 1.52 & $109.08 * * *$ & 2.02 & $137.60 * * *$ & 2.79 \\
\hline Fall score $^{3}$ & $0.78 * * *$ & 0.04 & $0.57 * * *$ & 0.03 & $0.54 * * *$ & 0.03 & $0.32 * * *$ & 0.03 & $0.45 * * *$ & 0.04 & $0.43 * * *$ & 0.04 \\
\hline Male & -0.56 & 1.00 & 0.44 & 0.87 & -0.15 & 0.77 & $-2.68 * *$ & 0.88 & -0.58 & 1.16 & -4.91 & 1.46 \\
\hline Age (months) ${ }^{3}$ & $-0.31 * *$ & 0.11 & -0.10 & 0.08 & $-0.58 * * *$ & 0.08 & $-0.77 * * *$ & 0.10 & -0.13 & 0.13 & $0.20 * * *$ & 0.20 \\
\hline Hispanic & -1.90 & 2.99 & -2.45 & 2.57 & -0.96 & 2.30 & -0.47 & 2.63 & 1.92 & 3.46 & -0.05 & 4.29 \\
\hline Free/reduced lunch & -1.83 & 1.41 & -0.87 & 1.21 & -0.66 & 1.08 & -0.37 & 1.24 & -2.49 & 1.60 & $-3.71 \dagger$ & 1.99 \\
\hline African American & $-3.67 *$ & 1.71 & $-3.30 *$ & 1.49 & 1.46 & 1.33 & -2.48 & 1.51 & -1.78 & 1.99 & -3.05 & 2.45 \\
\hline ELL & -1.03 & 2.09 & -1.76 & 1.87 & 0.47 & 1.66 & -0.53 & 1.85 & -2.10 & 2.45 & 4.23 & 3.01 \\
\hline Low self-regulation & $-7.04 * * *$ & 1.36 & $-5.25 * * *$ & 1.20 & $-3.95 * * *$ & 1.06 & $-6.60 * * *$ & 1.17 & $-9.04 * * *$ & 1.59 & $-9.21 * * *$ & 2.49 \\
\hline ES mean ${ }^{3}$ & 3.09 & 1.93 & $3.36^{*}$ & 1.40 & 0.25 & 1.26 & 0.29 & 1.74 & $4.60 \dagger$ & 2.27 & -2.23 & 4.19 \\
\hline
\end{tabular}

Note. ${ }^{1}$ Norm-reference score. ${ }^{2}$ Composite raw score. ${ }^{3}$ Mean-centered predictor. ELL $=$ English Language Learner. ES $=$ Emotional Support. PPVT $=$ Peabody Picture Vocabulary Test. T-CRS = Teacher-Child Rating Scale. TEMA = Test of Early Math Ability. TOPEL-DV = Test of Preschool Early Literacy - Definitional Vocabulary. TOPEL-PA = Test of Preschool Early Literacy - Phonological Awareness. TOPEL-PK = Test of Preschool Early Literacy - Print Knowledge. $\dagger \mathrm{p} \leq .08 . * \mathrm{p} \leq .05 . * * \mathrm{p} \leq .01 . * * * \mathrm{p} \leq .001$. 


\section{Table 9}

Associations Between Spring Cognitive and Social-Emotional Skills, Fall Cognitive and Social-Emotional Skills, Child Characteristics, and Classroom Emotional Support (Main Effects and Cross-Level Interactions)

\begin{tabular}{|c|c|c|c|c|c|c|c|c|c|c|c|c|}
\hline & \multicolumn{2}{|c|}{ Spring TEMA ${ }^{1}$} & \multicolumn{2}{|c|}{ Spring PPVT $^{1}$} & \multicolumn{2}{|c|}{$\begin{array}{c}\text { Spring } \\
\text { TOPEL-DV }{ }^{1}\end{array}$} & \multicolumn{2}{|c|}{$\begin{array}{c}\text { Spring } \\
\text { TOPEL-PK }^{1} \\
\end{array}$} & \multicolumn{2}{|c|}{$\begin{array}{c}\text { Spring } \\
\text { TOPEL-PA }^{1}\end{array}$} & \multicolumn{2}{|c|}{ Spring T-CRS ${ }^{2}$} \\
\hline & $b$ & SE & $b$ & SE & $b$ & SE & $b$ & SE & $b$ & SE & $b$ & SE \\
\hline Intercept & $106.42 * * *$ & 1.72 & $109.01 * * *$ & 1.47 & $99.62 * * *$ & 1.31 & $120.96 * * *$ & 1.52 & $109.08 * * *$ & 2.02 & $137.60 * * *$ & 2.79 \\
\hline Fall score ${ }^{3}$ & $0.78 * * *$ & 0.04 & $0.57 * * *$ & 0.03 & $0.54 * * *$ & 0.03 & $0.32 * * *$ & 0.03 & $0.45 * * *$ & 0.04 & $0.43 * * *$ & 0.04 \\
\hline Male & -0.56 & 1.00 & 0.44 & 0.87 & -0.15 & 0.77 & $-2.68 * *$ & 0.88 & -0.58 & 1.16 & $-4.91 * * *$ & 1.46 \\
\hline Age (in months) ${ }^{3}$ & $-0.31 * *$ & 0.11 & -0.10 & 0.08 & $-0.58 * * *$ & 0.08 & $-0.77 * * *$ & 0.10 & -0.13 & 0.13 & 0.20 & 0.20 \\
\hline Hispanic & -1.90 & 2.99 & -2.45 & 2.57 & -0.96 & 2.30 & -0.47 & 2.63 & 1.92 & 3.46 & -0.05 & 4.29 \\
\hline African American & $-3.67 *$ & 1.71 & $-3.30 *$ & 1.49 & 1.46 & 1.33 & -2.48 & 1.51 & -1.78 & 1.99 & -3.05 & 2.45 \\
\hline ELL & -1.03 & 2.09 & -1.76 & 1.87 & 0.47 & 1.66 & -0.53 & 1.85 & -2.10 & 2.45 & 4.23 & 3.01 \\
\hline Low self-regulation & $-7.04 * * *$ & 1.36 & $-5.25 * * *$ & 1.20 & $-3.95 * * *$ & 1.06 & $-6.60 * * *$ & 1.17 & $-9.04 * * *$ & 1.59 & $-9.21 * * *$ & 2.49 \\
\hline ES mean ${ }^{3}$ & 3.09 & 1.93 & $3.36^{*}$ & 1.40 & 0.25 & 1.26 & 0.29 & 1.74 & $4.60 \dagger$ & 2.27 & -2.23 & 4.19 \\
\hline ES mean x Male & 0.79 & 2.56 & 1.16 & 2.23 & 1.72 & 1.98 & 2.99 & 2.25 & -5.04 & 2.95 & -2.73 & 3.66 \\
\hline ES mean $x$ Age & -0.12 & 0.29 & 0.15 & 0.22 & 0.05 & 0.20 & 0.30 & 0.25 & -0.37 & 0.35 & -0.34 & 0.50 \\
\hline ES mean $x$ Hispanic & 2.73 & 9.08 & 6.23 & 7.81 & -0.58 & 6.96 & 1.96 & 8.00 & 8.20 & 10.51 & 2.09 & 13.13 \\
\hline ES mean x Af. Am. & -0.75 & 3.96 & 3.05 & 3.39 & -1.03 & 3.03 & -2.15 & 3.49 & 4.11 & 4.58 & 0.86 & 5.74 \\
\hline ES mean $x$ ELL & 6.72 & 5.37 & 2.63 & 4.61 & $7.76 \dagger$ & 4.10 & 5.70 & 4.74 & 9.34 & 6.22 & 5.40 & 7.78 \\
\hline ES mean $x$ Low SR & -0.36 & 3.12 & -0.01 & 2.71 & 1.98 & 2.41 & 0.67 & 2.75 & 2.12 & 3.60 & -0.14 & 4.45 \\
\hline
\end{tabular}

Note. ${ }^{1}$ Norm-reference score ${ }^{2}$ Composite raw score. ${ }^{3}$ Mean-centered predictor. Af. Am. $=$ African American. ELL $=$ English Language Learner. ES $=$ Emotional Support. F/R Lunch = Free/reduced lunch eligible. PPVT = Peabody Picture Vocabulary Test. SR = Self-regulation. T-CRS = Teacher-Child Rating Scale. TEMA = Test of Early Math Ability. TOPEL-DV = Test of Preschool Early Literacy - Definitional Vocabulary. TOPEL-PA $=$ Test of Preschool Early Literacy - Phonological Awareness. TOPEL-PK = Test of Preschool Early Literacy - Print Knowledge.

$\uparrow \mathrm{p} \leq .08 . * \mathrm{p} \leq .05 . * * \mathrm{p} \leq .01 . * * * \mathrm{p} \leq .001$ 


\section{Table 10}

Associations Between Spring Cognitive and Social-Emotional Skills, Fall Cognitive and Social-Emotional Skills, and Classroom Emotional Support

\begin{tabular}{|c|c|c|c|c|c|c|c|c|c|c|c|c|}
\hline & \multicolumn{2}{|c|}{ Spring TEMA ${ }^{1}$} & \multicolumn{2}{|c|}{ Spring PPVT ${ }^{1}$} & \multicolumn{2}{|c|}{$\begin{array}{c}\text { Spring } \\
\text { TOPEL-DV }^{1} \\
\end{array}$} & \multicolumn{2}{|c|}{$\begin{array}{c}\text { Spring } \\
\text { TOPEL-PK }{ }^{1}\end{array}$} & \multicolumn{2}{|c|}{$\begin{array}{c}\text { Spring } \\
\text { TOPEL-PA }^{1} \\
\end{array}$} & \multicolumn{2}{|c|}{ Spring T-CRS ${ }^{2}$} \\
\hline & $b$ & SE & $b$ & SE & $b$ & SE & $b$ & SE & $b$ & SE & $b$ & $\mathrm{SE}$ \\
\hline Intercept & $99.94 * * *$ & 0.76 & $104.59 * * *$ & 0.47 & $99.67 * * *$ & 0.74 & $115.93 * * *$ & 1.05 & $103.51 * * *$ & 0.79 & $128.44 * * *$ & 1.65 \\
\hline Fall score ${ }^{3}$ & $0.85 * * *$ & 0.04 & $0.62 * * *$ & 0.02 & $0.54 * * *$ & 0.02 & $0.37 * * *$ & 0.03 & $0.55^{* * *}$ & 0.04 & $0.58 * * *$ & 0.03 \\
\hline ES consistency ${ }^{3}$ & $8.32 *$ & 3.87 & $9.53 * * *$ & 2.38 & 2.40 & 3.78 & 4.99 & 5.38 & $13.59 * *$ & 4.02 & 3.37 & 8.31 \\
\hline
\end{tabular}

Note. ${ }^{1}$ Norm-reference score. ${ }^{2}$ Composite raw score. ${ }^{3}$ Mean-centered predictor. ES $=$ Emotional Support. PPVT $=$ Peabody Picture Vocabulary Test. TCRS $=$ Teacher-Child Rating Scale TEMA $=$ Test of Early Math Ability. TOPEL-DV = Test of Preschool Early Literacy - Definitional Vocabulary. TOPEL-PA = Test of Preschool Early Literacy - Phonological Awareness. TOPEL-PK = Test of Preschool Early Literacy - Print Knowledge. $\dagger \mathrm{p} \leq .08 . * \mathrm{p} \leq .05 . * * \mathrm{p} \leq .01 . * * * \mathrm{p} \leq .001$ 


\section{Table 11}

Associations Between Spring Cognitive and Social-Emotional Skills, Fall Cognitive and Social-Emotional Skills, Child Characteristics, and Classroom Emotional Support Consistency (Main Effects)

\begin{tabular}{|c|c|c|c|c|c|c|c|c|c|c|c|c|}
\hline & \multicolumn{2}{|c|}{ Spring TEMA $^{1}$} & \multicolumn{2}{|c|}{ Spring PPVT ${ }^{1}$} & \multicolumn{2}{|c|}{$\begin{array}{c}\text { Spring } \\
\text { TOPEL-DV }\end{array}$} & \multicolumn{2}{|c|}{$\begin{array}{c}\text { Spring } \\
\text { TOPEL-PK }^{1}\end{array}$} & \multicolumn{2}{|c|}{$\begin{array}{c}\text { Spring } \\
\text { TOPEL-PA }^{1}\end{array}$} & \multicolumn{2}{|c|}{ Spring T-CRS ${ }^{2}$} \\
\hline & $b$ & SE & $b$ & $\mathrm{SE}$ & $b$ & $\mathrm{SE}$ & $b$ & SE & $b$ & SE & $b$ & SE \\
\hline Intercept & $106.28 * * *$ & 1.72 & $108.69 * * *$ & 1.43 & $99.46 * * *$ & 1.31 & $120.72 * * *$ & 1.51 & $108.78 * * *$ & 1.99 & $137.53 * * *$ & 2.80 \\
\hline Fall score $^{3}$ & $0.77 * * *$ & 0.04 & $0.57 * * *$ & 0.03 & $0.54 * * *$ & 0.03 & $0.32 * * *$ & 0.03 & $0.46^{* * *}$ & 0.04 & $0.43 * * *$ & 0.04 \\
\hline Male & -0.51 & 1.00 & 0.58 & 0.86 & -0.12 & 0.77 & $-2.65 * *$ & 0.88 & -0.51 & 1.16 & $-4.92 * *$ & 1.46 \\
\hline Age (in months) ${ }^{3}$ & $-0.28 * *$ & 0.10 & -0.05 & 0.07 & $-0.58 * * *$ & 0.07 & $-0.77 * * *$ & 0.09 & -0.07 & 0.12 & 0.18 & 0.19 \\
\hline Hispanic & -1.91 & 2.98 & -2.50 & 2.55 & -0.92 & 2.29 & -0.46 & 2.62 & 1.92 & 3.44 & -0.01 & 4.29 \\
\hline Free/reduced lunch & -1.69 & 1.41 & -0.60 & 1.20 & -0.56 & 1.08 & -0.21 & 1.24 & -2.23 & 1.60 & $-3.69 \dagger$ & 1.99 \\
\hline African American & $-3.64 *$ & 1.71 & $-3.23 *$ & 1.47 & 1.53 & 1.32 & -2.37 & 1.51 & -1.73 & 1.98 & -3.03 & 2.46 \\
\hline ELL & -0.96 & 2.09 & -1.51 & 1.84 & 0.52 & 1.65 & -0.48 & 1.84 & -1.86 & 2.44 & 4.21 & 3.01 \\
\hline Low self-regulation & $-7.11 * * *$ & 1.36 & $-5.42 * * *$ & 1.20 & $-3.97 * * *$ & 1.06 & $-6.61 * * *$ & 1.17 & $-9.09 * * *$ & 1.59 & $-9.16 * * *$ & 2.49 \\
\hline ES consistency ${ }^{3}$ & $6.94 \dagger$ & 3.58 & $9.06 * * *$ & 2.26 & 3.18 & 2.29 & $6.12 \dagger$ & 3.07 & $12.46^{* *}$ & 3.92 & 0.22 & 8.01 \\
\hline
\end{tabular}

Note.${ }^{1}$ Norm-reference score. ${ }^{2}$ Composite raw score. ${ }^{3}$ Mean-centered predictor. ELL $=$ English Language Learner. ES $=$ Emotional Support. PPVT $=$ Peabody Picture Vocabulary Test. T-CRS $=$ Teacher-Child Rating Scale. TEMA = Test of Early Math Ability. TOPEL-DV = Test of Preschool Early Literacy - Definitional Vocabulary. TOPEL-PA = Test of Preschool Early Literacy - Phonological Awareness. TOPEL-PK = Test of Preschool Early Literacy - Print Knowledge. $\dagger \mathrm{p} \leq .08 . * \mathrm{p} \leq .05 . * * \mathrm{p} \leq .01 . * * * \mathrm{p} \leq .001$. 


\section{Table 12}

Associations Between Spring Cognitive and Social-Emotional Skills, Fall Cognitive and Social-Emotional Skills, Child Characteristics, and Classroom Emotional Support Consistency (Main Effects and Cross-Level Interactions)

\begin{tabular}{|c|c|c|c|c|c|c|c|c|c|c|c|c|}
\hline & \multicolumn{2}{|c|}{ Spring TEMA ${ }^{1}$} & \multicolumn{2}{|c|}{ Spring PPVT ${ }^{1}$} & \multicolumn{2}{|c|}{$\begin{array}{c}\text { Spring } \\
\text { TOPEL-DV } \\
\end{array}$} & \multicolumn{2}{|c|}{$\begin{array}{c}\text { Spring } \\
\text { TOPEL-PK }^{1}\end{array}$} & \multicolumn{2}{|c|}{$\begin{array}{c}\text { Spring } \\
\text { TOPEL-PA }^{1}\end{array}$} & \multicolumn{2}{|c|}{ Spring T-CRS ${ }^{2}$} \\
\hline & $b$ & SE & $b$ & SE & $b$ & SE & $b$ & SE & $b$ & SE & $b$ & SE \\
\hline Intercept & $106.28 * * *$ & 1.72 & $108.69^{* * *}$ & 1.43 & $99.46^{* * *}$ & 1.31 & $120.72 * * *$ & 1.51 & $108.78 * * *$ & 1.99 & $137.53 * * *$ & 2.80 \\
\hline Fall score ${ }^{3}$ & $0.77 * * *$ & 0.04 & $0.57 * * *$ & 0.03 & $0.54 * * *$ & 0.03 & $0.32 * * *$ & 0.03 & $0.46^{* * *} *$ & 0.04 & $0.43 * * *$ & 0.04 \\
\hline Male & -0.51 & 1.00 & 0.58 & 0.86 & -0.12 & 0.77 & $-2.65 * *$ & 0.88 & -0.51 & 1.16 & $-4.92 * *$ & 1.46 \\
\hline Age (in months) ${ }^{3}$ & $-0.28 * *$ & 0.10 & -0.05 & 0.07 & $-0.58 * * *$ & 0.07 & $-0.77 * * *$ & 0.09 & -0.07 & 0.12 & 0.18 & 0.19 \\
\hline Hispanic & -1.91 & 2.98 & -2.50 & 2.55 & -0.92 & 2.29 & -0.46 & 2.62 & 1.92 & 3.44 & -0.01 & 4.29 \\
\hline Free/reduced lunch & -1.69 & 1.41 & -0.60 & 1.20 & -0.56 & 1.08 & -0.21 & 1.24 & -2.23 & 1.60 & $-3.69 \dagger$ & 1.99 \\
\hline African American & $-3.64 *$ & 1.71 & $-3.23 *$ & 1.47 & 1.53 & 1.32 & -2.37 & 1.51 & -1.73 & 1.98 & -3.03 & 2.46 \\
\hline ELL & -0.96 & 2.09 & -1.51 & 1.84 & 0.52 & 1.65 & -0.48 & 1.84 & -1.86 & 2.44 & 4.21 & 3.01 \\
\hline Low self-regulation & $-7.11 * * *$ & 1.36 & $-5.42 * * *$ & 1.20 & $-3.97 * * *$ & 1.06 & $-6.61 * * *$ & 1.17 & $-9.09 * * *$ & 1.59 & $-9.16 * * *$ & 2.49 \\
\hline ES consistency ${ }^{3}$ & $6.94 \dagger$ & 3.58 & $9.06 * * *$ & 2.26 & 3.18 & 2.29 & $6.12 \dagger$ & 3.07 & $12.46 * *$ & 3.92 & 0.22 & 8.01 \\
\hline ES cons. $x$ Male & -1.95 & -4.87 & 5.87 & -4.20 & 4.33 & -3.76 & 4.40 & -4.27 & -3.48 & -5.63 & -3.50 & -6.95 \\
\hline ES cons. $x$ Age & -0.37 & -0.59 & 0.14 & -0.41 & -0.34 & -0.41 & -0.56 & -0.50 & -0.45 & -0.66 & -0.59 & -1.02 \\
\hline ES cons. $\mathrm{x}$ Hispanic & 9.07 & -14.22 & 16.76 & -12.12 & 0.81 & -10.91 & -0.49 & -12.51 & 9.84 & -16.39 & 4.85 & -20.53 \\
\hline ES cons. $x$ F/R lunch & -4.20 & -6.32 & 5.40 & -5.40 & -1.95 & -4.86 & -3.65 & -5.56 & 4.90 & -7.32 & -2.50 & -9.14 \\
\hline ES cons. x Af. Am. & -11.65 & -7.16 & -1.02 & -6.08 & 0.48 & -5.50 & -5.13 & -6.32 & -2.87 & -8.30 & -6.38 & -10.43 \\
\hline ES cons. $x$ ELL & 11.06 & -9.84 & 7.32 & -8.31 & $16.78 *$ & -7.48 & 10.69 & -8.64 & 15.72 & -11.32 & 19.90 & -14.24 \\
\hline ES cons. x Low SR & -3.00 & -6.18 & 4.63 & -5.35 & 6.74 & -4.78 & 0.16 & -5.44 & 11.79 & -7.12 & 0.40 & -8.82 \\
\hline
\end{tabular}

Note. ${ }^{1}$ Norm-reference score. ${ }^{2}$ Composite raw score. ${ }^{3}$ Mean-centered predictor. Af. Am. = African American. ELL = English Language Learner. ES

Cons. = Emotional Support Consistency. F/R Lunch $=$ Free/reduced lunch eligible. PPVT $=$ Peabody Picture Vocabulary Test. SR $=$ Self-regulation. TCRS = Teacher-Child Rating Scale. TEMA = Test of Early Math Ability. TOPEL-DV = Test of Preschool Early Literacy - Definitional Vocabulary. TOPEL-PA = Test of Preschool Early Literacy - Phonological Awareness. TOPEL-PK = Test of Preschool Early Literacy - Print Knowledge. $\uparrow \mathrm{p} \leq .08 . * \mathrm{p} \leq .05$. ** $\mathrm{p} \leq .01 . * * * \mathrm{p} \leq .001$. 


\section{Table 13}

Associations Between Spring Cognitive and Social-Emotional Skills, Fall Cognitive and Social-Emotional Skills, Child Characteristics, Classroom Emotional Support, and Classroom Emotional Support Consistency

\begin{tabular}{|c|c|c|c|c|c|c|c|c|c|c|c|c|}
\hline & \multicolumn{2}{|c|}{ Spring TEMA ${ }^{1}$} & \multicolumn{2}{|c|}{ Spring PPVT ${ }^{1}$} & \multicolumn{2}{|c|}{$\begin{array}{c}\text { Spring } \\
\text { TOPEL-DV }^{1}\end{array}$} & \multicolumn{2}{|c|}{$\begin{array}{c}\text { Spring } \\
\text { TOPEL-PK }^{1}\end{array}$} & \multicolumn{2}{|c|}{$\begin{array}{c}\text { Spring } \\
\text { TOPEL-PA }^{1}\end{array}$} & \multicolumn{2}{|c|}{ Spring T-CRS ${ }^{2}$} \\
\hline & $b$ & SE & $b$ & SE & $b$ & SE & $b$ & SE & $b$ & SE & $b$ & $\mathrm{SE}$ \\
\hline Intercept & $106.29 * * *$ & 1.72 & $108.68 * * *$ & 1.43 & $99.40 * * *$ & 1.31 & $120.57 * * *$ & 1.49 & $108.76^{* * *}$ & 1.99 & $137.52 * * *$ & 2.79 \\
\hline Fall score ${ }^{3}$ & $0.77 * * *$ & 0.04 & $0.57 * * *$ & 0.03 & $0.53 * * *$ & 0.03 & $0.32 * * *$ & 0.03 & $0.46 * * *$ & 0.04 & $0.43 * * *$ & 0.04 \\
\hline Male & -0.52 & 1.00 & 0.59 & 0.86 & -0.07 & 0.77 & $-2.55 * *$ & 0.88 & -0.50 & 1.16 & -4.89 & 1.46 \\
\hline Age (in months) ${ }^{3}$ & $-0.29 * *$ & 0.11 & -0.04 & 0.08 & $-0.56 * * *$ & 0.07 & $-0.72 * * *$ & 0.09 & -0.06 & 0.12 & 0.22 & 0.20 \\
\hline Hispanic & -1.90 & 2.98 & -2.51 & 2.55 & -0.95 & 2.29 & -0.58 & 2.61 & 1.91 & 3.44 & -0.06 & 4.29 \\
\hline Free/reduced lunch & -1.71 & 1.42 & -0.58 & 1.20 & -0.48 & 1.08 & -0.03 & 1.24 & -2.21 & 1.60 & -3.64 & 2.00 \\
\hline African American & $-3.64 *$ & 1.72 & $-3.24 *$ & 1.48 & 1.51 & 1.32 & -2.38 & 1.50 & -1.73 & 1.99 & -3.02 & 2.46 \\
\hline ELL & -0.98 & 2.09 & -1.49 & 1.84 & 0.63 & 1.65 & -0.27 & 1.84 & -1.84 & 2.44 & 4.27 & 3.02 \\
\hline Low self-regulation & $-7.09 * * *$ & 1.36 & $-5.45 * * *$ & 1.20 & $-4.04 * * *$ & 1.06 & $-6.71 * * *$ & 1.17 & $-9.10 * * *$ & 1.59 & $-9.20 * * *$ & 2.50 \\
\hline ES mean ${ }^{3}$ & 0.84 & 2.80 & -0.51 & 1.77 & -2.13 & 1.76 & $-4.56 \dagger$ & 2.24 & -0.67 & 3.07 & -5.03 & 6.14 \\
\hline ES consistency $^{3}$ & 5.78 & 5.27 & $9.76^{* *}$ & 3.32 & $6.12 \dagger$ & 3.29 & $12.43 * *$ & 4.22 & $13.38 *$ & 5.77 & $7.24 * *$ & 11.67 \\
\hline
\end{tabular}

Note. ${ }^{1}$ Norm-reference score. ${ }^{2}$ Composite raw score. ${ }^{3}$ Mean-centered predictor. ELL $=$ English Language Learner. ES $=$ Emotional Support. PPVT $=$ Peabody Picture Vocabulary Test. T-CRS $=$ Teacher-Child Rating Scale. TEMA = Test of Early Math Ability. TOPEL-DV = Test of Preschool Early Literacy - Definitional Vocabulary. TOPEL-PA = Test of Preschool Early Literacy - Phonological Awareness. TOPEL-PK = Test of Preschool Early Literacy - Print Knowledge. $\uparrow \mathrm{p} \leq .08 . * \mathrm{p} \leq .05 . * * \mathrm{p} \leq .01 . * * * \mathrm{p} \leq .001$. 


\section{Table 14}

Associations Between Spring Cognitive and Social-Emotional Skills, Fall Cognitive and Social-Emotional Skills, Child Characteristics, and Classroom Group Membership

\begin{tabular}{|c|c|c|c|c|c|c|c|c|c|c|c|c|}
\hline & \multicolumn{2}{|c|}{ Spring TEMA ${ }^{1}$} & \multicolumn{2}{|c|}{ Spring PPVT ${ }^{1}$} & \multicolumn{2}{|c|}{$\begin{array}{c}\text { Spring } \\
\text { TOPEL-DV }{ }^{1}\end{array}$} & \multicolumn{2}{|c|}{$\begin{array}{c}\text { Spring } \\
\text { TOPEL-PK }^{1}\end{array}$} & \multicolumn{2}{|c|}{$\begin{array}{c}\text { Spring } \\
\text { TOPEL-PA }^{1}\end{array}$} & \multicolumn{2}{|c|}{ Spring T-CRS ${ }^{2}$} \\
\hline & $b$ & SE & $b$ & SE & $b$ & $\overline{S E}$ & $b$ & SE & $b$ & SE & $b$ & SE \\
\hline Intercept & $108.35 * * *$ & 1.93 & $110.71 * * *$ & 1.56 & $100.10^{* * * *}$ & 1.42 & $121.54 * * *$ & 1.63 & $111.29 * * *$ & 2.28 & $138.62 * * *$ & 3.44 \\
\hline Fall score $^{3}$ & $0.77 * * *$ & 0.04 & $0.57 * * *$ & 0.03 & $0.53 * * *$ & 0.03 & $0.32 * * *$ & 0.03 & $0.45 * * *$ & 0.04 & $0.43 * * *$ & 0.04 \\
\hline Male & -0.54 & 1.00 & 0.52 & 0.87 & -0.14 & 0.77 & $-2.66 * *$ & 0.88 & -0.56 & 1.16 & $-4.97 * *$ & 1.46 \\
\hline Age (in months) ${ }^{3}$ & $-0.30 * *$ & 0.11 & -0.07 & 0.08 & $-0.57 * * *$ & 0.08 & $-0.74 * * *$ & 0.09 & -0.08 & 0.13 & 0.18 & 0.20 \\
\hline Hispanic & -1.81 & 2.98 & -2.55 & 2.56 & -0.86 & 2.29 & -0.51 & 2.61 & 1.90 & 3.46 & 0.27 & 4.29 \\
\hline Free/reduced lunch & -1.68 & 1.41 & -0.76 & 1.21 & -0.50 & 1.08 & -0.02 & 1.24 & -2.35 & 1.60 & $-3.65 \dagger$ & 1.99 \\
\hline African American & $-3.47 *$ & 1.72 & $-3.14^{*}$ & 1.49 & 1.66 & 1.33 & -2.18 & 1.51 & -1.67 & 2.00 & -2.79 & 2.46 \\
\hline ELL & -1.08 & 2.09 & -1.62 & 1.86 & 0.53 & 1.65 & -0.37 & 1.83 & -2.00 & 2.45 & 4.12 & 3.02 \\
\hline Low self-regulation & $-7.13 * * *$ & 1.36 & $-5.38 * * *$ & 1.20 & $-4.05 * * *$ & 1.06 & $-6.67 * * *$ & 1.17 & $-9.13 * * *$ & 1.59 & $-9.28 * * *$ & 2.50 \\
\hline Group 3 & $-4.33 \dagger$ & 2.12 & $-2.80 \dagger$ & 1.48 & $-2.46 \dagger$ & 1.36 & $-4.35^{*}$ & 1.68 & -3.90 & 2.51 & -7.78 & 4.54 \\
\hline Group 4 & $-3.77 *$ & 1.70 & $-3.87 * *$ & 1.17 & -1.32 & 1.09 & -2.13 & 1.35 & $-4.90 *$ & 2.01 & 0.27 & 3.70 \\
\hline
\end{tabular}

Note. ${ }^{1}$ Norm-reference score. ${ }^{2}$ Composite raw score. ${ }^{3}$ Mean-centered predictor. ELL = English Language Learner. ES $=$ Emotional Support. PPVT $=$ Peabody Picture Vocabulary Test. T-CRS = Teacher-Child Rating Scale. TEMA = Test of Early Math Ability. TOPEL-DV = Test of Preschool Early Literacy - Definitional Vocabulary. TOPEL-PA = Test of Preschool Early Literacy - Phonological Awareness. TOPEL-PK = Test of Preschool Early Literacy - Print Knowledge.. Group 2 contains low emotional support mean/high emotional support consistency classrooms. Group 3 contains high emotional support mean/low emotional support consistency classrooms. Group 4 contains low emotional support mean/low emotional support consistency classrooms. $\dagger \mathrm{p} \leq .08$. $* \mathrm{p} \leq .05 . * * \mathrm{p} \leq .01 . * * * \mathrm{p} \leq .001$ 


\section{References}

Administration for Children and Families. (n.d.). History of Head Start. Retrieved from http://www.acf.hhs.gov/programs/ohs/about/history-of-head-start

Ainsworth, M. D. S (1979). Infant-Mother attachment. American Psychologist, 34(10), 923-937.

AppleTree Institute for Education Innovation (2014). AppleTree Institute for Education Innovation. Retrieved from http://www.appletreeinstitute.org/institute/appletreeinstitute-for-education-innovation/

Arnett, J. (1998) Caregiver Interaction Scale. Retrieved from http://www.eec.state.ma.us/docs1/qris/20110121_arnett_scale.pdf

Aud, S., Wilkinson-Flicker, S., Kristapovich, P., Rathbun, A., Wang, X., \& Zhang, J. (2014). The Condition of Education 2014. Washington, DC: U.S. Department of Education, National Center for Education Statistics. Retrieved from http://nces.ed.gov/pubs2014/2014083.pdf

Barnett, W. S., Carolan, M. E, Squires, J. H., \& Clarke-Brown, K. (2014). State of Preschool 2013: First Look. Washington, DC: U.S. Department of Education, National Center for Education Statistics. Retrieved from http://nces.ed.gov/pubsearch

Beatty, B. (1995). Preschool Education in America: The Culture of Young Children from the Colonial Era to the Present. New Haven, CT: Yale University Press.

Bell, S. M. \& Ainsworth, M. D. S. (1972). Infant crying and maternal responsiveness. Child Development, 43(4), 1171-1190.

Birch, S. H. \& Ladd, G. W. (1997). The teacher-child relationship and children's early school adjustment. Journal of School Psychology, 35(1), 61-79.

Blair, C. \& Diamond, A. (2008). Biological processes in prevention and intervention: The promotion of self-regulation as a means of preventing school failure. Development and Psychopathology, 20(03), 899-911.

Bornstein, M. H., Tamis-LeMonda, C. S., Hahn, C.-S., \& Haynes, M. O. (2008). Maternal Responsiveness to young children at three ages: Longitudinal analysis of a multidimensional, modular, and specific parenting construct. Developmental Psychology, 44(3), 867-874. doi: 10.1037/0012-1649.44.3.867

Bowlby, J. (1969). Attachment and Loss, Volume 1: Attachment. New York, NY: Basic Books.

Bowlby, J. (1973). Attachment and Loss, Volume II: Separation. New York, NY: Basic Books.

Bretherton, I. (1985). Attachment theory: Retrospect and prospect. Monographs of the Society for Research in Child Development, 50(1/2), 3-35.

Brock, L. L. \& Curby, T. W. (2014). Emotional support consistency and teacher-child relationships forecast social competence and problem behaviors in prekindergarten and kindergarten. Early Education and Development, 25(5), 661680. doi: 10.1080/10409289.2014.866020.

Brock, L. L., Rimm-Kaufman, S. E., Nathanson, L., \& Grimm, K. J. (2009). The contributions of 'hot' and 'cool' executive function to children's academic 
achievement, learning-related behaviors, and engagement in kindergarten. Early Childhood Research Quarterly, 24, 337-349. doi:10.1016/j.ecresq.2009.06.001

Bronfenbrenner, U. (1979). The ecology of human development: Experiments by nature and design. [Google books version] Cambridge, MA: Harvard University Press. Retrieved from books.google.com

Bronfenbrenner, U. \& Ceci, S.J. (1994). Nature-nurture reconceptualization in developmental perspective: A bioecological model. Psychological Review, 101(4) 568-586.

Bronfenbrenner, U. \& Morris, P.A. (1998). The ecology of developmental processes. In W. Damon \& R.M. Lerner (Eds.), Handbook of Child Psychology: Vol. 1: Theoretical models of human development. (5th ed., pp. 993-1028). Hoboken, NJ: Wiley.

Bronfenbrenner, U., \& Morris, P. A. (2006). The bioecological model of human development. In W. D. \& R. M. Lerner (Eds.), Handbook of Child Psychology: Vol. I. Theoretical models of human development. (6th ed., pp. 793-828). Hoboken, NJ: Wiley.

Brooks-Gunn, J., \& Markman, L. (2005). The contribution of parenting to ethnic and racial gaps in school readiness. The Future of Children, 15(1), 139-168.

Bracey, G. (2007). 'The first time everything changed': the $17^{\text {th }}$ Bracey report on the condition of public education, 89(2), 119-136. Retrieved from http://216.78.200.159/RandD/Bracey,\%20Gerrald/Bracey\%20Report\%202007.pdf

Burchinal, M., Howes, C., Pianta, R., Bryant, D., Early, D., Clifford, R., \& Barbarin, O. (2008) Predicting child outcomes at the end of kindergarten from the quality of pre-kindergarten teacher-child interactions and instruction. Applied Developmental Science, 12(3), 140-153. doi: 10.1080/10888690802199418

Burchinal, M., McCartney, K., Steinberg, L., Crosnoe, R., Friedman, S. L., McLoyd, V., \& Pianta, R. (2011). Examining the black-white achievement gap among lowincome children using the NICHD study of early child care and youth development. Child Development, 82(5), 1404-1420.

Burchinal, M., Vandergrift, N., Pianta, R., \& Mashburn, A. (2010). Threshold analysis of association between child care quality and child outcomes for low-income children in pre-kindergarten programs. Early Childhood Research Quarterly, 25, 266-176. doi: 10.1016/j.ecresq.2009.10.004

Burchinal, M., McCartney, K., Steinberg, L., Crosnoe, R., Friedman, S. L., McLoyd, V., \& Pianta, R. (2011). Examining the black-white achievement gap among lowincome children using the NICHD study of early child care and youth development. Child Development, 82(5), 1404-1420.

Camilli, G., Vargas, S., Ryan, S., \& Barnett, W. S. (2010). Meta-analysis of the effects of early education interventions on cognitive and social development. Teachers College Record 112(3), 579-620.

Campbell, F.A., Wasika, B.H, Pungello, E., Burchinal, M., Barbarin, O., Kainz, K., Sparling, J.J., Ramey, C.T. (2008). Young adult outcomes of the Abecedarian and CARE early childhood educational interventions. Early Childhood Research Quarterly, 23, 452-466. doi: 10.1016/j.ecresq.2008.03.003

Campbell, F. A., Pungello, E. P, Burchinal, M., Kainz, K., Pan, Y., Wasik, B. H., ... 
Ramey, C. T. (2012). Adult outcomes as a function of an early childhood educational program: An Abecedarian Project follow-up. Developmental Psychology, 48(4), 1033-1043. doi: 10.1037/a0026644

Center for Public Education (2007). Preparing English language learners for academic success. Alexandria, VA. Retrieved from

http://www.centerforpubliceducation.org/Main-Menu/Instruction/What-researchsays-about-English-language-learners-At-a-glance/Preparing-English-languagelearners-for-academic-success.html

Child Care Aware of America (2013). Child Care in America: 2013 State Fact Sheet. Retrieved from http://usa.childcareaware.org/public-policy/resources/child-carestate-fact-sheets-0

Claessens, A., Duncan, G., \& Engel, M. (2009). Kindergarten skills and fifth-grade achievement: Evidence from the ECLS-K. Economics of Education Review, 28(4), 415-427. doi: 10.1016/j.econedurev.2008.09.003

Clasien de Shipper, J., Van IJzendoorn, M. H., Tavecchio, L. W. C. (2004) Stability in center day care: Relations with children's well-being and problem behavior in day care. Social Development, 13(4), 531-550.

Colorin Colorado (2015). 8 Strategies for Preschool ELLs' Language and Literacy Development. Retrieved from http://www.colorincolorado.org/article/36679/

Community-University Partnership for the Study of Children, Youth, and Families (2011). Review of the Peabody Picture Vocabulary Test, Fourth Edition (PPVT4). Edmonton, Alberta, Canada. Retrieved from http://www.cup.ualberta.ca/wpcontent/uploads/2012/06/FINAL_PPVT-4_May-2012.pdf

Consistency [Def. 1.1]. (2014). In Oxford Dictionaries. Retrieved from http://www.oxforddictionaries.com/us/definition/american_english/consistency?q $=$ consistency

Curby, T. W., Brock, L. L., \& Hamre, B. K. (2013). Teachers' emotional support consistency predicts children's achievement gains and social skills. Early

Education and Development, 24(3), 292-309. doi: 10.1080/10409289.2012.665760

Curby, T.W., LoCasale-Crouch, J., Konold, T.R., Pianta, R., Howes, C., Burchinal, M., Bryant, D., Clifford, R., Early, D., \& Barbarin, O. (2009). The relations of observed pre-K classroom quality profiles to children's achievement and social competence. Early Education and Development, 20(2), 346-372. doi: 10.1080/10409280802581284

Curby, T. W., Stuhlman, M., Grimm, K., Mashburn, A., Chomat-Mooney, L., Downer, J. T. ... Pianta, R. C. (2011). Within-day variability in the quality of classroom interactions during third and fifth grade. The Elementary School Journal, 112(1), 16-37. Article stable URL: http://www.jstor.org/stable/10.1086/660682

Duncan, G. J., Dowsett, C. J., Claessens, A., Magnuson, K., Huston, A. C., Klebanov, P., ... \& Japel, C. (2007). School readiness and later achievement. Developmental Psychology, 43(6), 1428-1446. doi: 10.1037/0012-1649.43.6.1428

Dunifon, R., \& Gill, L. (2013). Maternal employment and child well-being. Rochester, NY: Cornell University. Retrieved from 
http://www.human.cornell.edu/pam/outreach/parenting/research/upload/FINALResearch-Brief-Maternal-Employment.pdf

Dunn, L. M., \& Dunn, D. M. (2007). The Peabody Picture Vocabulary Test, Fourth Edition. Bloomington, MN: NCS Pearson, Inc.

Dunn, L.M., \& Dunn, D.M. (2013). Peabody Picture Vocabulary Test, Fourth Edition Technical Report. Retrieved from http://images.pearsonassessments.com/images/assets/ppvt-4/2013-PPVT-TechRPT.pdf

Early, D. M., Maxwell, K. L., Burchinal, M., Alva, S., Bender, R. H., Bryant, D., ... Zill, N. (2007). Teachers' education, classroom quality, and young children's academic skills: Results from seven studies of preschool programs. Child Development, 78(2), 558-580. Article stable URL: http://www.jstor.org/stable/4139245

Ginsburg, H. P., \& Baroody, A. J. (2003). Test of Early Mathematics Ability - Third edition. Austin TX: Pro-Ed.

Halle, T., Forry, N., Hair, E., Perper, K., Wandner, L., Wessel, J., \& Vick, J. (2009). Disparities in early learning and development: Lessons from the Early Childhood Longitudinal Study - Birth Cohort (ECLS-B) Executive Summary. Child Trends. Retrieved from http://www.childtrends.org/wp-content/uploads/2013/05/200952DisparitiesELExecSumm.pdf

Hamre, B. K. \& Pianta, R. C. (2005). Can instructional and emotional support in the firstgrade classroom make a difference for children at risk of school failure? Child Development, 76(5), 949-967. Article stable URL: http://www.jstor.org/stable/3696607

Hamre, B. K., Goffin, S. G., \& Kraft-Sayre, M. (2009). Classroom Assessment Scoring System (CLASS) Implementation Guide: Measuring and improving classroom interactions in early childhood settings. Center for Advanced Study of Teaching and Learning. Retrieved from http://curry.virginia.edu/research/centers/castl/publications

Harms, T., Clifford, R. M., \& Cryer, D. (2005). Early Childhood Environment Rating Scale-Revised edition, updated (ECERS-R). New York: Teachers College Press.

Heckman, J. (n.d.) Invest in early childhood development: Reduce deficits, strengthen the economy. Retrieved from http://heckmanequation.org/content/resource/investearly-childhood-development-reduce-deficits-strengthen-economy

Howes C., \& Ritchie, S. (1999). Attachment organizations in children with difficult life circumstances. Development and Psychopathology, 11, 251-268.

Howes, C., Burchinal, M., Pianta, R., Bryant, D., Early, D., Clifford, R., \& Barbarin, O. (2008). Ready to Learn? Children's pre-academic achievement in pre-

Kindergarten programs. Early Childhood Research Quarterly, 23, 27-50. doi: 10.1016/j.ecresq.2007.05.002

Howse, R. B., Calkins, S. D., Anastopoulos, A. D., Keane, S. P., \& Shelton, T. L. (2003). Regulatory contributors to children's kindergarten achievement. Early Education \& Development, 14(1), 101-119.

Kena, G., Aud, S., Johnson, F., Wang, X., Zhang, J., Rathbun, A., Wilkinson-Flicker, S., and Kristapovich, P. (2014). The Condition of Education 2014. U.S. Department 
of Education, National Center for Education Statistics. Washington, DC. Retrieved from http://nces.ed.gov/pubs2014/2014083.pdf

Landry, S. H., Smith, K. E, Swank, P. R., Assel, M. A., \& Vellet, S. (2001). Does early responsive parenting have a special importance for children's development or is consistency across early childhood necessary? Developmental Psychology, 37(3), 387-403. doi: 10.1037/0012-1649.37.3.387

Landry, S. H., Smith, K. E., \& Swank, P. R. (2003). The importance of parenting during early childhood for school-age development. Developmental Neuropsychology, 24(2\&3), 559-591. doi: 10.1080/87565641.2003.9651911

La Paro, K. M., \& Pianta, R. C. (2000). Predicting children's competence in the early school years: A meta-analytic review. Review of educational research, 70(4), 443-484.

Lonigan, C. J., Wagner, R. K., Torgesen, J. K., \& Rashotte, C .A. (2007). Test of Preschool Early Literacy. Austin, TX: Pro-Ed.

Magnuson, K. A. \& Waldfogel, J. (2005). Early childhood care and education: Effects on ethnic and racial gaps in school readiness. The Future of Children, 15(1), 169196.

Mashburn, A. J. (2104). The importance of quality prekindergarten programs for promoting school readiness skills. In S.H. Landry \& C.L. Cooper (Eds.), Wellbeing in Children and Families (pp. 271-296). Hoboken, NJ: WileyBlackwell.

Mashburn, A. J., Pianta, R. C., Hamre, B. K., Downer, J. T., Barbarin, O. A., Bryant, D., ... Howes, C. (2008). Measures of classroom quality in prekindergarten and children's development of academic, language, and social skills. Child

Development, 79(3), 732-749. doi: 10.1111/j.1467-8624.2008.01154.x

Matthews, J.S., Ponitz, C.C., \& Morrison, F.J. (2009). Early gender differences in selfregulation and academic achievement. Journal of Educational Psychology, 101(3), 689-704. doi: 10.1037/a0014240

McCabe, P. C. \& Marshall, D. J. (2006). Measuring the social competence of preschool children with specific language impairment: Correspondence among informant ratings and behavioral observations. Topics in Early Childhood Special Education 26(4), 234-236. doi: 10.1177/02711214060260040401

McClelland, M. M., Cameron, C. E., McDonald Connor, C., Farris, C. L., Jewkes, A. M., \& Morrison, F. J. (2007). Links between early self-regulation and preschoolers' literacy, vocabulary, and math skills. Developmental Psychology, 33, 947-959.

Moffitt, T. E., Arseneault, L., Belsky, D., Dickson, N., Hancox, R. J., Harrington, H., ... \& Caspi, A. (2011). A gradient of childhood self-control predicts health, wealth, and public safety. Proceedings of the National Academy of Sciences, 201010076.

Molfese, V. J., Brown, E. T., Adelson, J. L., Beswick, J., Jacobi-Vessels, J., Thomas, L., ... Culver, B. (2012). Examining associations between classroom environment and processes and early mathematics performance from pre-kindergarten to kindergarten. Gifted Children, 5(2).

Montes, G., Hightower, A. D., Brugger, L., \& Moustafa, E. (2005). Quality child care and socio-emotional risk factors: No evidence of diminishing returns for urban 
children. Early Childhood Research Quarterly, 20, 361-372. doi:

10.1016/j.ecresq.2005.07.006

More Muelle, C. (2005). The history of kindergarten: From Germany to the United States. Retrieved from

http://digitalcommons.fiu.edu/cgi/viewcontent.cgi? article $=1110 \&$ context $=$ sferc

Morrison, F.J., Ponitz, C.C., \& McClelland, M.M. (2010). Self-regulation and academic achievement in the transition to school. In S.D. Calkins \& M.A. Bell (Eds.), Child development at the intersection of emotion and cognition (pp. 203-224).

Washington, DC: American Psychological Association. doi:10.1037/12059-011

Muennig, P., Schweinhart, L., Montie, J., \& Neidell, M. (2009). Effects of a prekindergarten educational intervention on adult health: 37-year follow-up results of a randomized controlled trial. American Journal of Public Health, 99(8), 1431-1437.

The National Center on Quality Teaching and Learning (2012). Understanding and using CLASS for program improvement. Retrieved from http://eclkc.ohs.acf.hhs.gov/hslc/tta-system/teaching/docs/class-brief.pdf

National Institute for Early Education Research. ECE Consensus Letter for Researchers. (2014). Retrieved from http://nieer.org/publications/ece-consensus-letterresearchers.

National Institute for Child Health and Human Development Early Child Care Research Network (1999). Child outcomes when child care center classes meet recommended standards of quality. American Journal of Public Health, 89(7), 1072-1077.

National Institute for Child Health and Human Development Early Child Care Research Network (2002). Child-care structure $\rightarrow$ process $\rightarrow$ outcome: Direct and indirect effects of child-care quality on young children's development. Psychological Science, 13(3), 199-206. doi: 10.1111/1467-9280.00438

National Research Council and Institute of Medicine (2000) From Neurons to Neighborhoods: The Science of Early Childhood Development. Committee on Integrating the Science of Early Childhood Development. Jack P. Shonkof and Deborah A. Philips, eds. Board on Children, Youth, and Families, Commission on Behavioral and Social Sciences and Education. Washington, D.C.: National Academy Press.

O'Brien, E. M. \& Dervarics, C. (2007). Pre-Kindergarten: What the research shows. Alexandria, VA: Center for Public Education. Retrieved from http://www.centerforpubliceducation.org/Main-Menu/Pre-kindergarten/PreKindergarten/Pre-kindergarten-What-the-research-shows.html

Peisner-Feinberg, E. S., \& Burchinal, M. R. (1997). Relations between preschool children's child-care experiences and concurrent development: The Cost, Quality, and Outcomes Study. Merrill-Palmer Quarterly, 451-477.

Perkins, P., \& Hightower, A. (2002). T-CRS 2.1 Teacher-Child Rating Scale: Examiner's manual. Rochester, NY: Children's Institute.

Pianta, R. C., La Paro, K. M, \& Hamre, B. K. (2008). Classroom Assessment Scoring System (CLASS) Manual-Pre-K. Baltimore, MD: Paul H. Brookes Publishing. 
Pianta, R. C., Nimetz, S. L., \& Bennett, E. (1997). Mother-child relationships, teacherchild relationships, and school outcomes in preschool and kindergarten. Early Childhood Research Quarterly, 12(3), 263-280. doi: 10.1016/S08852006(97)90003-X

Pro-Ed, Incorporated (2012). TEMA-3: Test of Early Math Ability - Third Edition. Retrieved from http://www.proedinc.com/customer/productView.aspx?ID=2891

Qi, C. H., \& Kaiser, A. P. (2003). Behavior problems of preschool children from lowincome families review of the literature. Topics in Early Childhood Special Education, 23(4), 188-216.

R Core Team (2013). R: A language and environment for statistical computing. Vienna, Austria: R Foundation for Statistical Computing. URL http://www.R-project.org/

Raudenbush, S. W. \& Bryk, A. S. (2002). Hierarchical Linear Models: Applications and Data Analysis Methods [Google Books version]. Thousand Oaks, CA: Sage Publications. Retrieved from books.google.com

Reardon, S.F. (2011). The widening academic achievement gap between the rich and the poor: New evidence and possible explanations. Retrieved from http://cepa.stanford.edu/sites/default/files/reardon\%20whither\%20opportunity\%2 0-\%20chapter\%205.pdf

Reynolds, A. J., Temple, J. A., Robertson, D. L., \& Mann, E. A. (2001). Age 21 costbenefit analysis of the Title I Chicago Child-Parent Center Program: Executive Summary. Retrieved from http://www.cehd.umn.edu/icd/research/cls/Cbaexecsum4.html

Reynolds, A. J., Temple, J. A., White, B. A., Ou, S.-R., \& Robertson, D. L. (2011). Age26 cost-benefit analysis of the Child-Parent Center early education program. Child Development, 82(1), 379-404. doi:10.1111/j.1467-8624.2010.01563.x

Rimm-Kaufman, S. E., Curby, T. W., Grimm, K. J., Nathanson, L., \& Brock, L. L. (2009). The contribution of children's self-regulation and classroom quality to children's adaptive classroom behaviors in the kindergarten classroom. Developmental Psychology, 45(4), 958-972. doi: 10.1037/a0015861

Santrock, J. W. (2011). Life-span development. New York, NY: McGraw-Hill International

Schaffer, H. R. \& Emerson, P. E. (1964). The development of social attachment in infancy. Monographs of the Society for Research in Child Development, 29(3), 177.

Schweinhart, L. J., Montie, J., Xiang, Z., Barnett, W. S., Belfield, C. R., \& Nores, M. (2005). The High/Scope Perry Preschool Study through age 40: Summary, conclusions, and frequently asked questions. Ypsilanti, MI: High/Scope Educational Research Foundation. Retrieved from http://www.highscope.org/file/Research/PerryProject/specialsummary_rev2011_0 2_2.pdf

Skinner, E. A., Kindermann, T. A., Roeser, R. W., Mashburn, A. J., Steele, J., \& Smith , C. (in prep). Applied developmental systems science: Everything you always wanted to know about theories, meta-theories, methods, and interventions but didn't realize you needed to ask. An Advanced Textbook. 
Smith, M. W., Brady, J. P., \& Anastasopoulos, L. (2008). Early Language \& Literacy Classroom Observation: Pre-K Tool (ELLCO). Baltimore, MD: Paul H. Brookes, Inc.

Stipek, D. J., \& Ryan, R. H. (1997). Economically disadvantaged preschoolers: ready to learn but further to go. Developmental Psychology, 33(4), 711-723.

Tudge, J. R .H., Mokrova, I., Hatfield, B. E., \& Karnik, R. B. (2009) Uses and misuses of Bronfenbrenner's bioecological theory of human development. Journal of Family Theory \& Review, 1, 198-201.

University of Minnesota (2014). Chicago Longitudinal Study. Retrieved from http://www.cehd.umn.edu/icd/research/cls/program.html

U.S. Department of Health and Human Services (2012). 2012 HHS poverty guidelines. Retrieved from http://aspe.hhs.gov/poverty/12poverty.shtml

Vandell, D. L. \& Wolfe, B. (2000). Child care quality: Does it matter and does it need to be improved? Report to U.S. Department of Health and Human Services.

Retrieved from http://gse.uci.edu/childcare/pdf/questionnaire_interview/Vandell\%20and\%20Wolf e\%202000f.pdf.

Vinco, M. H. (2013). Assessment of preschool vocabulary: Expressive and receptive knowledge of word meanings. Electronic Theses, Treatises and Dissertations. Paper 8652. Retrieved from http://diginole.lib.fsu.edu/cgi/viewcontent.cgi?article=7868\&context=etd

The White House, Office of the Press Secretary (2013). Fact Sheet: President Obama's Plan for Early Education for all Americans. Retrieved from http://www.whitehouse.gov/the-press-office/2013/02/13/fact-sheet-presidentobama-s-plan-early-education-all-americans

The White House, Office of the Press Secretary (2104). Fact Sheet: Invest in US: The White House Summit on Early Childhood Education. Retrieved from http://www.whitehouse.gov/the-press-office/2014/12/10/fact-sheet-invest-uswhite-house-summit-early-childhood-education

Wilson, S. B. \& Lonigan, C. J. (2009). An evaluation of two emergent literacy screening tools for preschool children. Annals of Dyslexia, 59(2), 115-131. doi: 10.1007/s11881-009-0026-9

Wood, J. J. (2007). Academic competence in preschool: Exploring the role of close relationships and anxiety. Early Education and Development, 18(2), 223-242. doi: $10.1080 / 10409280701282868$

Zill, N., \& West, J. (2001). Findings from the Condition of Education 2000: Entering Kindergarten Children (NCES 2001-035). Washington, DC: National Center for Education Statistics.

Zinsser, K. M., Bailey, C. S., Curby, T. W., Denham, S. A., \& Bassett, H. H. (2013). Exploring the predictable classroom: preschool teacher stress, emotional supportiveness, and students' social-emotional behavior in private and Head Start classrooms. Dialog, 16(2), 90-108 